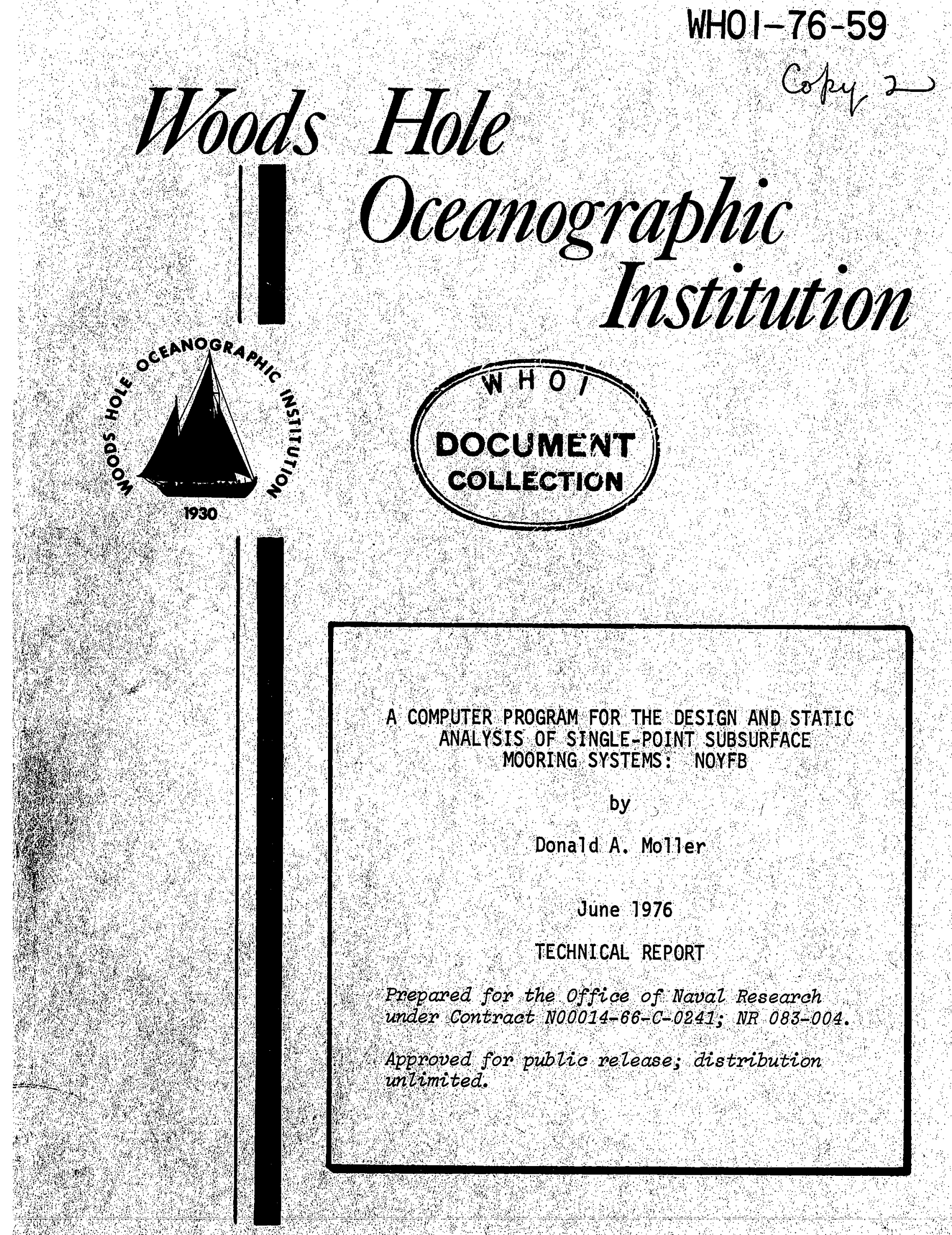

WOODS HOLE, MASSACHUSETTS 02543 


\title{
A COMPUTER PROGRAM FOR THE DESIGN AND STATIC \\ ANALYSIS OF SINGLE-POINT SUBSURFACE \\ MOORING SYSTEMS: NOYFB
}

\author{
by \\ Donald A. Moller \\ WOODS HOLE OCEANOGRAPHIC INSTITUTION \\ Woods Hole, Massachusetts 02543
}

June 1976

\section{TECHNICAL REPORT}

Prepared for the Office of Naval Research under Contract N00014-66-C-0241; NR 083-004.

Reproduction in whole or in part is permitted for cony purpose of the United States Govermment. In citing this manuscript in a'bibliography, the reference should be followed by the phrase:

UNPUBLISHED MANUSCRIPT.

Approved for public release; distribution uniimited.

Approved for Distribution

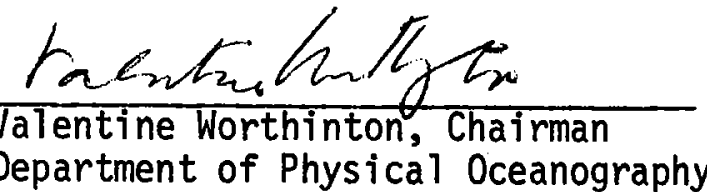


TABLE OF CONTENTS

Page

No.

ABSTRACT. . . . . . . . . . . . . . . . . . . . . 1

1.0 INTRODUCTION . . . . . . . . . . . . . . . . . . 2

2.0 OBJECTIVES . . . . . . . . . . . . . . . . . 2

3.0 APPROACH . . . . . . . . . . . . . . . . . . . . 3

3.1 Computer system . . . . . . . . . . . . . . 3

3.2 Program Language. ................ 3

3.3 Program Operation ................ 3

3.4 Features. . . . . . . . . . . . . . . 4

4.0 COMPUTER PROGRAM SOLUTION. . . . . . . . . . . . . . 5

4.1 Parameters Considered . . . . . . . . . . . . 5

4.2 General Description . . . . . . . . . . . . 6

4.3 Specific Description. . . . . . . . . . . . 7

4.3.1 Launch Transients. . . . . . . . . . . . 7

4.3.2 Current velocity .............. 10

4.3.3 Gravity and Resistive Forces . . . . . . . . 12

4.3.4 Equilibrium Equations. . . . . . . . . . . 14

4.3.5 Elongation and Elastic Properties. . . . . . . 17

4.3.6 Segment Displacement . . . . . . . . . . . 24

4.3.7 Automatic Component Length Adjustment. . . . . . 25

4.3.8 Reserve Buoyancy . . . . . . . . . . . . . 25

4.3.9 Component Terminations . . . . . . . . . . 26

5.0 REFERENCES . . . . . . . . . . . . . . . . . . . 27

ACKNOWLEDGMENTS . . . . . . . . . . . . . . . . . 28

APPENDICES: A. Operating Instructions for NOYFB. . . . . . . . 29

B. Options (Output and Change) . . . . . . . 55

C. Coding Summary - Standard WHOI Components . . . . 57

D. Standard Component Characteristics. . . . . . 58

E. Description of output . . . . . . . . . . 63

F. Sample Run. . . . . . . . . . . . . 70

G. Glossary - Program Variables. . . . . . . . 81

H. Program Listing . . . . . . . . . . 86 


\section{LIST OF FIGURES}

No.

1. Horizontal Current Profile Input. . . . . . . . . . . . . . 9

2. Resolution of Current Vector Components . . . . . . . . . . 11

3. Normal and Tangential Components of Hydrodynamic

Resistance and Gravity Forces . . . . . . . . . . . . . 13

4. Equilibrium Conditions - The Balance of Forces. . . . . . 15

5. General stress-Strain Relations - DACRON (components 6-10). 20

6. General Stress-Strain Relations - NYLON (components 11-15). 21

7. Stretch Curves - DACRON (components 6-10) . . . . . . . . 22

8. Stretch Curves - NYLON (components 11-15) . . . . . . . . 23 
ABSTRACT

This report describes computer program NOYFB: a method of determining the static configuration of sub-surface oceanographic moorings for the purposes of system design and analysis of performance. Operating instructions and the program listing are included as appendices.

The program is written in Fortran II specifically for W.H.O.I. Hewlett-Packard 2100 series shipboard computer systems. The user acts as the computer operator in a decision-making capacity, specifying, evaluating, and modifying the mooring composition and control and environmental parameters. Principle features of the program are:

a) useable both at sea and ashore,

b) real time selection of output formats and devices,

c) standard W.H.O.I. mooring component characteristics are stored in the program with the option of user modification,

d) capable of handling complex, non-uniform current profiles,

e) automatic component length adjustment for depth critical instruments,

f) calculation of launch transients and reserve buoyancy,

g) the ability to imput/output the mooring composition and characteristics from/to punched paper tape. 


\subsection{INTRODUCTION}

During the past six years the Moored Array Project of the Woods Hole Oceanographic Institution has developed and used operationally a subsurface oceanographic mooring system (Ref. 1). Composed of standardized mooring components and instrumentation, these moorings are deployed at a rate of approximately 40 per year. Because of the number involved it was felt that it would be efficient to use modern computer techniques to assist in the routine design of moorings. Each could then be conveniently tailored to specific scientific requirements, water depths, anticipated current regimes and logistical considerations.

Numerous computer programs for determining the static configuration and dynamic response of subsurface moorings exist (Ref. 2) including some highly relevant work produced at Woods Hole (Ref. 3). However, it is judged that on the whole these programs have the undesirable feature, for our application, of being geared to sophisticated engineering evaluation of system performance. This generally requires detailed knowledge of component characteristics, complex input/output procedures and involves considerable time delay in obtaining final or acceptable results.

Computer program NOYFB was written to eliminate the need for procedural complexity and to provide, in real time, a description of the mooring and its performance from an operational point of view.

It is the intent of this report to describe the composition, operation, and utilization of computer program NOYFB.

\subsection{OBJECTIVES}

The main objective of the program is to provide to the mooring designer and the person responsible for its construction the statistics of the static configuration of W.H.O.I. subsurface single point oceanographic moorings. Secondary objectives are:

- To provide a single program useable both at sea and in the laboratory.

- To permit the operator/designer to act in real time on-line with the computer in a decision-making role, evaluating and modifying successive runs.

- To make the program simple to use with a minimum of training in computer operation.

- To have the program lead the user step by step through successive input and option procedures. 
1d:

- To provide output in a format directly useable by those responsible for constructing the mooring in commonly used units (pounds, meters, degrees, etc.).

- To produce a permanent record on paper tape or magnetic tape of details of the composition of the mooring.

- To assure a high degree of flexibility so the program would be readily useable for special purpose applications and be easily manipulated by the experienced and sophisticated user.

\subsection{APPROACH}

\subsection{Computer System}

The Hewlett-Packard 2100 series computer system was selected for this application. These computers are readily available at W.H.O.I. as standard shipboard systems and as general usage systems ashore. All systems contain $16 \mathrm{~K}$ of memory. A variety of peripheral devices (CRT terminals, line printers, paper tape I/O, magnetic tape, cassette, and disc) give the operator flexibility in the method of data input and output. The machines are physically compact and easy to operate with a minimum of instruction.

\subsection{Program Language}

The program is written in Fortran II. This commonly-used language and the use of frequent annotation in the source program should permit convenient understanding of logic and flow in the event program modification is desired.

\subsection{Program Operation}

The computer systems are designed for on-line program user control. The program takes advantage of this feature by presenting data to the operator for real time evaluation and provides the means for convenient alteration of control and environmental parameters and of mooring components. This permits rapid optimization of the mooring design and evaluation of its performance. In addition, input errors can be detected and remedied without significant time delay.

To obtain simplicity of operation, all standard mooring component characteristics (buoyancy, area, elastic properties, etc.) are written into the program and stored in arrays at initialization. The user inputs the mooring component type and the program assigns characteristics as appropriate. 
In another attempt to obtain simplicity of operation, step by step instructions for program operation are displayed to the user (in English) with the sequence determined by his selection of options. This eliminates the need for a pre-run prepared set of control and input parameters with the attendant likelihood for error.

Flexibility of program application and of operation is attained by providing the option to change any component characteristic either at program initialization or at a subsequent run. Provision is made for the addition of non-standard components with unique elastic properties and coefficients of drag. Proper manipulation of these characteristics and of input parameters permits the program to be used for varied and complex sub-surface mooring systems.

\subsection{Features}

The program offers the following features:

a. All possible statistics generated by the program of the mooring configuration and the forces acting upon the mooring can be output. The user selects the information to be presented by sense switch option control (see Appendix E for details).

b. I/O flexibility by manual selection of five I/O devices at program initialization. Further, by exercising various options when running, the user can vary the input/output devices within those five devices. Judicious selection of the devices will provide for hard and/or soft copy, manual and/or machine input, and visual and/or machine output.

c. The ability to output to perforated paper tape (or any similar read/write device) the composition and characteristics of a mooring. Similarly, the ability to input a previously designed mooring from paper tape is provided. This feature provides a permanent record of the mooring and a means for efficient and rapid duplication of the mooring for future runs.

d. The ability to input a complex profile of horizontal current varying with depth in both speed and direction, i.e., not co-planar.

e. An omni-directional external force (point force) of any magnitude can be applied to the top of the upper component. This feature provides the ability to model the effects of components which are not integral to the mooring, such as surface markers and tag lines, upon the system.

f. Operator control of the maximum length of segments used in defining the discrete units for the calculation process. In effect, this gives the user the ability to vary the degree of approximation to the true shape of the mooring. It also controls the time required for the completion of each run. 
g. Operator comments are written in all output options providing headings and mooring identification.

h. All standard W.H.O.I. mooring components and their characteristics are written into the program and are accessed by code.

i. The operator has the option of altering any component characteristic or input parameter that is written into the program. This can be done both at initialization and after each run.

j. The program displays instructions for the operator to lead him through the proper sequence for initialization and the use of the change options.

k. The program has an automatic component length adjustment feature which places components at specified depths. The lengths of up to ten components will be adjusted so as to place a paired component at a desired depth.

\subsection{COMPUTER PROGRAM SOLUTION}

It is the intent of this section to describe the basic equations and logic used to determine the static configuration of subsurface moorings. Since the solution uses generally accepted theories for resolving and balancing the forces acting upon a mooring system, the description of the theoretical background is minimal.

\subsection{Parameters Considered}

The following parameters are considered in the calculation of the mooring configuration.

a. Component buoyancy, area, and length.

b. Component shape: reflected in the assigned coefficients of drag.

c. Elastic properties of wire and line.

d. Termination length and buoyancy.

e. Method of measuring synthetic lines, i.e,, slack or under $200 d^{2}$ tension.

f. Depth of water.

g. Horizontal currents varying with depth in both speed and direction. 
h. Maximum tensile loading during launch (launch transients).

i. Anchor weight and effective resistive area.

j. Application of an external load at the top component.

\subsection{General Description}

The program operates on the premise that subsurface moorings placed in a horizontal current velocity field react to drag-induced forces by spatial displacement with no significant alteration of tension. Horizontal displacement results in a subsequent vertical "dipping" of the mooring in a pseudo-cosine response which alters the position and attitude of the mooring in the forcing current regime. The equilibrium condition of the mooring system is determined in an iterative process in which the mooring configuration is recalculated for successively refined assumed current regimes. An assumed depth of the top component is calculated for each iteration. When the calculated depth and the assumed depth coincide ( $<2$ meters), i.e., the true and assumed current regimes are identical, the resulting mooring configuration is considered to be in a state of equilibrium.

The mooring is composed of individual components of given length which creates non-uniform buoyancy and area distribution over the length of the mooring. For this reason a finite element method is used to establish the equilibrium configuration and the loading of the mooring. Components are divided into discrete units (segments), the maximum length of which is user designated. segments are treated as inflexible but elastic cylinders with nodes of freedom at each end. The gravity and resistive forces acting on each segment are determined and balanced against the external restraining forces to obtain the equilibrium condition. This is done in an iterative process in which the inclination and azimuth of the segment are evaluated and recomputed (as are the gravity and resistive forces) until the change between successive steps is minimal ( $<0.1$ degree). Segment elongation is calculated, if appropriate, and the $\mathrm{X}, \mathrm{Y}$, and $\mathrm{Z}$ displacements of the stretched length are determined.

Computation is self-initiated at the termination of 'input. The measured length of all components is totaled and subtracted from the water depth to establish the assumed depth of the top component in the current profile. The peak loading of each component in a free-falling anchor launch is calculated. Where appropriate this is used in the calculation of segment elongation. Starting at the top component and proceeding sequentially along the mooring, the number of segments in each component is determined. The length, buoyancy, area, and assumed depth of the mid-point of each segment and the current velocity at that depth are computed. With 
these values the gravity and resistive (drag) forces are determined and the resulting attitude, displacement and loading of the segment are calculated as described above. The displacements of the segments within each component are summed and stored in arrays as are the inclination and axial tension of the lowest segment and the accumulative normal drag and the elongation of the component. These values are the source of the output statistics.

When these computations are complete the calculated depth of the top component is compared to the assumed depth used for those calculations. If the difference exceeds 2 meters a new assumed depth is determined and the configuration is recalculated. When the difference is less than 2 meters, the mooring is considered to be in equilibrium and the routine for automatic component length adjustment is entered. The depths of specified components are evaluated and the lengths of their paired component are adjusted to position them at desired depths. The entire computation sequence is then re-initiated. When all depth requirements are met the statistics are output.

\section{$4.3 \quad$ Specific Description}

A description of the significant aspects of the computer solution is given. Sections to be discussed are:

a. Launch transients

b. Current profile and point velocities

c. Gravity and resistive (drag) forces

d. Equilibrium equations

e. Component elongation and elastic properties

f. Displacement of segments and components

g. Automatic component length adjustment

h. Reserve or back-up buoyancy

\subsubsection{Launch Transients}

The maximum loading of each component of the mooring during free-fall anchor descent is calculated. Transients are considered the history of stress for synthetic lines which is required for the calculation of permanent elongation. Launch transients are calculated in the following manner. 


$$
\cdot T_{i}=\sum_{1, i} w+v^{2} \frac{1}{2} \rho \sum_{1, i} C_{D} A
$$

where

$$
\begin{aligned}
T_{i} & =\text { tension in component } i \text { in pounds } \\
\sum_{1, i} \mathrm{~W} & =\text { sum of the buoyancies of components } 1 \text { through } i \\
V & =\text { terminal velocity of the anchor in } \mathrm{ft} / \mathrm{sec} \\
\sum_{1, i} C_{D} \mathrm{~A} & =\text { sum of drag coefficient times effective area } \\
& \text { for components } 1 \text { through } i \\
\rho & =\text { mass density, taken to be } 2.0 \text { slugs } / \mathrm{ft}^{3}
\end{aligned}
$$

The terminal velocity* is found as

$$
v^{2}=\frac{w_{a}-w_{t}}{\frac{1}{2} \rho\left[\sum C_{D} A+C_{D} A\right]}
$$

where

$$
\begin{aligned}
w_{a}= & \text { weight of the anchor in pounds } \\
w_{t}= & \begin{array}{l}
\text { net buoyancy of the mooring components at the } \\
\text { anchor }
\end{array} \\
\sum_{D} A= & \begin{array}{l}
\text { sum of the drag coefficient times effective } \\
\text { area of all components }
\end{array} \\
C_{D} A_{a}= & \begin{array}{l}
\text { arag coefficient times effective area of the } \\
\text { anchor }
\end{array}
\end{aligned}
$$

*The program utilizes one set of drag coefficients for all calculations of hydrodynamic resistance. Coefficients for high velocity regimes are generally lower in value than those representative of low velocity regimes because of associated larger Reynolds numbers. Therefore, the calculated terminal velocity may be in error when the standard (programmed) coefficients of drag are used. However, this fault produces no significant error in the calculated values of launch tension for standard mooring components. 


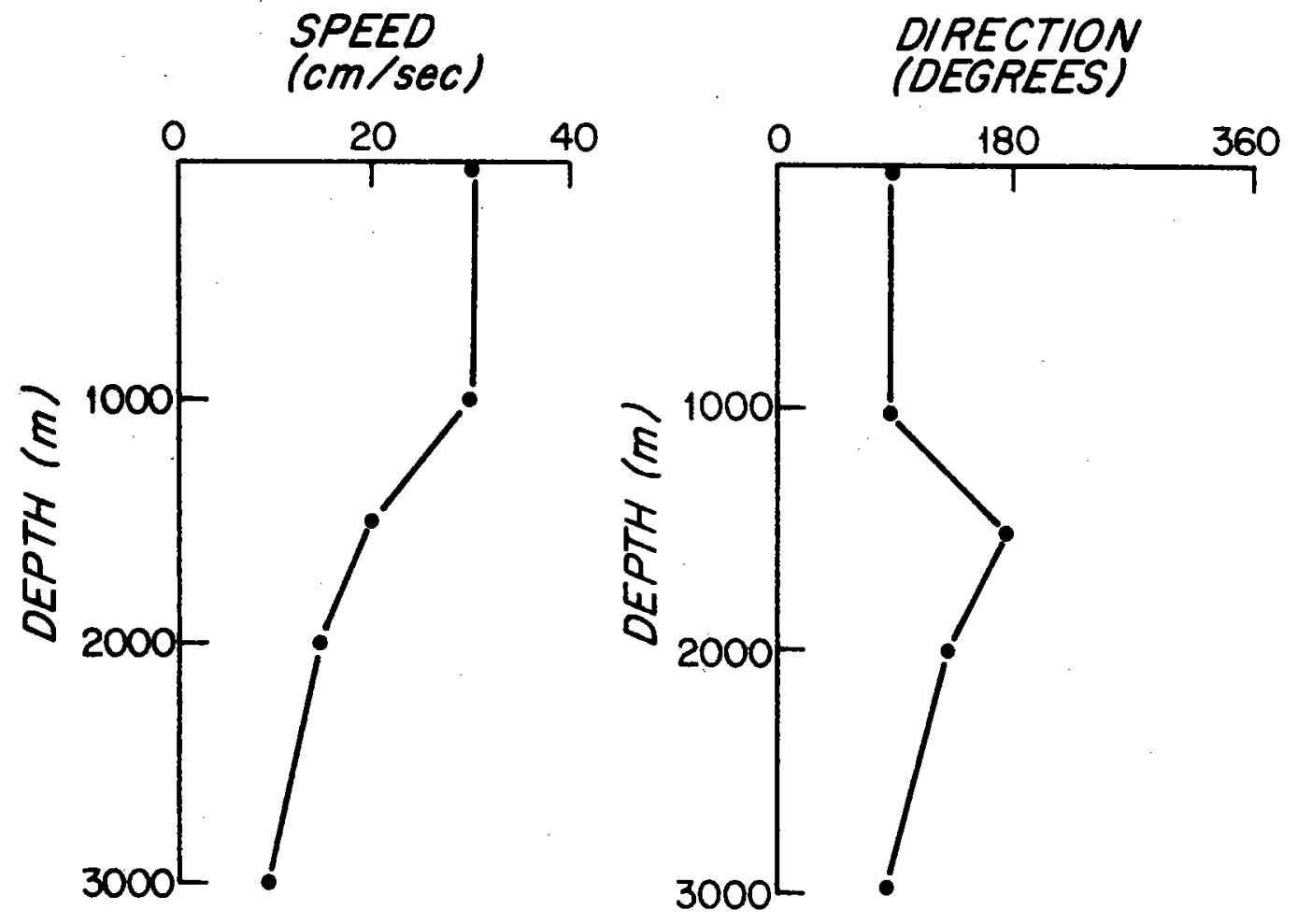

Fig. 1. Horizontal Current Profile Input. 


\subsubsection{Current velocity}

Horizontal current induced drag forces are the prime source of perturbation to subsurface mooring systems. Ocean current velocities can vary over the length of the mooring in a complex manner. The horizontal current field is an input parameter which is entered as a vertical profile of current velocities (see Fig. 1). The velocity profile is input as speed and direction at specified depths. The velocity at any point in the profile is obtained by linear interpolation between inclusive input values and is indexed by the assumed depth of the mid-point of the segment under consideration.

The velocity of a given point is broken into two components (see Fig. 2); one, $v_{u}$, lying in the plane of the segment, which tends to incline, and one, $v_{v}$, normal to the plane of the segment, which tends to rotate. The equations are

$$
\begin{aligned}
& \mathrm{v}_{\mathrm{u}}=\mathrm{v}_{\mathrm{T}} \cos \gamma \text { or } \mathrm{V}_{\mathrm{T}} \cos (\beta-\theta) \\
& \mathrm{v}_{\mathrm{v}}=\mathrm{v}_{\mathrm{T}} \sin \gamma \text { or }
\end{aligned}
$$

where

$$
\begin{aligned}
& \mathrm{v}_{\mathrm{T}}=\text { current vector speed } \\
& \beta=\text { current vector direction (relative to north) } \\
& \theta=\text { azimuth of segment } \mathrm{n} \\
& \gamma=\text { current direction relative to the plane of segment } \mathrm{n} \\
& \mathrm{v}_{\mathrm{u}}=\text { tangential component of velocity (incline) } \\
& \mathrm{v}_{\mathrm{v}}=\text { normal component of velocity (rotate) }
\end{aligned}
$$

$\mathrm{v}_{\mathrm{u}}$ and $\mathrm{v}_{\mathrm{v}}$ are recalculated with a new $\theta$ for each segment iteration. 


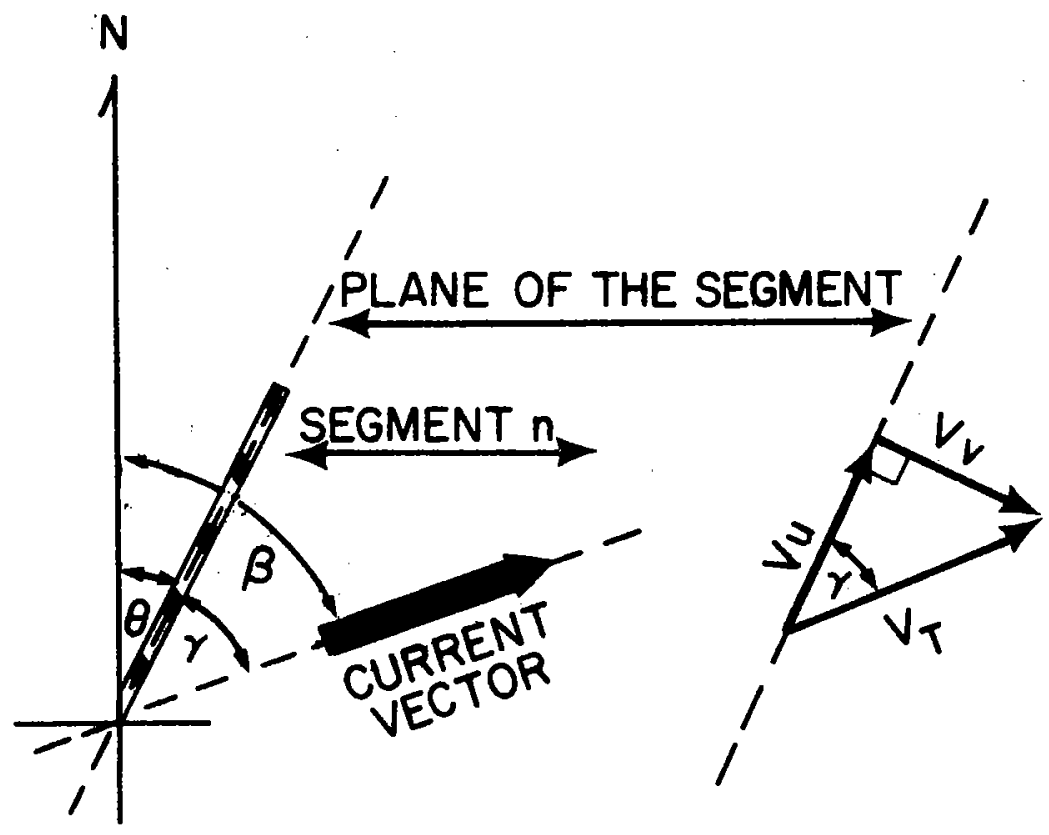

$$
\begin{aligned}
& V_{u}=V_{T} \cos (\gamma) \\
& V_{v}=V_{T} \sin (\gamma)
\end{aligned}
$$

Fig. 2. Resolution of Current Vector Components. 


\subsubsection{Gravity and Resistive Forces}

Two forces act on the segments of the mooring: gravity and hydrodynamic resistance (drag).* Gravity forces act in the vertical plane and the drag forces act in the horizontal plane. Each is broken into components relative to the vertical plane of the segment $n$ (see Fig. 3 ).

Gravity forces act only in the plane of the segment. They are defined as the buoyancy $(+/-)$ per unit length (lbs/meter) of the immersed component $i$. The buoyancy of the segment is

$$
w_{n}=w_{i} d s
$$

and

$$
\begin{aligned}
& \mathrm{w}_{\mathrm{N}}=\mathrm{w}_{\mathrm{n}} \sin \phi_{\mathrm{n}} \\
& \mathrm{w}_{\mathrm{T}}=\mathrm{w}_{\mathrm{n}} \cos \phi_{\mathrm{n}}
\end{aligned}
$$

where

$$
\begin{aligned}
& w_{n}=\text { buoyancy of segment } n \text { in pounds } \\
& w_{i}=\text { buoyancy per unit length of component } i \\
& d s=\text { length of segment } n \text { in meters } \\
& w_{N}=\text { normal component of buoyancy } \\
& w_{T}=\text { tangential component of buoyancy } \\
& \phi_{\mathrm{n}}=\text { angle of inclination to the vertical of segment } n . \\
& \text { Drag forces are considered to be uniform over the length } \\
& \text { of the segment and are separated into three orthogonal components } \\
& \text { relative to the axis of the segment: one, } D_{N u} \text {, normal to the }
\end{aligned}
$$

\footnotetext{
*A thixd force, the external point force, is not relevant to this
} discussion. 

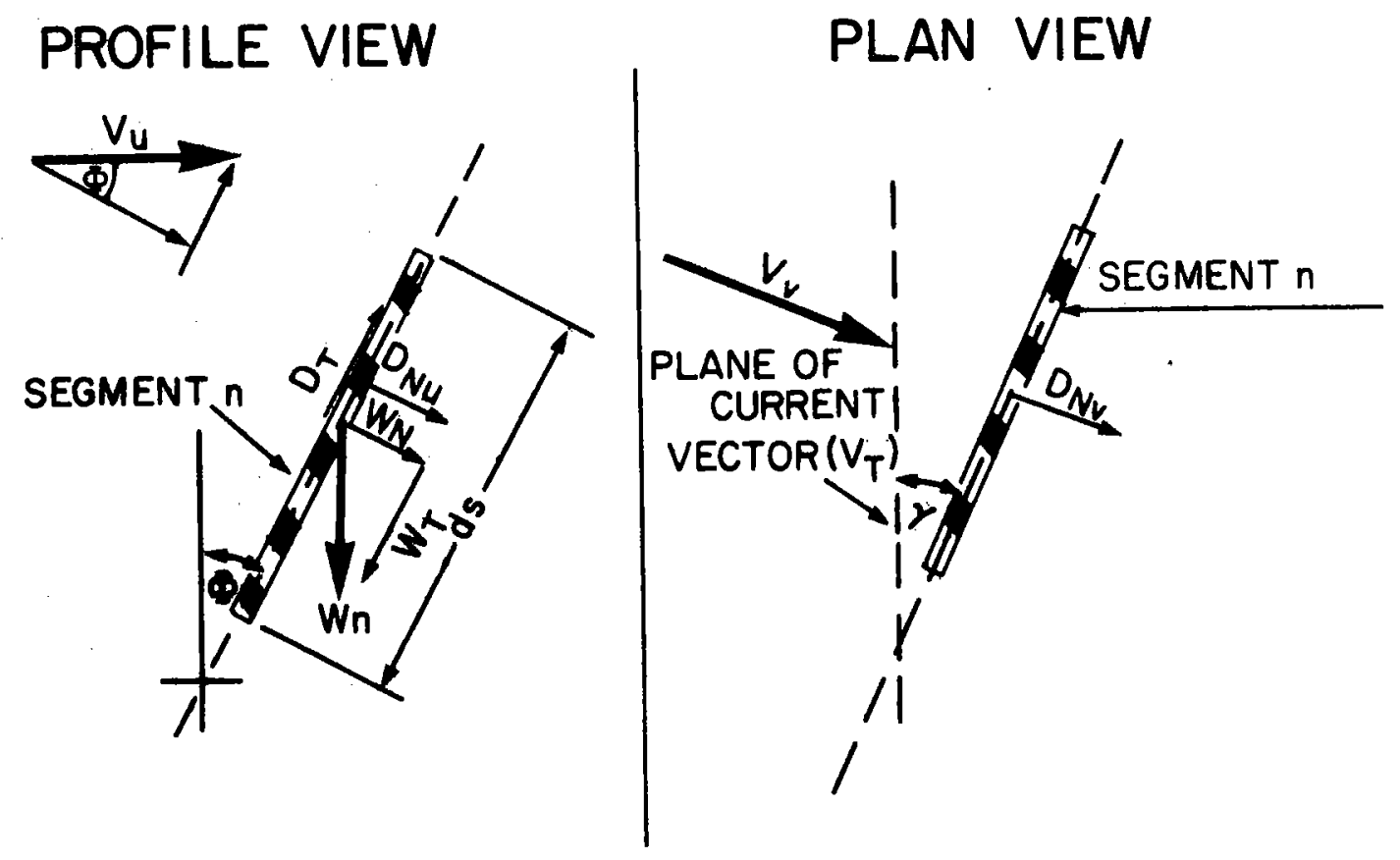

$$
\begin{aligned}
& W_{N}=W_{n} \sin \Phi \\
& W_{T}=W_{n} \cos \Phi \\
& D_{N u}=1 / 2 \rho C_{D N} \text { ds } A\left|V_{u} \cos \Phi\right| V_{u} \cos \Phi \\
& D_{N v}=1 / 2 \rho C_{D N} \text { ds } A\left|V_{V}\right| V_{V} \\
& D_{T}=1 / 2 \rho C_{D T} \pi \text { ds } A\left|V_{u} \sin \Phi\right| V_{u} \sin \Phi
\end{aligned}
$$

Fig. 3. Normal and Tangential Components of Hydrodynamic Resistance and Gravity Forces. 
segment in the vertical plane of the segment; one, $D_{\mathrm{NV}}$, normal to the vertical plane of the segment; and one, $D_{T}$, tangential to the segment (see Fig. 3). The expressions defining these components are

$$
\begin{aligned}
D_{\mathrm{Nu}} & =\frac{1}{2} \rho \mathrm{C}_{\mathrm{DN}} \text { ds } \mathrm{A}\left|\mathrm{V}_{\mathrm{u}} \cos \phi_{\mathrm{n}}\right| \mathrm{V}_{\mathrm{u}} \cos \phi_{\mathrm{n}} \\
\mathrm{D}_{\mathrm{NV}} & =\frac{1}{2} \rho \cdot \mathrm{C}_{\mathrm{DN}} \text { ds } \mathrm{A}\left|\mathrm{V}_{\mathrm{v}}\right| \mathrm{V}_{\mathrm{v}} \\
\mathrm{D}_{\mathrm{T}} & =\frac{1}{2} \rho C_{\mathrm{DT}} \pi \text { ds } \mathrm{A}\left|\mathrm{v}_{\mathrm{u}} \sin \phi_{\mathrm{n}}\right| \mathrm{v}_{\mathrm{u}} \sin \phi_{\mathrm{n}}
\end{aligned}
$$

where

$$
\begin{aligned}
\mathrm{D}_{\mathrm{Nu}}= & \text { normal component of drag in the plane of the } \\
& \text { segment (acting to incline) } \\
\mathrm{D}_{\mathrm{NV}}= & \begin{array}{l}
\text { component of drag normal to the plane of the } \\
\text { segment (acting to rotate) }
\end{array}
\end{aligned}
$$

$$
\begin{aligned}
A & =\text { area per unit length }\left(\mathrm{m}^{2} / \mathrm{m}\right) \\
D_{T} & =\text { tangential component of drag (axial) } \\
\rho & =\text { mass density of the fluid (assumed to be } 2.0 \text { ) } \\
C_{D N} & =\text { coefficient of normal drag } \\
C_{D T} & =\text { coefficient of tangential drag. }
\end{aligned}
$$

Variations in the shape of mooring components are reflected in the values assigned to $C_{D_{N}}$ and $C_{D T}$ permitting the use of a single set of expressions for drag calculations. $W_{N}, W_{T}$, $D_{\mathrm{Nu}}, \mathrm{D}_{\mathrm{Nv}}$, and $\mathrm{D}_{\mathrm{T}}$ are reclaculated for each iteration.

\subsubsection{Equilibrium Equations (see Fig. 4)}

A mooring is composed of components which are, for calculation purposes, subdivided into discrete units of varied length known as segments. The equilibrium condition of each segment is calculated in an iterative process where gravity 

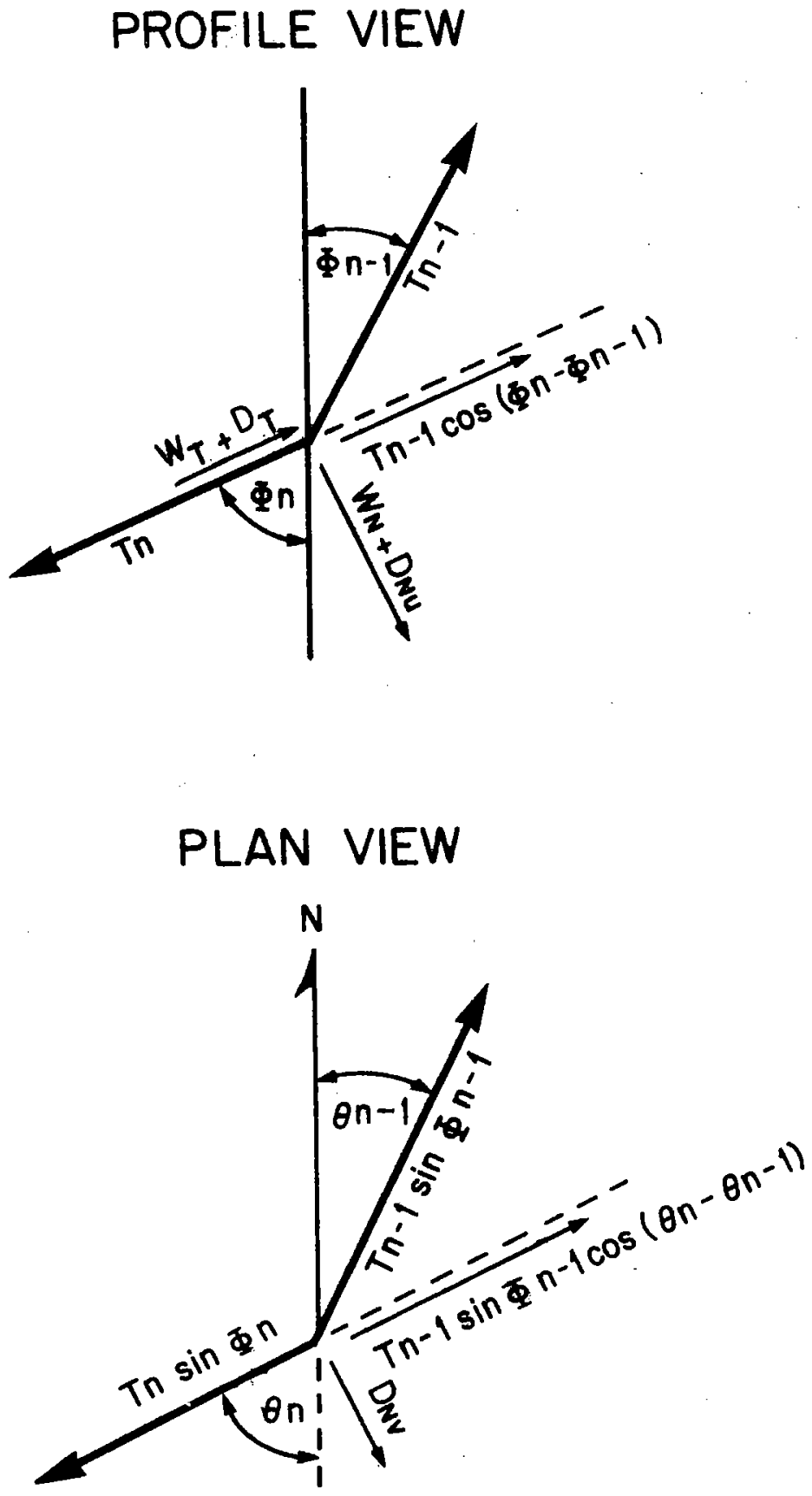

Fig. 4. Equilibrium Conditions - The Balance of Forces. 
and resistive forces are balanced against external restraining forces. The equilibrium conditions are

$$
\begin{aligned}
\mathrm{W}_{T}+D_{T} & =T_{n}-T_{n-1} \cos \left(\phi_{n}-\phi_{n-1}\right) \\
W_{N}+D_{N u} & =T_{n-1} \sin \left(\phi_{n}-\phi_{n-1}\right) \\
D_{N v} & =T_{n-1} \sin \phi_{n-1} \sin \left(\theta_{n}-\theta_{n-1}\right)
\end{aligned}
$$

where

$$
\begin{aligned}
& T=\text { axial tension } \\
& \phi=\text { inclination of the segment } \\
& \theta=\text { azimuth of the segment. }
\end{aligned}
$$

The state of equilibrium is described by the attitude of the segment in terms of axial tension, inclination to the vertical and azimuth. The program converges to the balance of forces by the following expressions:

$$
\begin{aligned}
& \phi_{n}=\Delta \phi^{\prime}+\phi^{\prime} \\
& \theta_{n}=\Delta \theta^{\prime}+\theta^{\prime}
\end{aligned}
$$

where

$$
\begin{aligned}
\phi^{\prime} \text { and } \theta^{\prime}= & \text { the inclination and azimuth from the im- } \\
& \text { mediately preceding iteration } \\
\Delta \phi^{\prime} \text { and } \Delta \theta^{\prime}= & \text { the change in inclination and azimuth be- } \\
& \text { tween successive iterations }
\end{aligned}
$$

Substituting $\phi^{\prime}$ and $\theta^{\prime}$ for $\phi_{n}$ and $\theta_{n}$ in expressions (11), (12), (13), and by further substituting the transposed expressions (11), (12), (13) for $\Delta \phi^{\prime}$ and $\Delta \theta^{\prime}$, the following equations result. 


$$
\begin{aligned}
& T_{n}=T_{n-1} \cos \left(\phi^{\prime}-\phi_{n-1}\right)+D_{T}+W_{T} \\
& \phi_{n}=\tan ^{-1}\left[\frac{D_{N u}+W_{N}-T_{n-1} \sin \left(\phi^{\prime}-\phi_{n-1}\right)}{T_{n}}\right]+\phi^{\prime} \\
& \theta_{n}=\tan ^{-1}\left[\frac{D_{N v}-T_{n-1} \sin \left(\phi_{n-1}\right) \sin \left(\theta^{\prime}-\theta_{n-1}\right)}{T_{n} \sin \phi_{n}}\right]+\theta^{\prime}
\end{aligned}
$$

Gravity and drag force components are recalculated for each iteration using the values $\phi^{\prime}$ and $\theta^{\prime}$. Therefore, the values of $\Delta \phi^{\prime}$ and $\Delta \theta^{\prime}$ tend to converge to zero. The equilibrium condition is considered to exist when $\phi_{n}-\phi^{\prime}$ and $\theta_{n}-\theta^{\prime}$ are $<0.1$ degree.

At the start of each iteration procedure $\phi^{\prime}$ and $\theta^{\prime}$ are set equal to $\phi_{n-1}$ and $\theta_{n-1}$.

At program initialization $\mathrm{T}_{\mathrm{n}-1}, \phi_{\mathrm{n}-1}, \theta_{\mathrm{n}-1}$ are set equal to the input values of the external point force at the top component.

\subsubsection{Elongation and Elastic Properties}

The elastic responses of mooring cables are considered in this study. Elastic components fall into two categories: wire rope and synthetic line.

When stressed, wire rope elongates by mechanical deformation of the cable structure and by the elastic response of its metallic components.

Structural elongation is found by

$$
\varepsilon_{\mathrm{m}}=\frac{\mathrm{T}}{\mathrm{RBS}} \cdot \mathrm{K}
$$

Elastic elongation is found by (Hooke's Law)

$$
\varepsilon_{\mathrm{e}}=\frac{\sigma}{\mathrm{E}} \text { or } \quad \varepsilon_{\mathrm{e}}=\frac{\mathrm{T}}{\mathrm{AW} \cdot \mathrm{E}}
$$

Expressions (19), (20) are combined in the equation:

$$
\varepsilon_{\mathrm{T}}=\left(\frac{\mathrm{T}}{\mathrm{RBS}} \cdot \mathrm{K}+\frac{\mathrm{T}}{\mathrm{AW} \cdot \mathrm{E}}\right) \times \mathrm{L}_{\mathrm{O}}
$$


where

$$
\begin{aligned}
& \varepsilon_{\mathrm{T}}=\text { total strain or elongation (meters) } \\
& \varepsilon_{\mathrm{m}}=\text { structural strain as percent elongation } \\
& \varepsilon_{\mathrm{e}}=\text { elastic strain as percent elongation } \\
& \sigma=\text { stress on the wire or tension/area (psi) } \\
& \mathrm{E}=\text { modulus of elasticity (psi) } \\
& T=\text { axial tension on the wire segment (1bs) } \\
& \mathrm{RBS}=\text { rated breaking strength (1bs) } \\
& \mathrm{K}=\text { coefficient of structural stretch } \\
& \text { Aw }=\text { metallic cross-sectional area of the wire (in }{ }^{2} \text { ) } \\
& \mathrm{L}_{\mathrm{O}}=\text { slack or measured length of the wire (meters) }
\end{aligned}
$$

In the program, $\mathrm{K}$ and $\mathrm{E}$ are considered stretch characteristic constants of wire and are stored in an array as $\mathrm{E}(1)$ and $E(2)$ respectively.

Standard W.H.O.I. mooring wire is manufactured by U. S. Steel. Structural stretch at the elastic limit (70\% of RBS) is approximately 18 and is assumed to decrease linearly to zero at no load. The modulus of elasticity (Youngs) of the wire is $20.5 \times 10^{6}$. Therefore,

$$
\begin{aligned}
& E(1)=0.01 / .7 \text { or } 1.43 \times 10^{-2} \\
& E(2)=20.5 \times 10^{6}
\end{aligned}
$$

The stretch of synthetic line in response to tensile loading is the sum of permanent and elastic elongation. Permanent elongation represents the residual deformation or strain resulting from the "history" of stress. Elastic elongation represents the additional strain caused by elastic response to instantaneous loading. Elongation is defined in terms of percent of measured length. 
A single expression is used to define the relationship of tension to both permanent and elastic elongation of all synthetic line. Measurement at $200 \mathrm{~d}^{2}$ is assumed.*

$$
\left.\frac{T}{d^{2}}=A\left[\frac{L-L_{O}}{L_{\circ}}\right)\right]^{B}
$$

where

$$
\begin{aligned}
T & =\text { tension in pounds } \\
\mathrm{d} & =\text { diameter of the line in inches } \\
\mathrm{L} & =\text { stretched length of the line } \\
\mathrm{L}_{\mathrm{O}} & =\text { slack or measured length of the line } \\
\mathrm{A} & =\text { linear coefficient of elongation } \\
\mathrm{B} & =\text { exponential coefficient of elongation }
\end{aligned}
$$

Elongation of the line is found by

$$
\varepsilon_{T}=\left(\frac{T_{m}}{d^{2} A_{p}}\right)^{\frac{1}{B_{p}}}+\left(\frac{T_{i}}{d^{2} A_{e}}\right)^{\frac{1}{B_{e}}}
$$

where

$$
\begin{aligned}
& \varepsilon_{T}=\text { total strain or percent elongation } \\
& T_{m}=\text { maximum stress in the history of the line (lbs) } \\
& T_{i}=\text { instantaneous tension (lbs) } \\
& d=\text { diameter of the line (inches) } \\
& A_{p}=\text { linear coefficient (permanent) } \\
& B_{p}=\text { exponential coefficient (permanent) } \\
& A_{e}=\text { linear coefficient (elastic) } \\
& B_{e}=\text { exponential coefficient (elastic). }
\end{aligned}
$$

\footnotetext{
*In order to standardize procedures for relaxed measurement of synthetic line manufacturers have adopted the technique of loading the line to a tension in pounds equal to $200 d^{2}$ where $d$ is the nominal diameter of the line in inches.
} 


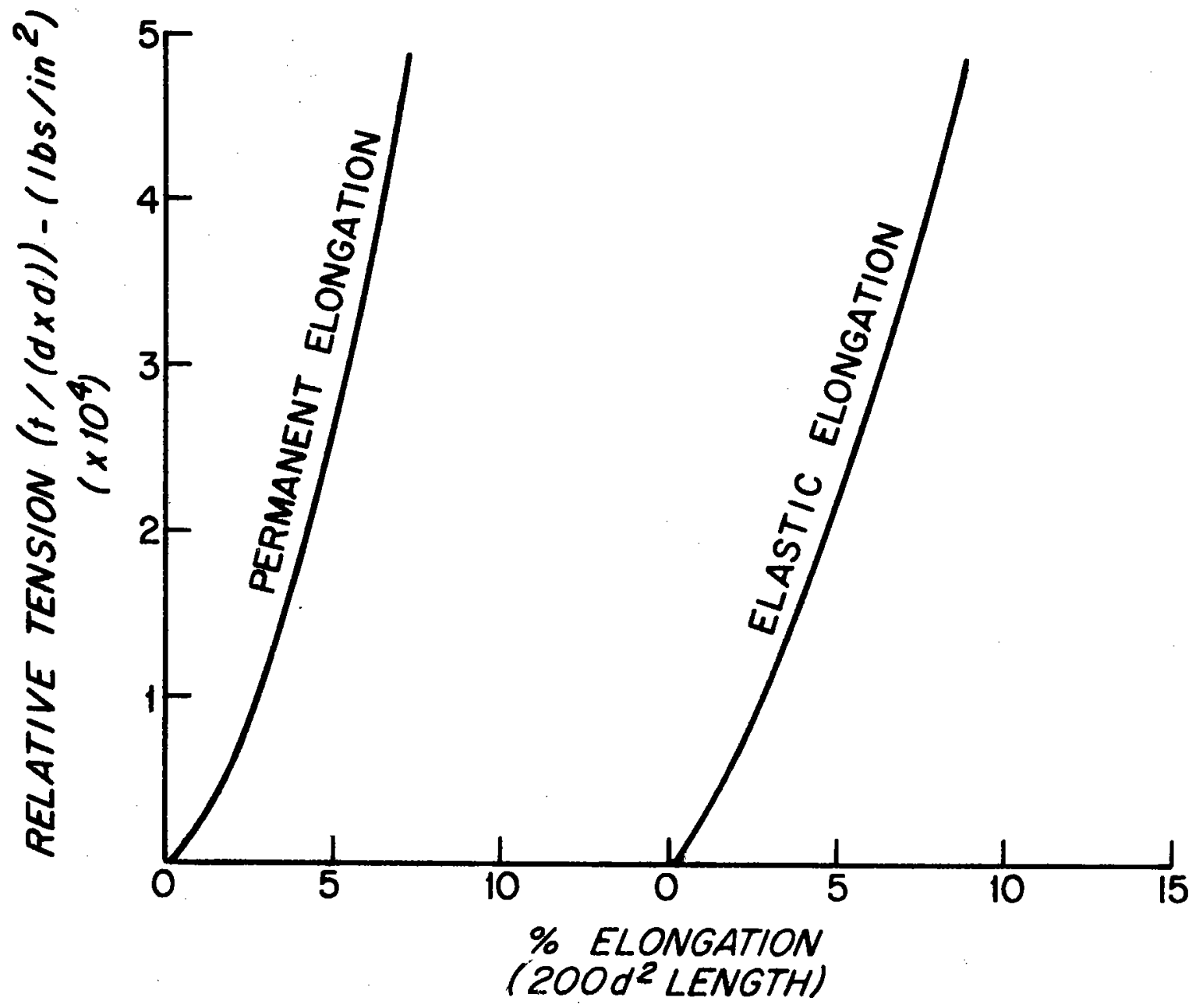

Fig. 5. General Stress-Strain Relations - DACRON (components 6-10) 


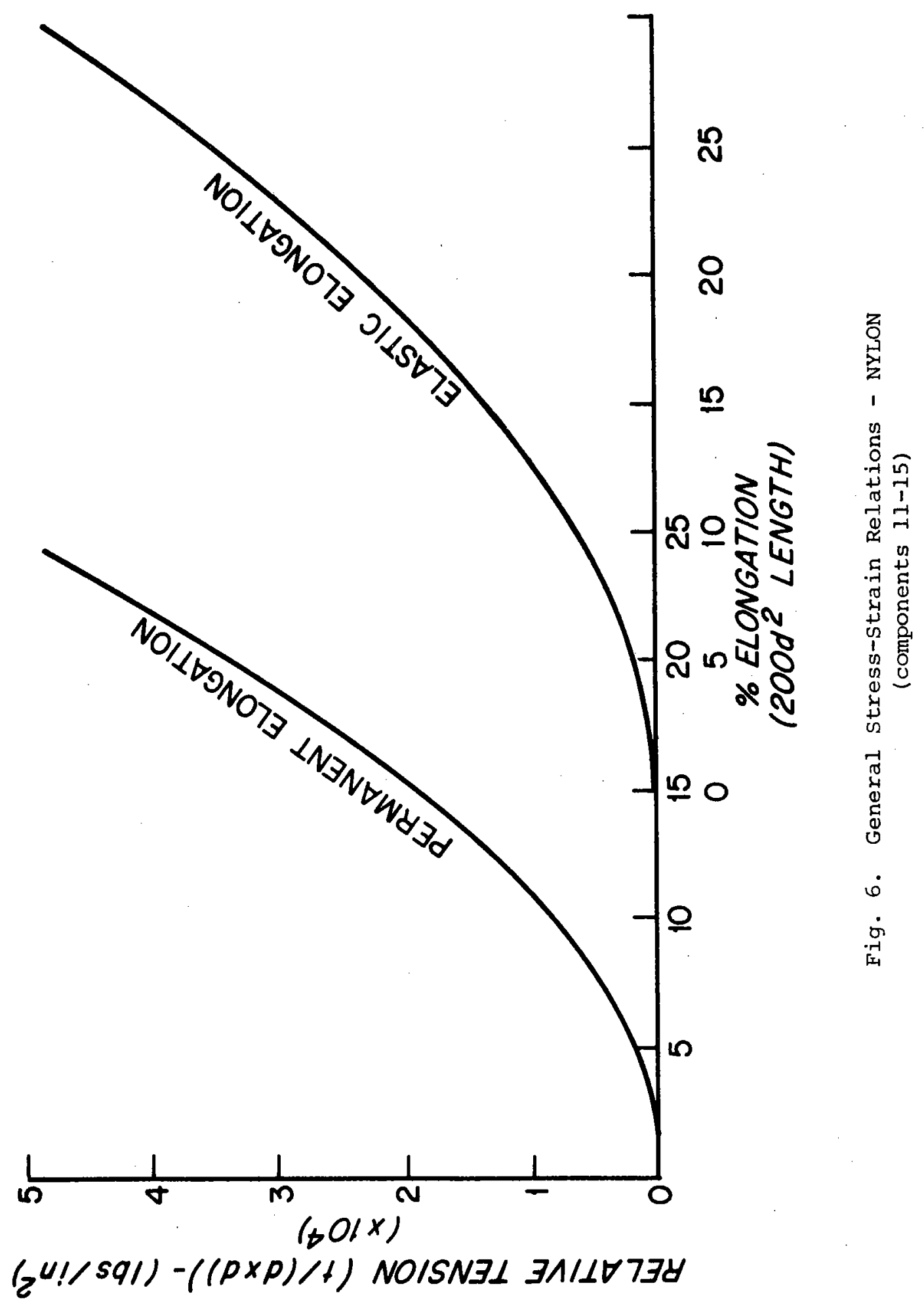




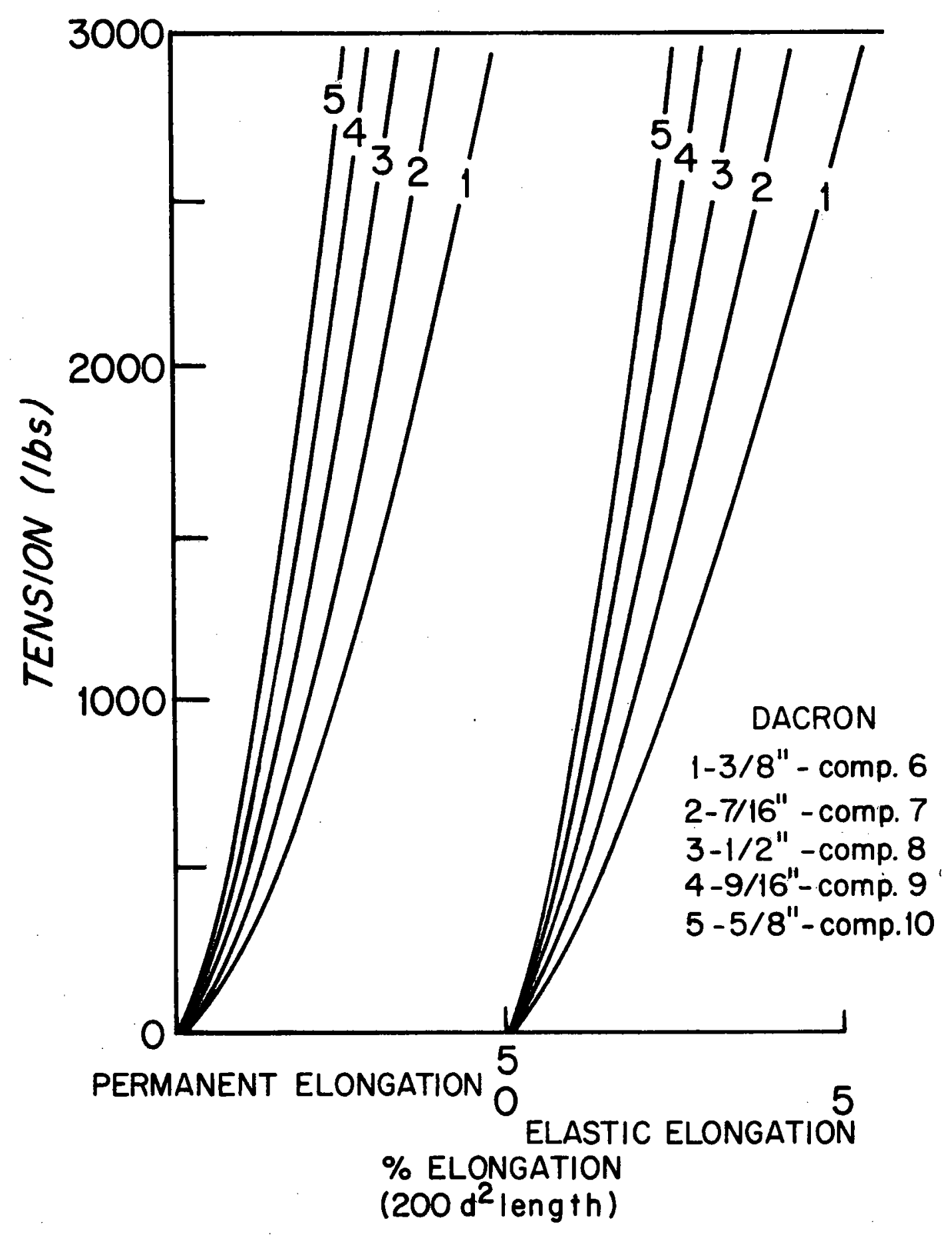

Fig. 7. Stretch Curves - DACRON
(components 6-10) 


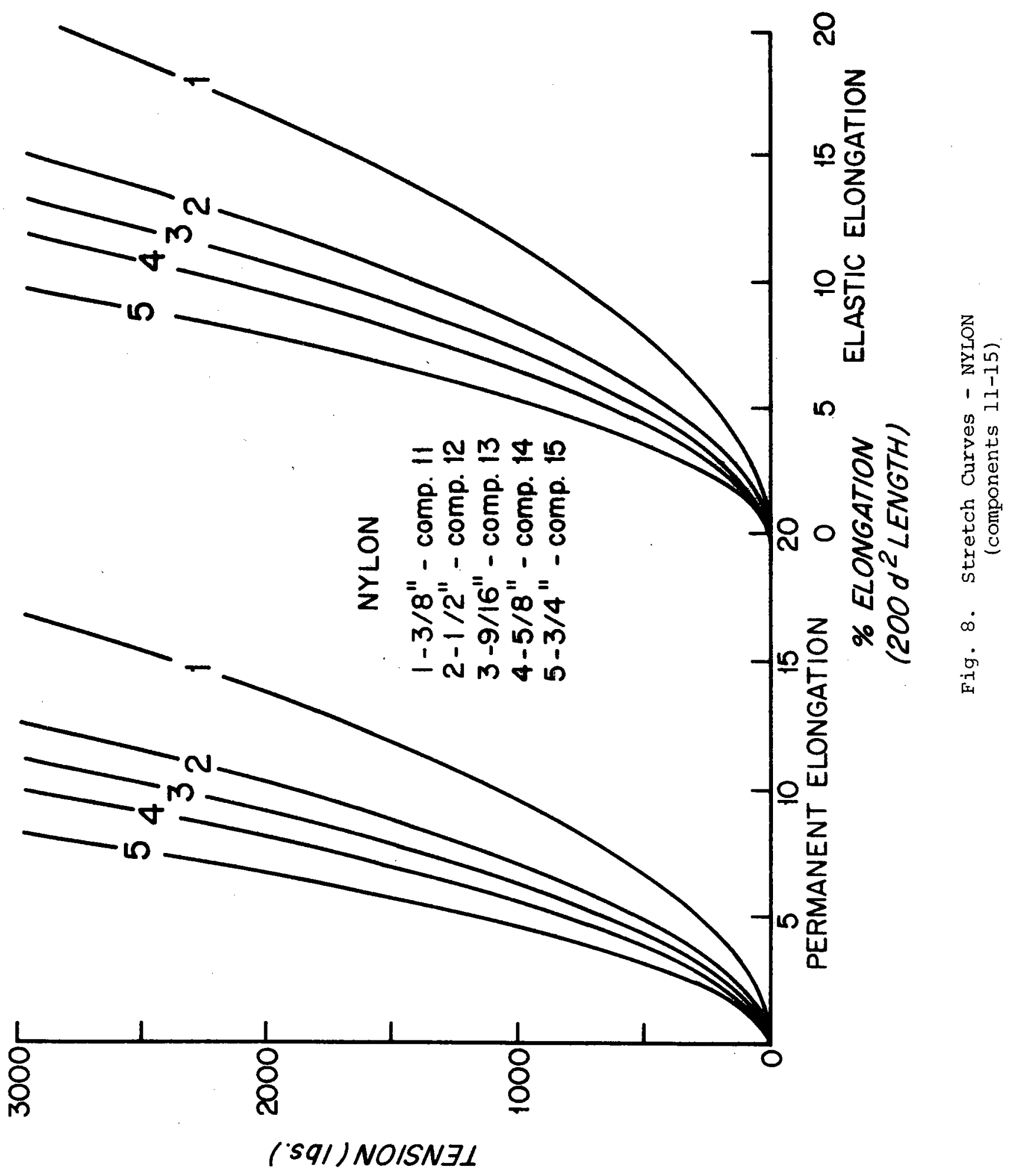


The coefficients $A_{p}, B_{p}, A_{e}, B_{e}$ are considered the stretch characteristic constants of synthetic line. They are stored (in array E) as a set of four coefficients for each of the three types of synthetic line: dacron, nylon, and unspecified.

The coefficients that appear in the program for standard W.H.O.I. synthetic line components result from a series of laboratory tests on dacron and nylon line specimens. They represent the best fit to a series of stress-strain curves obtained for new and used dacron and nylon. Their use allows a reliable prediction of the elongation of lines of similar construction and manufacture under normal loading conditions. Figures 5 and 6 show the general Stress-Strain relationship these coefficients yield for dacron and nylon respectively. The stretch curves obtained for sizes in common use at W.H.O.I. are shown in Figures 7 and 8 .

\section{$\underline{4.3 .6}$ Segment Displacement}

The configuration or shape of the mooring is described in terms of depth below the surface and horizontal displacement from the anchor. The relative displacements of the top from the bottom of each segment are summed with those of the segments below to obtain the absolute displacements or those relative to the anchor. The relative displacements of each segment are found by:

$$
\begin{aligned}
& \mathrm{X}=\mathrm{L}_{\mathrm{s}} \times \sin \phi_{\mathrm{n}} \cos \theta_{\mathrm{n}} \\
& \mathrm{Y}=\mathrm{L}_{\mathrm{s}} \times \sin \phi_{\mathrm{n}} \sin \theta_{\mathrm{n}} \\
& \mathrm{z}=\mathrm{L}_{\mathrm{s}} \times \cos \phi_{\mathrm{n}}
\end{aligned}
$$

where

$$
\begin{aligned}
\mathrm{X} & =\mathrm{X} \text { component of horizontal displacement (meters) } \\
\mathrm{Y} & =\mathrm{Y} \text { component of horizontal displacement (meters) } \\
\mathrm{Z} & =\text { vertical height of the inclined segment } \mathrm{n} \text { (meters) } \\
\mathrm{L}_{\mathrm{S}} & =\text { stretched length of segment } \mathrm{n} \text { (meters). }
\end{aligned}
$$




\subsubsection{Automatic Component Length Adjustment}

One of the most time consuming and mundane tasks for the mooring designer is the adjusting of the lengths of elastic line or wire so as to place instruments at desired operating depths. The program is capable of adjusting the lengths of up to ten components each of which is paired with a depth critical component, generally an instrument. In operation, the configuration of a mooring system is determined and the calculated depths of the designated components are compared with the input objective depths. If a discrepancy exists, the length of the appropriate component is adjusted and the configuration of the modified mooring is recomputed. Corrections to component lengths simply are

$$
L_{c}=I_{i}+\left(D_{C}-D_{d}\right)
$$

where

$$
\begin{aligned}
& L_{c}=\text { corrected length of adjustable component } \\
& L_{i}=\text { original length of adjustable component } \\
& D_{C}=\text { calculated depth } \\
& D_{d}=\text { desired depth. }
\end{aligned}
$$

The evaluation procedure starts at the deepest designated component in the mooring system and proceeds upward checking each in turn. Only one component is adjusted at a time. The depths of all designated components are evaluated at the completion of each calculation cycle. Adjustment will continue until all critical depths are satisfied.

\subsubsection{Reserve Buoyancy}

Reserve buoyancy is the net buoyancy in the mooring (w/o anchor) below a given component. It indicates the ability to recover the lower portion of a mooring in the event the mooring should part at a higher component. For this reason it is also known as the back-up buoyancy (Ref. 4). The reserve buoyancy at the top component is the sum of the buoyancies of all components to and including the release but not those below it (components below the release are not recoverable). At the upper end of each component, the reserve is 


$$
R_{i}=R_{t}-\sum_{1, i-1} w
$$

where

$$
\begin{aligned}
R_{i} & =\text { reserve buoyancy at component } i \text { (lbs) } \\
R_{t} & =\text { total reserve buoyancy of the mooring system } \\
\sum_{1, i-1} W & =\text { sum of the buoyancies of all higher components. }
\end{aligned}
$$

\subsubsection{Component Terminations}

Terminations at the ends of mooring components and the hardware used to couple components in tandem produce concentrations of weight which must be taken into consideration when calculating buoyancy distribution over the length of the mooring. The program is designed so that the lowest segment of each component has added to it, the weight and length of the hardware at that junction. The weight and length can be designated by the operator and are considered similar for all component junctions in the mooring. The area of the termination is neglected. 


\subsection{REFERENCES}

1. Heinmiller, R. H. and R. G. Walden. "Details of Woods Hole Moorings," W.H.O.I. Report 73-71, October 1973, unpublished manuscript.

2. Albertsen, N. D. "A Survey of Techniques for the Analysis and Design of Submerged Mooring Systems," Naval Civil Engineering Laboratory, Port Hueneme, California, Report R-815, August 1974 .

3. Berteaux, H. O. and N, K. Chhabra. "Computer Programs for the Static Analysis of Single Point Moored Surface and Subsurface Buoy Systems," W.H.O.I. Report 73-22, March 1973, unpublished manuscript.

4. Berteaux, H. O. and R. H. Heinmiller. "Back-up Recovery of Deep Sea Moorings," Marine Technology Journal, vol. 7, \#3, May 1973. 
The author wishes to thank the many individuals in the Woods Hole buoy group who through their ideas and criticism contributed to the development of this program. I especially acknowledge the influence and assistance of Susan Schultz Tapscott and Henri Berteaux. I am particularly grateful to Doris Haight and the Graphic Arts Department for their assistance and patience.

The work was performed with the support of the office of Naval Research under contract N00014-66-CO241; NR 083-004. 
APPENDIX A

OPERATING INSTRUCTIONS FOR NOYFB

(Revision 9.1)

Program NOYFB is written in Fortran II and designed specifically to be run on $16 \mathrm{~K}$ Hewlett-Packard 2100 series computer systems.

The user is assumed to have a basic knowledge of computer operation and the ability to load and initialize the program. He is also assumed to have a basic knowledge of mooring design and construction.

It is the objective of this appendix to explain the mechanics of running the program and to describe, in detail, the procedures involved. All known restrictions or limits to the use of the program are described as are all the recognized pitfalls or sources of error. Useful tidbits of information, which will assist the operator in understanding the processes, are included.

The program has three basic modes of operation from the users point of view: a) program initialization or initial set up, b) calculation of statistics and output, c) input parameter modification. During program initialization or initial set up, the program leads the user through a fixed input procedure. During the calculation of mooring statistics, the operator has no control of the program other than to manually abort the run. In the input parameter modification mode, the operator selects the sequence of the input procedure through the use of "change options".

The operator responds to machine instructions by means of entries on the keyboard input device.

There are sixteen categories of control and mooring parameters which the operator either must or has the option of entering into the computer. The procedures for entering these parameters are described in the sequence in which machine instructions are displayed to the operator. The meaning of each instruction, the criteria for selection of a response and the input formats are detailed. The operating procedures are broken down into $22 \mathrm{sec}-$ tions: 1 through 16 describe the use of the sixteen basic categories; 17 deals with the use of change options; 18 through 22 provide addition instructions for the use of select change option. The sections are: 
1. Input/Output Devices

2. Use of Paper Tape

3. Component Constants or Characteristics

4. Stretch Characteristics or Constants

5. Mooring Components

6. Measurement of Synthetic Line

7. Anchor Weight and Area

8. Operator Comments

9. Water Depth

10. Current Profile

11. Drag Coefficients

12. Segment Length

13. Automatic Length Adjustment

14. Point Force

15. Terminations

16. Run or Error Correction

17. Change Options

18. Option 3 - Mooring Configuration

19. Option 6 - Water Depth

20. Option 14 - Rerun w/o Recalculation

21. Option 15 - Input Mooring from PTR

22. Option 16 - Output Mooring to PP

GENERAL NOTES

a) The description in this Appendix can be supplemented by reference to Appendices B, C, D, F.

b) The use of sense switch options, a form of operator control, is described in Appendix B.

c) In general, when responding to a machine generated instruction, the meaning of the following entries are:

$$
\begin{aligned}
& 1 \text { - for yes or affirmative } \\
& \varnothing \text { - for no or negative } \\
& 99 \text { - terminates an input sequence. }
\end{aligned}
$$


d) When assigning component codes to non-standard components, the operator must note these designations in some manner for future reference. The memory space available on W.H.O.I. HP-2100 computers did not permit alphanumeric labelling of component types in the output of this program.

1. Input/Output Devices (see text $2.4 . \mathrm{b}, 3.4 . \mathrm{c}$ )

Machine Instruction:

ENTER FIVE I/O DEVICES

SOFT COPY, HARD COPY, PAPER PUNCH, KEYBOARD, PAPER READER STANDARD URN ARE:

$2,6,4,1,5$

The Unit Reference Numbers of potential I/O devices are manually entered at program initialization. The use of these devices is controlled by sense switch and change options (Appendix B). Five device numbers must be entered. Dummy values must be inserted for nonexistent or omitted devices. The operator enters the unit reference numbers of the I/O devices in the format $a, b, c, d, e$, where:

a - is the soft copy output device

b - is the hard copy output device

c - is the paper tape punch or similar device

d - is the keyboard input device

e - is the paper tape reader or similar device

NOTES :

a) Standard W.H.O.I. unit reference numbers for I/O devices are:

$$
\begin{aligned}
& 2 \text { - Tektronix } 4010 \text { C.R.T. (soft copy) } \\
& 6 \text { - line printer (hard copy) } \\
& 4 \text { - paper tape punch } \\
& 1 \text { - Tektronix } 4010 \text { keyboard } \\
& 5 \text { - paper tape reader }
\end{aligned}
$$

b) Magnetic tape, disc, and cassette I/O devices may be used in lieu of paper tape devices but, because the program is not capable of file management, their use is awkward and not recommended.

c) Specification of I/O devices as described in this section is performed only at program initialization. To modify the I/O devices the program must be reinitialized and the entire initialization 
procedure performed. (This should not be confused with the exercise of sense switch option control of the I/O devices.)

2. Use of Paper Tape (see text 3.4.C and Appendix E)

Machine Instruction:

INITIAI RUN FROM P.T. ?: 1 - YES, $\varnothing$ - NO

A punched paper tape, generated by a previous run, can be used to input the mooring composition, component characteristics, stretch coefficients, drag coefficients, anchor characteristics, comments, and water depth. Manual initialization resumes at section $10-$ Current Profile.

To read from paper tape the reader should be powered on, the tape loaded and the reader placed in the "READ" mode before the response " 1 " is input. A " $\varnothing$ " response, indicating full manual initialization, continues initialization at section 3 - Component Constants.

The paper tape input modifies all programmed variables regardless of their applicability to that mooring composition. Therefore, when changing component types to modify the mooring composition, the operator should exercise caution and verify that the desired component characteristics, stretch constants, and drag coefficients are in memory.

When the tape is completely read, the soft copy output device will display the water depth. This information is required for a correct input of the current profile.

3. Component Constants or Characteristics (see Appendices C, D)

Machine Instruction:

CHANGE COMP. CONSTANTS $?: 1$ - YES, $\varnothing$ - NO

A "I" response enables the operator to modify any component characteristic of buoyancy (components 1-42), resistive area (components 1-42), Rated Breaking Strength (components 1-24), and crosssectional metallic area (components 1-5). A " $\varnothing$ " response by-passes this section and initialization resumes at section 4 - Stretch. Characteristics.

A "1" response generates the machine instruction:

ENTER CODING : 1-W(I), 2-A (I), 3-RBS (I), 4-AW(I) THEN TYPE COMPONENT CODE NO. AND NEW VALUE 
The operator responds in the format $a, I, C$, where:

a - is the indicator of the variable to be changed.

1 - for buoyancy $(W(I))$

2 - for profile area (A(I))

3 - for Rated Breaking Strength (RBS(I))

4 - for metallic cross sectional area of wire (AW(I))

I - is the component type code (1-42)

c - is the new value

Example: $1,23,-8.5$

In the example the buoyancy of component type $23,1 / 2$ " chain, is modified to $-8.5 \mathrm{lbs} /$ meter, i.e., $\mathrm{W}(23)=-8.5$.

After the change is entered the machine instructs:

NEXT OR 99

An operator response of "99" will end the sequence and cause initialization to be resumed at section 4 - stretch Constants. If another characteristic is to be modified (or an error in the preceding input corrected) the operator enters the next change in the format described above.

NOTES :

a) The new value for buoyancy or area is considered to be the buoyancy or profile area per meter length. The new value therefore must be the total buoyancy or profile area of the component divided by the total component length. For example, the values of $W(25)$ and A(25) for a VACM with a buoyancy of $-75 \#$, a profile area of $0.30001 \mathrm{~m}^{2}$ and a length of $1.9 \mathrm{~m}$ would be $W(25)=-39.4737$ and $A(25)=0.1579$. If these values were to be input as changes, the formats would be

$$
1,25,-39.4737
$$

and.

$$
2,25,0.1579
$$

b) The term "area" is considered to be the profile area of a vertically oriented component measured as meters ${ }^{2}$ per meter length. For wire the area should be considered the maximum diameter. For synthetic lines the area should be considered the diameter of the line at $200 \mathrm{~d}^{2}$ loading. For chain, the area is considered the maximum 
outside diameter of the link. For instruments or any irregular shaped component of fixed length, the area should be considered as the total profile area divided by the component length (the average area per meter). Area characteristics are used for the calculation of drag.forces and the elongation of synthetic lines. The single value of area for each component is used for normal and tangential drag calculations for both the static mooring configuration and the launch transients.

c) Rated Breaking Strength can be obtained from manufacturers' specs or tensile test results. It is used for the calculation of safety factors in the loading of wire, synthetic line, and chain (components 1-24). Values should be input as pounds.

d) Cross sectional metallic area of wire rope is used for the calculation of elastic elongation. Values are obtained from manufacturer's specs and input as inches ${ }^{2}$.

4. Stretch Characteristics or Constants (see text 4.3.5, Appendices $D, F)$

Machine Instruction:

CHANGE STRETCH CHARACTERISTICS ?: 1 - YES, $\varnothing$ - NO

A "1" response enables the operator to modify any coefficient of elongation for wire rope or synthetic line. A " $\varnothing$ " response by-passes this section and initialization resumes at section 5 - Mooring Components.

A "1" response generates the machine instruction:

ENTER: 1-WIRE，2-DACRON，3-NYLON, 4-UNSPEC

The operator enters a single number $1,2,3$, or 4 to indicate the type component he wishes to modify:

1 - for wire (component 1-5)

2 - for dacron (component 6-10)

3 - for nylon (component 11-15)

4 - for unspecified synthetic (component 16-20).

The machine then instructs:

NOW ENTER THE 4 CONSTANTS

The operator now enters all four constants (coefficients) required for the calculation of elongation for the indicated type of component. 
The values should be entered serially in the format $a, b, c, d$. Four values must be entered and the order is specific.

For wire, the values are:

$$
\begin{aligned}
& \text { a - coefficient of structural stretch } \\
& \text { b - modulus of elasticity (Youngs) } \\
& \text { c - dummy, always } \varnothing \\
& \text { d - dummy, always } \varnothing \text {. }
\end{aligned}
$$

For synthetic lines, the values are:

$$
\begin{aligned}
& \text { a - linear coefficient of permanent elongation } \\
& \text { b - exponential coefficient of permanent elongation } \\
& \text { c - linear coefficient of elastic elongation } \\
& \text { d - exponential coefficient of elastic elongation. }
\end{aligned}
$$

Examples:

$$
\begin{array}{ll}
\text { Wire } & 0.0143,20.5 \mathrm{E}+06,0,0 \\
\text { Dacron } & 2.81 \mathrm{E}+06,0.607,3.83 \mathrm{E}+06,0.74
\end{array}
$$

When the constants are entered the machine instructs:

$$
\text { NEXT OR } 99
$$

An operator response of "99" will cause initialization to be resumed at section 5 - Mooring Components. If another set of coefficients is to be modified (or an error corrected in the preceding input) the operator enters $a 1,2,3$, or 4 as if responding to the instruction "ENTER: 1-WIRE, 2-DACRON, 3-NYLON, 4-UNSPEC".

NOTES :

a) The use of exponential notation $(20.5 \mathrm{E}+06,2.81 \mathrm{E}+06,3.83 \mathrm{E}+06)$ as shown in the examples is required when integer values exceed 32,768 $\left( \pm 2^{15}\right)$.

b) The exponential coefficients of elongation for synthetic lines must be entered as reciprocals, i.e., 1/B, where $\mathrm{B}=$ exponential coefficient of elongation. For example: the exponential coefficient of permanent elongation for standard W.H.O.I. dacron line is 1.647 . The value stored as a constant is $1 / 1.647$ or 0.607 . A caution: The equation for the calculation of elongation uses the area of the line stored as a component characteristic which is in effect the diameter of the synthetic line. The unit of measure is meters. It is common 
practice, however to develop stretch coefficients using units of inches. If this is the case, the input coefficients must be converted for use with metric units.

c) Provisions are made for the use of non-standard synthetic lines. The variables allotted for the coefficients of elongation are programmed to be $=0.0$. Therefore, before using the component type codes 16 through 20 , the coefficients must be input manually using the provisions outlined in this section. This is not true if a mooring containing the same type synthetic line is input from paper tape as the coefficients are automatically modified.

d) All synthetic lines utilize the same equation for the calculation of elongation. Wire rope has a unique equation. Each grouping of components (wire - comp.1-5, dacron - comp.6-10, nylon - comp.11-15, unspecified - comp.16-20) has a unique set of coefficients, All components within a group use the same set of coefficients.

e) If component codes 1 through 20 are to be assigned to nonelastic mooring elements the associated elongation coefficients must be modified. For components $1-5$, set the coefficients $=0.0,9.9 \mathrm{E}+99,0,0$, For components $6-20$, set the coefficients $=9.9 \mathrm{E}+99,1.0,9.9 \mathrm{E}+99,1.0$. The use of these values produces elongation $\simeq 0.0$.

\section{Mooring Components (see Appendices C, D, F)}

Machine Instruction:

MOORING COMP. NO., TYPE, LENGTH OR NO. OF BALLS

This sequence provides the mechanism for manually entering the composition of the mooring. Component types and lengths are specified starting at the upper end of the mooring, proceeding sequentially: down the mooring to the lowest component. The anchor is not considered a mooring component. Component types are specified by code numbers which are listed in Appendix $C$ (Coding Summary). The lengths of standard W.H.O.I. fixed length components are listed in Appendix C. The lengths of non-standard components and components of variable lengths (wire, line, chain) are determined by the operator. A mooring may be composed of up to 65 components. Each component is specified individually in the format $a, b, c$, where:*

a - is the sequential number of the component in the mooring

$\mathrm{b}$ - is the component type by code number

c - is the length of the component in meters or the number of glass spheres in a cluster.

*Caution: This format is used only for initialization. A different format is required when modifying the mooring composition using change option 3 (see Sec, 18). 
Example:

\begin{tabular}{llll} 
& Component & \multicolumn{1}{c}{ Type } & Length \\
$1,38,1-$ & one, & radio float, & 1 meter \\
$2,23,2-$ - & two, & $1 / 2 "$ chain, & 2 meters \\
$3,40,20-$ & three, & 17" glass spheres, & 20 spheres \\
$4,1,1000-$ & - four, & $3 / 16 "$ wire, & 1000 meters
\end{tabular}

After each component is entered, the machine instructs:

NEXT OR 99

A response of "99" terminates the sequence and initialization resumes at section 6 - Line Measurement. If the mooring is incomplete, the operator inputs the next component in the format specified above, incrementing the sequential number by one.

NOTES:

a) Components 39 and 40 are assigned to the standard W.H.O.I. buoyancy package consisting of glass spheres mounted in tandem on 3/8" chain. The spheres are encased in "hard hats" which are attached to the chain at one meter intervals, i.e., 1 sphere per 1 meter of chain. Therefore, specifying the number of spheres in a cluster is equivalent to inputing the length of the cluster in meters. The standard area and weight characteristics reflect this one to one ratio of length to number of spheres. If this ratio is changed, i.e., < or $>1$ sphere per/meter of chain, the operator must enter the length of the chain rather than the number of spheres (which is no longer a valid input criterion). The operator must also modify the area and buoyancy characteristics of the component because the area and buoyancy per unit length will be different than the standard values stored in the program.

b) There are no input restrictions to the length of any component. The output length, however, is limited to 9999 meters.

C) Component codes $16-20,33,34,36,41,42$ are not assigned to standard components. Characteristics of area, weight, and RBS are assigned values $=0.0$, as are stretch and drag coefficients where applicable. When using these codes and when reassigning standard component codes, the operator must modify or assign values to the characteristics and coefficients. Reference to Appendix D and sections 3, 4, and 11 is useful for identifying the characteristics that need to be changed.

d) The top component of the mooring must be positively buoyant except when a point force is applied, provided that the point force is $\geq$ the negative buoyancy. 
e) Component code 35, assigned to the anchor release, should not be reassigned to any other type component. Code 35 is used as a flag for the calculation of reserve buoyancy. Only one component of the mooring should be specified as 35. If more than 1 release is to be used in the mooring, all but the lowest release should be assigned to a different code.

f) When selecting component codes for use as non-standard components care must be exercised to assure that those codes utilize the desired stretch and drag coefficients. Code numbers can be grouped by their use of specific sets of stretch and drag coefficients. The table shows this grouping as a function of the coefficient sets. A detailed explanation of the sets and a description of the coefficients contained in each set can be obtained by referring to sections 4 (stretch characteristics) and 11 (drag coefficients).

\begin{tabular}{clll} 
Component Code & Stretch Coefficient & & Drag Coefficient \\
\cline { 2 - 2 } $1-5$ & wire & wire \\
$6-10$ & dacron & line \\
$11-15$ & nylon & line \\
$16-20$ & unspecified & line \\
$21-24$ & none* & line \\
$25-35$ & none* & cylinder \\
$36-40$ & none* & sphere \\
$41-42$ & none* & unspecified
\end{tabular}

*Codes 21 through 42 are used for non-elastic components.

g) Sufficient positive buoyancy must be provided to support the weight of negatively buoyant components. The condition can exist, when the tension approaches zero, that a change in inclination of a single segment exceeds $90^{\circ}$ (relative to the preceding segment). This condition is similar to the one described in section 14 of this appendix, resulting in negative tension values, negative elongation of components, and other erroneous statistics. It may even cause the machine to self abort with an irrecoverable error necessitating a complete reinitialization of the program.

There are special cases where an extremely slack and pliant mooring is desired. In these cases, specifying a segment length of 1 or 2 meters (see section 12) may circumvent the problem. 
6. Measurement of Synthetic Line (see text 4.3.5)

Machine Instruction:

LINE MEASURED AT 200 (D) SQR ?: 1 - YES, $\varnothing$ - NO

This section enables the operator to specify whether the lengths of dacron and nylon line, as input, are determined by $200 \mathrm{~d}^{2}$ measurement or slack measurement techniques. The lengths of line measured at $200 \mathrm{~d}^{2}$ loading are longer than line measured at slack or zero loading. The average difference in measured length for standard W.H.O.I. dacron line is $3.2 \%$ and for nylon line is $4.2 \%$. Calculations of the elongation of dacron and nylon line are based on the length as measured at $200 \mathrm{~d}^{2}$ loading (standard W.H.O.I. practice). The program will compensate for this percent difference according to the response of this question. A " 1 " response specifies the dacron and nylon are measured at $200 \mathrm{~d}^{2}$ loading. A " $\varnothing$ " response specifies that dacron and nylon lines are measured at slack or zero loading and all input lengths of these components are increased by the above fixed percentages.

NOTES :

a) This section is not applicable to synthetic lines assigned to component codes 16-20 (unspecified).

b) The percentage values of $3.2 \%$ and $4.2 \%$ are fixed in the program and cannot be modified by the operator. These percentage values were determined by testing of used line. The lines were manufactured to W.H.O.I. specifications where the pic length or tightness of the braid is specified and rigidly controlled. When lengths of dacron and nylon lines are determined by techniques other than slack or $200 \mathrm{~d}^{2}$ measurement or when using lines of significantly different stretch characteristics or construction, the operator should manually compensate for the difference between the measured length and that which would have been obtained at $200 \mathrm{~d}^{2}$, and input that calculated length. His response to this instruction should be "l".

c) The assumption is made that the same measurement technique is used to obtain the lengths of all dacron and/or nylon line components of the mooring.

\section{Anchor Weight and Area (see text 4.3.1)}

Machine Instruction:

ENTER ANCHOR WT. (+ LBS), AREA (M) SQR)

The wet weight and effective resistive area of the anchor are entered in response to this instruction. These values are required for the calculation of terminal velocity and transient peak loading of components during free-fall anchor launch. Weight and area are entered in the format $a, b$, where: 
a - is the wet weight of the anchor in + pounds,

$b$ - is the effective resistive area during launch in meters ${ }^{2}$.

NOTES :

a) The anchor is not considered to be a mooring component and its weight and area are ignored when calculating the configuration of the mooring. Care must be taken when applying a point force at the top component that the tension in the lowest component does not exceed the anchor weight or holding power. Also, when using anchors that do not imbed or otherwise resist horizontal movement, the operator should calculate the horizontal component of the tension on the anchor to determine the force acting to drag the anchor along the bottom. The horizontal component of tension at the anchor is $\sin \phi \cdot T$, where $\phi$ is the inclination of and $T$ is the tension in the lowest component of the mooring.

b) The input anchor weight must be greater than the net buoyancy of the mooring. If not, an incorrect arithmetical operation occurs $(\sqrt{ }$ of a negative number) resulting in an error message and incorrect values of terminal velocity and component launch transients. Launch transients are critical to the calculation of permanent elongation of dacron and nylon lines. Of course, if the mooring were deployed in this manner it would float away.

c) Area is the total resistive area of a free-falling anchor. Only the normal component of drag forces on the anchor acting to retard its descent are considered. A unique drag coefficient of 1.15 is used for this application. The value is fixed in the program and cannot be modified by the operator.

d) If the combination of the drag coefficient 1.15 and the true or measured area of the anchor produces incorrect drag forces at the anchor, the input value of the area should be adjusted to obtain the desired result. For example, if the terminal velocity or the anchor shape is such that the drag coefficient should be 0.6 then the value entered for area should be approximately $1 / 2$ the true area. It should be noted that it is not likely that failure to make this adjustment would produce significant errors in the configuration of the mooring.

e) The length or height of the anchor is zero. If the anchor module should have an extended component, such as a length of chain, then that extension should be input as the last or lowest mooring component with a specified length and assigned characteristics (area, buoyancy, etc.). The weight of this extension should be subtracted from the input anchor weight.

8. Operator Comments

Machine Instruction:

ENTER COMMENTS - 1 LINE MAX. 
The operator may enter comments for the purpose of labelling or otherwise identifying the mooring or computer run. Comments are output on all hard and soft copy and on paper tape. Any combination of alphanumeric characters in standard ASC code may be used. Comments are restricted to a single line of $<72$ characters.

\section{Water Depth}

Machine Instruction:

ENTER: DEPTH OF WATER (METERS)

The operator enters the depth of water at the mooring site in meters. Any depth may be entered but output is limited to 9999 meters. NOTE :

The depth of water must be greater than the total length of the mooring including the elongation of lines. This will not always be the case when making preliminary rough estimates of line and wire lengths for long and near surface moorings. It is common practice in these cases to specify or input significantly shorter lengths of wire and line components than those known to be required and to use the automatic length adjustment feature to adjust those components to the correct length.

10. Current Profile (see text 4.3.2, Appendix F)

Machine Instruction:

INPUT CURRENT PROFILE DEPTH (METERS), SPEED (CM/SEC), DIRECTION (DEG)

The operator must enter a current profile consisting of horizontal current velocity values indexed by depth. The current velocity at significant points or levels in the water column are entered sequentially from the top. The velocity of each point is entered as speed and direction. The format used to input each point in the profile is $a, b, c$, where:

$$
\begin{aligned}
& \text { a - is depth in the water column in meters } \\
& \text { b - is the speed of the current in } \mathrm{cm} / \mathrm{sec} \\
& \text { c - is the direction of the current relative } \\
& \text { to North in degrees }
\end{aligned}
$$

The speed and direction may be entered as any positive value. The current profile may be unidirectional, may rotate either clockwise or counterclockwise in a complex manner, or may be reversing. Up to 20 velocity 
points may be input. At least two points must be input. The first point must be above the top component and the last point must be at a depth equal to the entered value for water depth. Examples of valid profiles are given below.

No machine instruction is given after the entry of each point. When a point at a depth $\geq$ the water depth is entered the profile is considered to be complete and initialization is automatically resumed at section 11 - Drag Coefficients.

NOTES :

a) For the calculations of the drag forces acting on a segment, the program determines the depth of the mid-point of the segment and, using this value, linearly interpolates between inclusive points of the input current profile to determine the current speed and direction at that intermediate level.

b) Examples of various profiles are given. In each case, the water depth is 1000 meters. In some cases an incorrect method is shown with the correct.

i) A zero current profile is input as:

Correct

$0,0,0$

$1000,0,0$

ii) A unidirectional current profile varying uniformly with depth is input as:

\begin{tabular}{|c|c|c|}
\hline Correct & & Correct \\
\hline $\begin{array}{l}0,50,0 \\
1000,10,0\end{array}$ & - or - & $\begin{array}{l}0,10,0 \\
1000,50,\end{array}$ \\
\hline
\end{tabular}

iii) A unidirectional current profile, varying nonuniformly with depth, i.e., with knuckles, would be input as:

\begin{tabular}{|c|c|c|}
\hline Correct & & Correct \\
\hline $0,50,0$ & \multirow{5}{*}{ - or - } & $0,40,0$ \\
\hline $200,50,0$ & & $100,50,0$ \\
\hline $400,25,0$ & & $200,50,0$ \\
\hline \multirow[t]{2}{*}{$1000,10,0$} & & $400,25,0$ \\
\hline & & $1000,10,0$ \\
\hline
\end{tabular}

iv) A current profile varying with depth in both speed and direction can be entered. For a simple profile with a clockwise sense of rotation, the input would be: 


\begin{tabular}{|c|c|c|c|c|}
\hline Correct & & Correct & & Correct \\
\hline 0.090 & - or & $\begin{array}{l}0,50,270 \\
1000,10,360\end{array}$ & - or & $\begin{array}{l}0,50,315 \\
1000,15,405\end{array}$ \\
\hline
\end{tabular}

Note that in each case the rotation is $90^{\circ}$ and when passing through $000^{\circ}$ (North), $360^{\circ}$ must be added to the direction. This is because, although direction is specified, it is the amount of angular difference that is important. An incorrect example would be:

$\begin{array}{ll}\text { Correct } & \text { Incorrect } \\ 0,50,315 & 0,50,315 \\ 1000,10,405 & 1000,10,045\end{array}$

The incorrect example would be interpreted as a $270^{\circ}$ angular difference with a counter-clockwise sense of rotation.

v) A simple profile with a counter-clockwise sense of rotation would be input as:

$\begin{array}{lll}\text { Correct } & \frac{\text { Correct }}{0,50,360} \text { Correct } \\ 0,50,090 & \text { - or }- & \frac{0,50,405}{1000,10,315} \\ 1000,10,000 & 1000,10,270\end{array}$

Note that again the rotation in each case is $90^{\circ}$ and when passing through $000^{\circ}$ (North), $360^{\circ}$ is added. Incorrect examples would be:

$\begin{array}{ll}\text { Correct } & \text { Incorrect } \\ 0,50,360 & 0,50,0 \\ 1000,10,270 & 1000,10,270 \\ \text { Correct } & \text { Incorrect } \\ 0,50,405 & 0,50,045 \\ 1000,10,315 & 1000,10,315\end{array}$

Both incorrect examples would be interpreted as a $270^{\circ}$ angular difference with a clockwise sense of rotation.

vi) A complex current profile varying with depth in both speed and direction would be input as:

\begin{tabular}{|c|c|c|}
\hline Correct & & Correct \\
\hline $0,40,0$ & & $9,40,315$ \\
\hline $100,40,010$ & & $100,40,325$ \\
\hline $200,50,090$ & & $200,50,405$ \\
\hline $300,50,070$ & & $300,50,385$ \\
\hline $450,25,180$ & - or - & $450,25,495$ \\
\hline $500,10,155$ & & $500,10,470$ \\
\hline $705,10,205$ & & $705,10,520$ \\
\hline $1000,10,270$ & & $1000,10,585$ \\
\hline
\end{tabular}


Note that the above examples are identical in depth, speed, and angular change. They differ only in that the direction of the initial point at the surface in one is North $\left(000^{\circ}\right)$ and the other is Northwest $\left(315^{\circ}\right)$. These profiles with the opposite sense of rotation would be input as:

\begin{tabular}{|c|c|c|}
\hline Correct & & Correct \\
\hline $0,40,360$ & & $0,40,315$ \\
\hline $100,40,350$ & & $100,40,305$ \\
\hline $200,50,270$ & & $200,50,225$ \\
\hline $300,50,290$ & & $300,50,245$ \\
\hline $450,25,180$ & - or - & $450,25,155$ \\
\hline $500,10,205$ & & $500,10,180$ \\
\hline $705,10,155$ & & $705,10,130$ \\
\hline $1000,10,090$ & & $1000,10,065$ \\
\hline
\end{tabular}

vii) A reversing current profile without a sense of rotation, i.e., an abrupt shear reversal or change in the direction would be input as:

$\begin{array}{ll}\text { Correct } & \text { Incorrect } \\ 0,50,0 & 0,50,0 \\ 200,50,0 & 200,50,180 \\ 201,50,180 & 1000,10,180 \\ 1000,10,180 & \end{array}$

The incorrect example would be interpreted as having a rotational direction change (clockwise sense) in the top 200 meters. Interpolation for current direction at the 100 meter depth would result in the erroneous value of $090^{\circ}$.

An abrupt shear in the current speed would be input as:

$\begin{array}{ll}\text { Correct } & \text { Incorrect } \\ 0,50,0 & 0,50,0 \\ 200,50,0 & 200,25,0 \\ 201,25,0 & 1000,10,0 \\ 1000,10,0 & \end{array}$

The incorrect example would be interpreted as having speed decrease uniformly from 50 to $25 \mathrm{~cm} / \mathrm{sec}$. Interpolation for current speed at the 100 meter depth would result in the erroneous value of $37.5 \mathrm{~cm} / \mathrm{sec}$.

11. Drag Coefficients (see text $4.3 .1,4.3 .3$ )

Machine Instruction:

CHANGE STANDARD CD ?: 1 - YES, $\varnothing$ - NO 
The operator has the option of changing the standard or programmed coefficients of normal and tangential drag. A " $\not$ " response to this instruction indicates no change and initialization resumes at section 12 - Segment Length. A "l" response produces the machine instruction:

ENTER: 1-WIRE, 2-LINE, 3-INSTR, 4-BALLS, 5-UNSPEC. THEN $C D(N), C D(T)$

There are 5 pairs of drag coefficients (normal and tangential). The pairs are used with specific component types grouped according to shape and/or texture. The groups are: 1) wire or smooth textured long cylinders, 2) line and chain or rough textured long cylinders, 3) cylindrical instruments, 4) spherical instruments or components, and 5) components of unspecified or irregular shape (non-standard). The table in section 5 - Mooring Components, shows the grouping of component types and applicable drag coefficients. The operator indicates which set of coefficients is to be modified and modifies those coefficients by responding to the above instruction in the format $a, b, c$, where:

a - is the indicator of the pair to be changed

1) wire (components 1-5)

2) line or chain (components 6-24)

3) instruments, cylindrical (components 25-35)

4) spheres, spherical instr. (components 36-40)

5) unspecified (components 41-42)

b - is normal drag coefficient

c - is tangential drag coefficient

An example of a modification of the normal drag coefficient used for wire would be:

$1,1.5,0.007$

After each entry the machine instructs:

NEXT or 99

An operator response of "99" will end the sequence and cause initialization to resume at section 12 - Segment Length. If another pair of coefficients is to be modified (or an error in the preceding entry corrected) the operator enters the next modification in the format described above. 
NOTES :

Commonly used drag coefficients for standard W.H.O.I. components at typical Reynold's numbers are stored in the program. The values are:

(4)

Wire Line Instruments Balls Unspecified

$\begin{array}{llllll}\text { Normal }(\mathrm{CDN}) & 1.3 & 1.3 & 1.2 & 0.5 & 0.0\end{array}$

Tangential (CDT)

$0.007 \quad 0.007$

0.9

0.5

0.0

12. Segment Length (see text 3.4.f, 4.2, and Appendix D - Segment Stats)

Machine Instruction:

SEGMENT LENGTH (METERS)?

The term "segment" defines the discrete units into which each component is broken for the purpose of calculating gravity and resistive forces. A segment is considered to be an inflexible but elastic bar. The operator must specify the maximum length of a segment in meters (non-zero). For tall moorings a segment length of 50 meters, and for short moorings a segment length of 10 meters are typical satisfactory input values, however, any length may be input. A rule of thumb is to set the segment length equal to approximately $1 \%$ of the total mooring length.

13. Automatic Length Adjustment (see text 4.3.7 and Appendix F)

Machine Instruction:

\section{AUTO LENGTH ADJUST ?: - $\varnothing$ TO $1 \varnothing$ COMPONENTS}

The operator has the option of having the program automatically adjust the lengths of up to 10 components, generally wire or line. A response of " $\emptyset$ " to this instruction indicates no adjustment is to be performed and initialization resumes at section 14 - Point Force. If adjustments are to be made the operator enters the total number of components $(1-10)$ to be adjusted. The machine then instructs:

ENTER: CRITICAL COMP., DESIRED DEPTH, ADJUST. COMP.

The purpose of this feature is to place critical components, generally instruments, at specific depths. A depth critical component is paired with a lower component, the length of which is to be adjusted to obtain the depth which is specified. This is accomplished by 
entering the sequential number in the mooring of the components of a pair along with the objective depth, using the format $a, b, c$, where:

a - the sequential number of the depth critical component

b - the desired or objective depth of "a" in meters

c - the sequential number of the adjustable component

Examples:

$$
\begin{aligned}
& 4,900,5 \\
& 6,1000,9
\end{aligned}
$$

In the first example, component number 4 is to be placed at a 900 meter depth by adjusting component 5 . In the second example, component number 6 is to be placed at a depth of 1000 meters by adjusting component 9. (Note that the paired components need not be adjacent to each other.)

The operator continues to input the component pairs until the total number he has specified are entered, at which point initialization is resumed at section 14 - Point Force. No intermediate machine instructions are generated between entries.

NOTES :

a) The length of any type of component will be adjusted because the adjustment process is keyed to the sequential number of the component in the mooring not the code number. The operator should assure himself that the code of the component he is adjusting is not assigned to a component of fixed length, such as an instrument.

b) It is recommended that the component pairs be entered in sequence starting at the top of the mooring. This reduces the time required for a run.

c) A component pair must not lie between or overlap the components of any other pair. This is best described by the following examples, both of which show an improper pairing.

$$
\begin{array}{ll}
\text { Incorrect } & \text { Incorrect } \\
1,500,9 & 1,500,6 \\
4,1000,6 & 4,1000,9
\end{array}
$$

In each example the process of adjusting the length of component 6 or 9 produces a simultaneous change in the depth of both 1 and 4 . The result is that one of the components is always at an incorrect depth. This condition produces, in effect, an endless 1oop which can only be overridden by aborting the run (sense switch 14). In these examples component 1 may only be paired with component 2 or 3 . 
Other improper entries are: 1) specifying the same depth for two or more critical components, 2) specifying a depth greater than the depth of water, 3) specifying the depth of a component at the top of the mooring to be deeper than that of a component lower in the mooring, 4) specifying a component to be depth critical more than once in a series, and 5) specifying a component to be adjustable more than once in a series.

d) The program will adjust the critical component depth to within 1 meter of the desired depth.

\section{Point Force (see text $3.4 . e$ )}

\section{Machine Instruction:}

ENTER MAGNITUDE, INCLINATION, AZIMUTH OF P.F.

An external static point force may be applied to the top of the first component in the mooring. The purpose of this feature is to provide a means of observing the effect upon the mooring of forces generated by components not integral to the mooring. This feature is designed for special purpose applications. For example, it has been used to model the effects of surface marker buoys and to determine the static zero current configuration of each leg of a multi-legged mooring.

To enter a point force, the operator must enter its magnitude, inclination to the vertical and azimuth using the format $a, b, c$, where:

a - is the magnitude in pounds

b. - is the inclination to the vertical in degrees

c - is the azimuth (direction) relative to North in degrees

Esample:

$$
250,030,135
$$

In the example a point force of 250 pounds is acting on the top component. It is pulling $30^{\circ}$ from the vertical in a direction of $135^{\circ}$.

If a point force is not to be applied, as is the usual case, the operator enters $0,0,0$. 
NOTES :

a) The magnitude may be any positive value. The inclination may be $0^{\circ}-180^{\circ}$. The azimuth may be $0^{\circ}-360^{\circ}$.

b) The program cannot handle a change in inclination of a single segment greater than $90^{\circ}$ (the cosine of the angle goes negative resulting in negative tensions). This may occur when the inclination of the point force is $>90^{\circ}$ and the ratio of the values of the point force magnitude and segment buoyancy (at the top component) is large. When the segment buoyancy is $>$ the magnitude of the point force a reduction of the segment length, thereby reducing the buoyancy, will eliminate the problem. When the magnitude of the point force is $>$ the segment buoyancy, the problem cannot be overcome.

\section{Terminations}

\section{Machine Instruction:}

CHANGE IN TERMINATION CONSTANTS ?: 1 - YES, $\varnothing$ - NO

A termination is the unit consisting of the fittings and hardware used to connect mooring components in tandem. The length and buoyancy (area is neglected) of the termination are added to the lower end (last segment) of each component of the mooring. Terminations are considered to be the same throughout the mooring. Standard W.H.O.I. terminations are composed of two $1 / 2$ " shackles and one $1 / 2 "$ sling link. At initialization the program sets the length and buoyancy of termination units to the standard values of 0.203 meters and -2.19 pounds.

If no change of the termination constants is wanted, the operator enters " $\emptyset$ " in response to the machine instruction and initialization resumes at section 16 - Run or Error Correction. A response of "1" indicates a change is desired and the machine generates the instruction:

ENTER TERM. LENGTH (METER), WT. (LBS)

The operator enters the new termination length and buoyancy in the format $a, b$, where:
a - is the length of the termination unit in meters
b - is the buoyancy of the termination unit in pounds

\section{Run or Error Correction}

Machine Instruction:

$$
\text { GO? - (99) OR OPTION? - (1 TO 16) }
$$


At this point initialization is complete. The operator has the option of correcting input errors or of going to the run mode to calculate the mooring statistics and configuration. A response of "99" initiates the run mode. Sense switch selection should be made at this point for the type of output desired (see Appendix B).

If a modification to the input values is desired, the operator responds as if exercising a change option at the end of the run. Instructions for this procedure are given in section 17 - Change Option.

\section{Change Option (see Appendix B)}

At the completion of a run, the computer halts in a "PAUSE" mode and displays the following instruction on the soft copy device:

$$
\text { SENSE SWITCH? - PUSH RUN }
$$

If the operator wishes to continue, he pushes the run button on the computer control panel and then may select the sense switch options for the next run. The following machine instruction is generated:

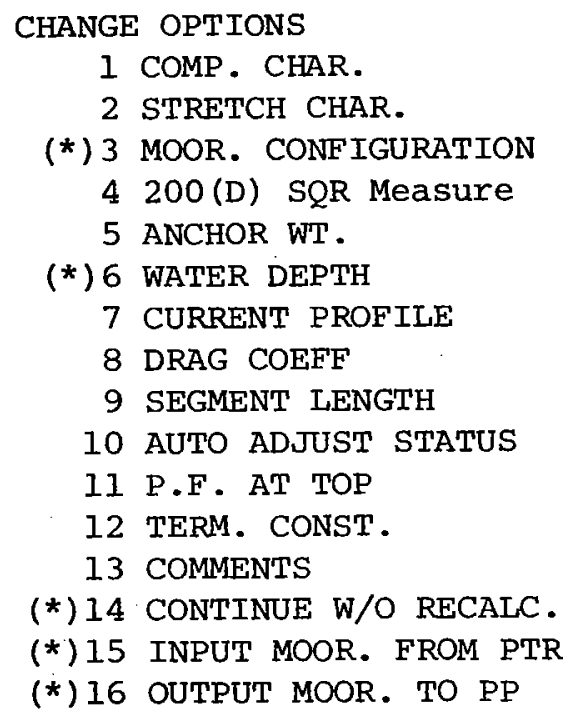

This display is meant to assist the operator in his selection of a change option. It indicates all possible options (except sense switch options) that can be exercised. An amplified definition of the displayed categories may be found in Appendix B. Any number of change options may be exercised in any order.

The operator initiates a change by entering the option code number $(1-16)$. The program branches to the applicable section and 
generates the appropriate instructions for the completion of the modification. The formats for completing a modification are the same as those for the program initialization procedure, found in sections 2-15 of this appendix. There are notable exceptions however. These are indicated by asterisks (*). The operating procedures for exercise of options 3,6 , and 15 require an additional or an entirely different set of instructions. Options 14 and 16 have not been described elsewhere in this appendix. Operating instructions for options $3,6,14,15$, and 16 are described below in sections 18-21.

At the completion of each option, the following instruction is displayed.

$$
\text { GO? - (99) OR OPTION? - (I TO 16) }
$$

The operator enters the code number of the next option he wishes to exercise (1-16) or enters "99" to initiate the run mode for calculations.

18. Option 3 - Mooring Configuration

This option provides the means of modifying the composition of the mooring. Existing components (i.e., from the previous run or from a paper tape input) may be changed or deleted or new components may be inserted. Selection of this option generates the machine instruction:

TYPE 1-CHANGE, 2-INSERT, 3-DELETION THEN

MOORING COMP. NO., TYPE, LENGTH OR NO. OF BALLS

The operator may make a series of modifications, altering 1 or more components. Each modification is entered using the format $a, b$, $c$, d, where:

a - is the type of modification to be made

1 - for change the specified component

2 - for insert after the specified component

3 - for delete the specified component

b - is the sequential number of the component in the mooring that is to be changed, inserted after, or deleted

c - is the code number of the new component

d - is the new value of the length or number of spheres of the component specified in " $c$ ". 
After each entry or modification, the machine instructs:

NEXT OF 99

If more modifications to the mooring composition are to be made, the operator enters the next change using the format described above. When no further modifications are desired, the operator enters "99" which terminates the sequence and generates the machine instruction "GO? - (99) OR CHANGE OPTION (1 TO 16)" described in section 17.

Examples:

Component number 10 is a VACM instrument (type code 25) with a length of 1.9 meters. This component was input during initialization in the format: $10,25,1.9$ (see section 5).

1) To change component 10 to an 850 current meter (type code 27) which is 1.8 meters long, the operator would enter, in the format described above:

$$
1,10,27,1.8
$$

2) To insert the 850 current meter into the mooring string between components 10 and 11 , the entry would be:

$$
2,10,27,1.8
$$

3) To delete or remove the VACM from the mooring string the entry would be:

$$
3,10
$$

Note that the component code and length are omitted.

NOTES :

a) Any number and any type of modifications may be made to the mooring composition in a series. It is recommended that component modification proceed in an ordered sequence starting at the top of the mooring string. This reduces confusion and the risk of assigning components to the wrong "slot" when using the insert and/or delete features. The modification procedure "keys" to the type of change and the component sequence numbers stored from the preceding run. The program "keeps track" of the order of components from the preceding run, allowing the operator to refer to those sequence numbers despite the insertion or deletion of components during the modification process. This eliminates the need to determine the new sequence numbers in the modified mooring. This relationship is lost when the operator enters a "99" and cannot be recovered. 
b) To insert more than one new component in a single "slot"; always enter the lowest component first, i.e., invert the order in the mooring string. For example, if it were desired to insert two components (a 20 meter length of 3/16" wire and an 850 current meter) immediately below component number 10 (a VACM) so that the final ordered sequence would be VACM, wire, 850 , the operator would make two entries: $2,10,27,1.8$ followed by $2,10,1,20$.

The same procedure would be used when inserting more than one new component below the last component of the preceding run.

c) To insert new components above the top component of the mooring, the procedure is more complicated. First, component 1 must be changed to the new top component. This produces a "single slot" between components 1 and 2. Second, the old top component is inserted below component 1 (the input would be $2,1,-,-)$ ). Third, additional new components (if more than one) would be inserted after component 1 in the manner described in (b) above.

d) The function of this option is to allow the operator to modify the existing mooring configuration without having to re-enter the entire mooring or go through the entire program initialization procedure. However, when numerous and complex modifications must be made to achieve the new mooring configuration, with the attendant likelihood of operator error and confusion, it might be simpler and more efficient to reinitialize the program and start from scratch.

e) When using this option, the criteria for the selection of component types and the assigning of lengths are identical to those used for the inital entry of the mooring composition. If he has not already done so, the operator should read section 5 (Mooring Components) of this appendix.

\section{Option 6 - Water Depth}

The criteria for selecting and formats for entering a new water depth are the same as those described in section 9 of this appendix.

When a new water depth is entered, the program automatically instructs the operator to enter a new current profile. The instruction, criteria, and format for entering the current profile are the same as those described in section 10 of this appendix. This procedure should not be construed to mean that the current profile cannot be changed independently of the water depth by use of Change Option 7.

\section{Option 14 - Continue w/o Recalculation}

This option allows the operator to output the statistics of the preceding run without the need to recalculate the mooring configuration. It is generally used in conjunction with the sense switch options to change the type of output and the output devices (soft 
to hard copy). At the completion of the output sequences initiated by this option the computer halts in the "PAUSE" mode as described in section 17 of this appendix. The operator proceeds from that point.

\section{Option 15 - Input Mooring from PTR}

The operator has the option of entering an entire new mooring, and its associated characteristics from punched paper tape. The instructions for doing so and a description of the parameters thereby modified are identical to those given in section 2 of this appendix. Use of this option is equivalent to a reinitialization of the program. The change option sequence is aborted and when the paper tape is read, the machine automatically resumes the initialization procedure as described in sections 10 through 16 of this appendix.

\section{Option 16 - Output Mooring to PP}

The operator has the ability to output the mooring composition existing in memory to a punched paper tape. In addition to the mooring composition, the entire contents of the arrays storing component characteristics, stretch coefficients, and drag coefficients, regardless of their applicability to the mooring, are output. The water depth, anchor characteristics, characteristics of terminations, comments, and type of synthetic line measurement are also output.

To obtain a paper tape output, the operator should turn on the punch device and manually punch a leader on the tape. He then enters "16" at which point the machine automatically punches the tape output. When output is complete, the operator must manually punch a tailer on the output tape. He then removes the tape from the device and stores it for future use. When output is complete the machine instruction "GO? - (99) OR OPTION (1 TO 16)" is generated and the operator proceeds as described in section 17 of this appendix.

NOTE:

It is advisable, although not necessary, to exercise this option before any other option (except option 14). This avoids the possibility of inadvertantly altering any characteristics or coefficients vital to the mooring to be output. 


\section{APPENDIX B}

\section{OPTIONS}

Output Options (Sense Switch)

Sense Switch

$$
\begin{array}{ll}
1 \text { - ON } & \text { output the input parameters } \\
2 \text { - ON } & \text { output detailed segment statistics } \\
3 \text { - ON } & \text { output supplemental statistics } \\
4 \text { - ON } & \text { output summary of mooring statistics } \\
5 \text { - ON } & \text { output component characteristics } \\
10-\text { ON } & \text { output to soft copy device } \\
10-\text { OFF } & \text { output to hard copy device } \\
14-\text { ON } & \text { abort run }
\end{array}
$$

The sense switch options may be exercised at any time and in any combination in the course of a run with the following exceptions:

1) once output begins the device cannot be altered,

2) the order in which the output is generated is fixed,

3) the run will abort only at the completion of a calculation or output sequence.

\section{Change Options--Manual Input}

At the completion of each run the operator has the option of changing existing (in memory) component characteristics, environmental and/or operational parameters. Sixteen options exist and can be exercised in any combination or sequence. 
Option

1 change component characteristics:

area - array A - types 1-42

buoyancy - array $\mathrm{W}$ - types 1-42

rated breaking strength - array RBS - types 1-24

metallic area - array AW - types 1-5,

2 change elastic characteristic constants of wire, dacron line, nylon line, or unspecified line,

3 alter mooring composition by changing, inserting and/or deleting components from the existing (in memory) mooring configuration,

4 restate whether measurement of synthetic line is at $200 \mathrm{~d}^{2}$ loading or slack,

5 change anchor weight and effective area,

6* change depth of water,

$7 \quad$ change current profile,

8 change normal and tangential drag coefficients,

9 change segment length,

10 instate auto adjust status (evaluate component depths and adjust lengths accordingly),

I1 change external point force at top of mooring,

12 change termination length and weight,

13 new operator comments,

14 continue; output the immediately preceding run without recalculation,

15 input new mooring in entirety from paper tape reader,

16 output existing (in memory) mooring to paper tape punch.

*Exercise of option 6 automatically requests new current profile. 
APPENDIX C

\section{CODING SUMMARY}

\section{Standard WHOI Components}

\begin{tabular}{|c|c|c|c|c|c|c|}
\hline Code & \multicolumn{3}{|c|}{ Type } & \multirow[t]{2}{*}{ Code } & Type & \multirow[t]{2}{*}{ Length } \\
\hline 1 & $3 / 16^{\prime \prime}$ & Wire, & Jacketed & & Instruments - Cylindrical & \\
\hline 2 & $1 / 4 "$ & $"$ & $"$ & 25 & VACM & $1.9 \mathrm{M}$ \\
\hline 3 & $5 / 16^{\prime \prime}$ & $"$ & $"$ & 26 & 850 - Lt. & 1.8 \\
\hline 4 & $3 / 8 "$ & $"$ & $"$ & 27 & 850 - Hvy. & 1.8 \\
\hline 5 & \multicolumn{3}{|c|}{ unspecified wire } & 28 & Engr. C.M. & 0.8 \\
\hline 6 & $3 / 8 "$ & \multicolumn{2}{|c|}{ Dacron, Sampson } & 29 & Inclinometer & 0.8 \\
\hline 7 & $7 / 16^{\prime \prime}$ & " & " & 30 & Depth Rec. & 0.8 \\
\hline 8 & $1 / 2 "$ & $"$ & $"$ & 31 & Tension Rec. & 0.8 \\
\hline 9 & $9 / 16^{\prime \prime}$ & $"$ & $"$ & 32 & Tensac & 1.6 \\
\hline 10 & $5 / 8 "$ & $"$ & $"$ & 33 & Unspecified & - \\
\hline 11 & $3 / 8 "$ & Nylon, & Columbia & 34 & Unspecified & - \\
\hline 12 & $1 / 2^{\prime \prime}$ & " & $"$ & 35 & Release & 1.8 \\
\hline 13 & $9 / 16^{\prime \prime}$ & $"$ & $"$ & & & \\
\hline 14 & $5 / 8^{\prime \prime}$ & $"$ & $"$ & & Instruments - Spher & \\
\hline 15 & $3 / 4^{\prime \prime}$ & $"$ & $"$ & 36 & Unspecified & - \\
\hline & & & & 37 & Pressure Rec. (MIT) & 0.4 \\
\hline 16 & \multicolumn{2}{|c|}{ Unspecified } & Iine & 38 & Radio Float & 1.0 \\
\hline 17 & \multicolumn{2}{|c|}{$"$} & $"$ & & & \\
\hline 18 & \multicolumn{2}{|c|}{$"$} & $"$ & & \multicolumn{2}{|l|}{ Spheres on Chain } \\
\hline 19 & \multicolumn{2}{|c|}{$"$} & $"$ & 39 & 16" Glass balls & 1.0 \\
\hline 20 & \multicolumn{2}{|c|}{$"$} & $"$ & 40 & 17" Glass balls & 1.0 \\
\hline 21 & $1 / 4 "$ & Chain & & & & \\
\hline 22 & $3 / 8^{\prime \prime}$ & $"$ & & & Undefined & \\
\hline 23 & $1 / 2 "$ & $"$ & & 41 & Unspecified & - \\
\hline 24 & $3 / 4 "$ & $"$ & & 42 & Unspecified & - \\
\hline
\end{tabular}


APPENDIX D

STANDARD COMPONENT CHARACTERISTICS

a) The characteristics for each mooring component are given as area, weight, rated breaking strength, and metallic cross sectional area as appropriate and stored in arrays in the following convention.

1) Area per unit length - stored in array A(1-42) units $=$ meter $^{2} /$ meter.

2) Buoyancy per unit length - stored in array w(1-42) units $=$ pounds $/$ meter .

3) Rated breaking strength - stored in array RBS(1-24) units $=$ pounds .

4) Metallic area (wire) - stored in array AW(1-5) units $=$ inches $^{2}$.

b) Constants used for the calculation of the elongation of wire and synthetic lines under tensile stress are stored in array $\mathrm{E}(1-16)$. The coefficients of elasticity of standard W.H.O.I. wire and line components are listed in the appropriate sections of this appendix. Their usage is described in the text (Equations (2I) and (23) are applicable) .

c) A total of 42 components are classified under the following headings by code numbers:
a) wire
f) cylindrical instruments
b) dacron line
g) spherical instruments
c) nylon line
h) complex components (spheres)
d) unspecified line
i) undefined
e) chain

d) All components of W.H.O.I. moorings are considered to be connected in tandem and bear tensile loads. Termination hardware typically consists of two 1/2" shackles and one 1/2" master link. The weight (as buoyancy) and length of this hardware unit are stored as constants.

$$
\begin{aligned}
\text { Buoyancy (TERMW) } & =-2.19 \mathrm{lbs} \\
\text { Length (TERML) } & =0.203 \text { meters. }
\end{aligned}
$$


WIRE - U. S. Steel torque balanced, jacketed

\begin{tabular}{|c|c|c|c|c|c|}
\hline Code & Size & Area* & Buoyancy & R.B.S. & Metallic Area \\
\hline 1 & $3 / 16^{\prime \prime}$ & .0065786 & -0.154 & 4000 & 0.01611 \\
\hline 2 & $1 / 4^{\prime \prime}$ & .0083566 & -0.266 & 6750 & 0.02738 \\
\hline 3 & $5 / 16^{\prime \prime}$ & .0099568 & -0.41 & 10300 & 0.04206 \\
\hline 4 & $3 / 8^{\prime \prime}$ & .0115824 & -0.594 & 14800 & 0.06015 \\
\hline \multirow[t]{5}{*}{5} & - & - & - & - & - \\
\hline & $E(1)=$ & 0.01428571 & & & \\
\hline & $E(2)=$ & $20.5 \times 10^{6}$ & & & \\
\hline & $E(3)=$ & 0.0 & my, not us & ed) & \\
\hline & $E(4)=$ & 0.0 & my, not us & ed) & \\
\hline
\end{tabular}

*Area is, in effect, the outside diameter of the wire.

DACRON - Sampson, single braid, W.H.O.I. specs.

$\begin{array}{ccccc}\text { Code } & \text { Size } & \underline{\text { Area* }} & \text { Bugyancy } & \text { R.B.S. } \\ 6 & 3 / 8^{\prime \prime} & .00890588 & -0.0375 & 5700 \\ 7 & 7 / 16^{\prime \prime} & .0103902 & -0.0516 & 7000 \\ 8 & 1 / 2 " & .0118745 & -0.0667 & 9000 \\ 9 & 9 / 16 " & .0133588 & -0.0851 & 11200 \\ 10 & 5 / 8 " & .0148431 & -0.1082 & 14000 \\ & E(5)=2.81 \times 10^{6} & \begin{array}{l}\left(A_{p}\right) * * \\ \left(1 / B_{p}\right)\end{array} \\ E(6)=0.607 & \left(A_{e}\right) \\ E(7)=3.83 \times 10^{6} & \left(1 / B_{e}\right)\end{array}$

*Area is, in effect, the outside diameter of the line. Listed value is $93.5 \%$ of nominal diameter, an approximation to the true diameter as measured.

** See the text (Section 4.3.5). 
NYLON - Columbia, plaited, W.H.O.I. specs.

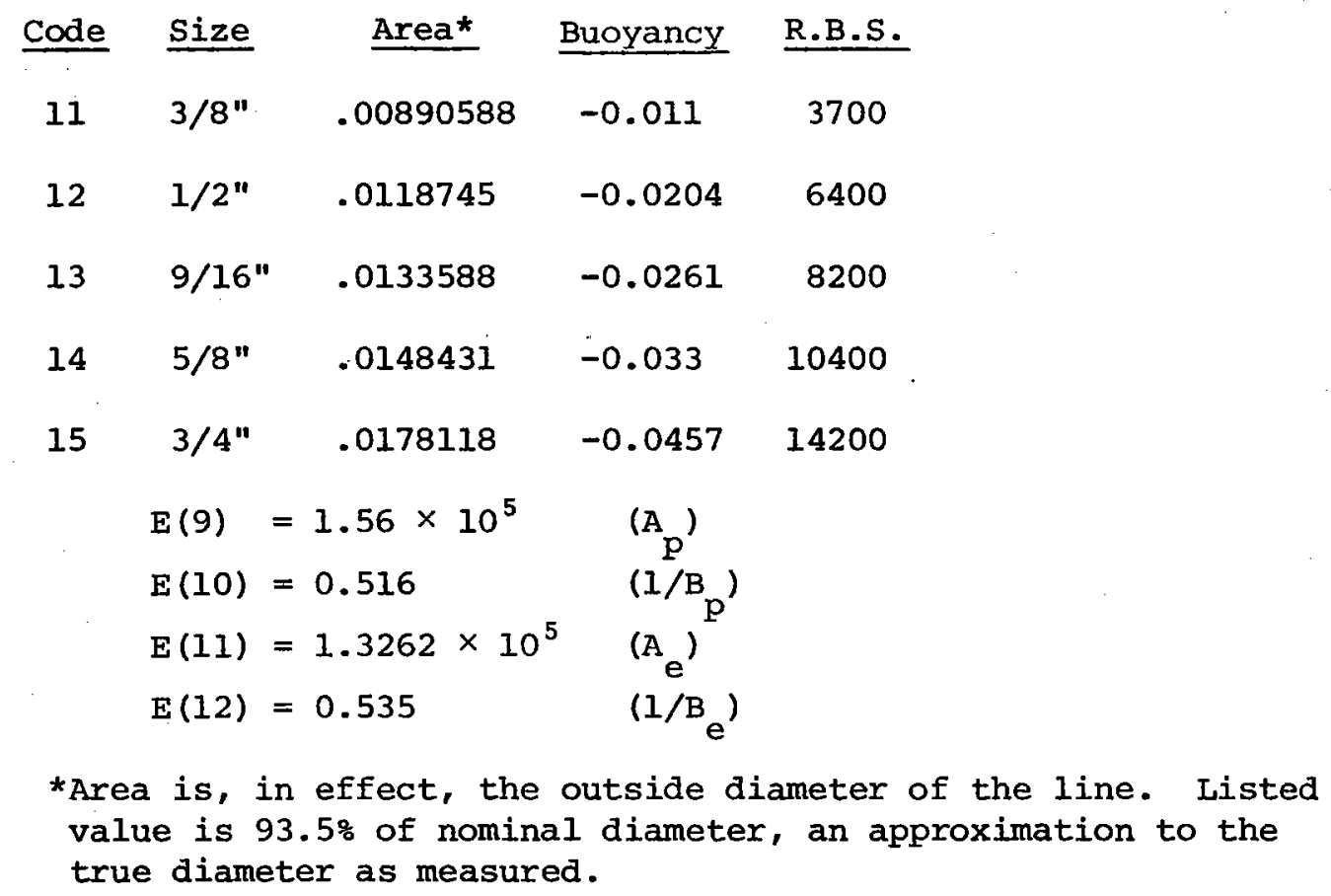

\section{UNSPECIFIED - Synthetic Line}

Code Size Area Buoyancy

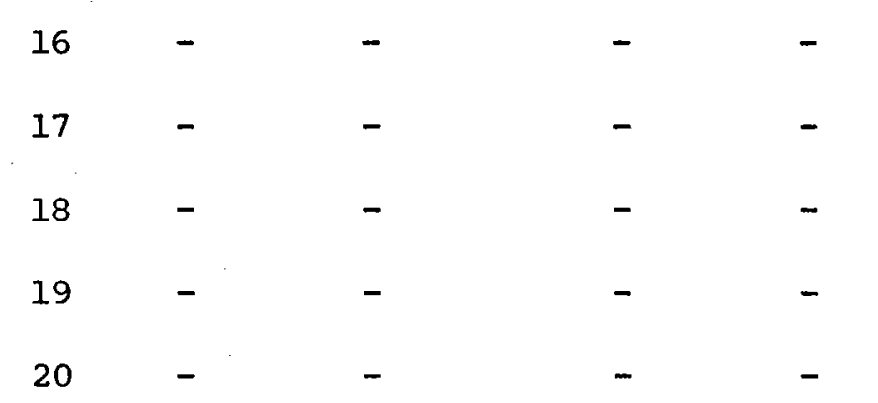

$$
\begin{array}{ll}
E(13)=0.0 & \left(A_{p}\right) \\
E(14)=0.0 & \left(1 / B_{p}\right) \\
E(15)=0.0 & \left(A_{e}\right) \\
E(16)=0.0 & \left(1 / B_{e}\right)
\end{array}
$$

Note: The elongation of components $16-20$ is computed by the same equation as dacron and nylon. 
CHAIN - Proof Coil, galvanized

$\begin{array}{ccccc}\text { Code } & \text { Size } & \text { Area* }^{*} & \text { Buoyancy } & \text { R.B.S. } \\ 21 & 1 / 4 " & .0274 & -2.33 & 5400 \\ 22 & 3 / 8 " & .037 & -5.12 & 12150 \\ 23 & 1 / 2 " & .048 & -9.02 & 21600 \\ 24 & 3 / 4 " & .0685 & -19.52 & 48600\end{array}$

*Area is, in effect, the maximum diameter of a link.

CYLINDRICAL INSTRUMENTS

\begin{tabular}{|c|c|c|c|c|}
\hline Code & Type & Area* & Buoyancy** & Length \\
\hline 25 & VACM & 0.30001 & -75.0 & 1.9 \\
\hline 26 & 850 - It. & 0.32251 & -40.0 & 1.8 \\
\hline 27 & 850 - Hvy. & 0.32251 & -50.0 & 1.8 \\
\hline 28 & Engr. C.M. & 0.12834 & -40.0 & 0.8 \\
\hline 29 & Inclinometer & $"$ & $"$ & $"$ \\
\hline 30 & Depth Rec. & $"$ & $"$ & $"$ \\
\hline 31 & Tension Rec. & $"$ & $"$ & $"$ \\
\hline 32 & Tensac & 0.27 & -70.0 & 1.6 \\
\hline 33 & - & - & - & - \\
\hline 34 & - & - & - & - \\
\hline 35 & Release & 0.26982 & -80.0 & 1.8 \\
\hline \multicolumn{5}{|c|}{$\begin{array}{l}\text { *The listed value is the total effective area (meters }{ }^{2} \text { ) of } \\
\text { irregularly shaped cylinder viewed in profile. Array A } \\
\text { stores this value divided by length. }\end{array}$} \\
\hline
\end{tabular}


SPHERICAL INSTRUMENTS

\begin{tabular}{|c|c|c|c|c|}
\hline Code & Type & Area* & Buoyancy** & Length \\
\hline 36 & - & - & - & - \\
\hline 37 & Pressure Rec. (MIT) & .0828 & -18.0 & 0.4 \\
\hline 38 & Radio Float & .26 & +41.0 & 1.0 \\
\hline \multicolumn{5}{|c|}{$\begin{array}{l}\text { *The listed value is the total effective area (meters }{ }^{2} \text { ) } \\
\text { of irregular basically spherical instruments (radio } \\
\text { float assumed to be spherical) viewed in profile. } \\
\text { Array A stores this value divided by length. }\end{array}$} \\
\hline
\end{tabular}

COMPLEX COMPONENTS - Spheres mounted on $3 / 8 "$ chain

$\begin{array}{lrccc}\text { Code } & \text { Type } & \text { Area* }^{*} & \text { Buoyancy * }^{*} & \text { Length } \\ 39 & 16 " \text { Sphere } & .25138 & +43.5 & 1.0 \\ 40 & 17 " \text { Sphere } & .26962 & +53.0 & 1.0\end{array}$

*The listed value is the area of the sphere with "hard hat" plus the area of one meter of $3 / 8$ " chain. Assumption is made that one sphere is mounted on one meter of chain.

**The listed value is the sum of buoyancies of one sphere and one meter of $3 / 8$ " chain.

UNDEFINED - (Unique drag coefficients)

\begin{tabular}{lcccc} 
Code & Type & Area & Buovancy & Length \\
41 & - & - & - & - \\
42 & - & - & - & - \\
\hline
\end{tabular}


There are five visual output options obtained by front panel sense switch selection. They are:

$$
\begin{aligned}
& 1 \text { - Input Parameters } \\
& 2 \text { - Mooring Statistics - Summary } \\
& 3 \text { - Supplemental Statistics } \\
& 4 \text { - Segment Statistics } \\
& 5 \text { - Component Characteristics }
\end{aligned}
$$

Collectively they present to the user, with some repetition, virtually all statistics on the configuration of the mooring and the forces causing that configuration that it is possible to generate with the program. The combined use of the Input parameter and Component Characteristic options provides all information required to duplicate the mooring.

It should be noted that the mixing of units (English and Metric) is deliberate in an attempt to produce output in a format readily understood by those not coached in engineering terminology. (Inform the Bos'n aboard ship that an anchor weighs 454 kilograms or 4448 newtons and the results may be rather amusing.)

Another form of output is available to the user; the paper tape* output (change option 16). This output "dumps" on perforated paper tape, all data on mooring composition, component characteristics and comments stored in memory for the existing run. This gives the user a permanent record of the mooring and the ability in the future to rapidly and conveniently reload the mooring into the machine.

The notations of $\mathbf{x x} \cdot \mathbf{x x}$ are meant to illustrate the resolution of the output, i.e., the places to the right of the decimal point.

When the automatic length adjustment feature is used the input lengths of the specified components are changed. The new calculated lengths are output rather than the input values which are lost.

\footnotetext{
*Magnetic tape and cassette units may be used in lieu of paper tape. However, in the absence of a File Management Executive their use is awkward.
} 
1) INPUT PARAMETERS - List, in a heading format, of the unique features of the mooring not appearing elsewhere. Also lists the current profile and external point force acting on the mooring.

INPUT PARAMETERS

DRAG COEFFICIENTS

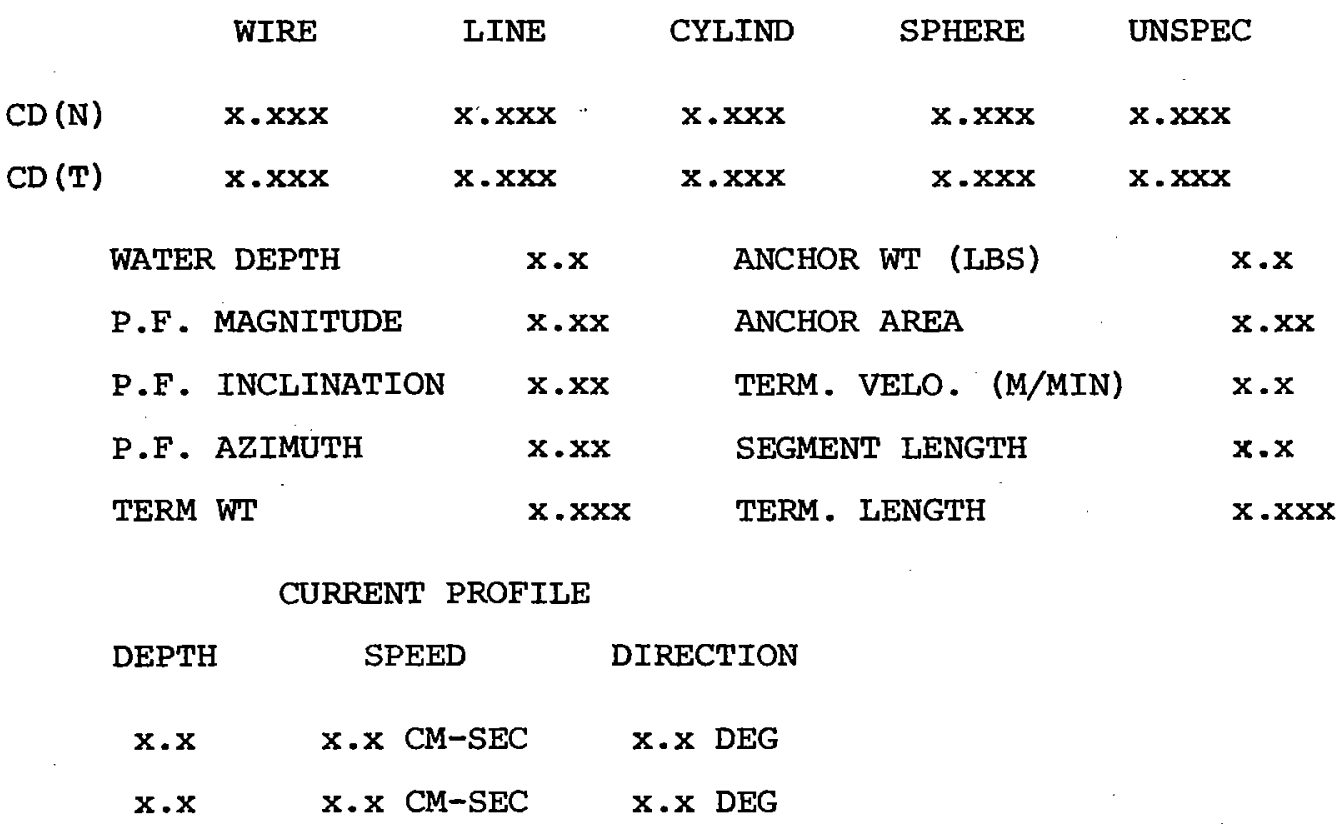

a) DRAG COEFFICIENTS:

$\mathrm{CD}(\mathrm{N})$ - (dimensionless), normal drag coefficient, array $\mathrm{CDN}(1-5)$

$\mathrm{CD}(\mathrm{T})$ - (dimensionless), tangential drag coefficient, array CDT (1-5)

WIRE - components 1-5, smooth cylinder

LINE - components 6-24, rough cylinder

CYLIND - components 25-35, cylindrical instruments

SPHERE - components 36-40, spherical instruments

UNSPEC. - components 41-42, undefined

b) WATER DEPTH - (meters)

c) P.F. MAGNITUDE - (pounds), magnitude of the external point force at top of mooring

d) P.F. INCLINATION - (degrees from vertical), inclination of the external point force at top of mooring

e) P.F. AZIMUTH - (degrees, horizontal), orientation of the external point force at top of mooring relative to north 
f) ANCHOR WT. - (+ pounds), weight of anchor in water

g) ANCHOR AREA - $\left(\right.$ meter $^{2}$ ), effective surface area of free-falling anchor

h) TERM. VELO. - (meter/min.), terminal velocity of free-falling mooring

i) SEGMENT LENGTH - (meters), maximum incremental component length

j) TERM. WT - (pounds), buoyancy of termination, one per component

k) TERM. LENGTH - (meters), length of termination, one per component

1) CURRENT PROFILE - lists current profile as input by operator.

$$
\begin{aligned}
& \text { DEPTH - (meters), from surface } \\
& \text { SPEED } \quad-(\mathrm{cm} / \mathrm{sec}) \\
& \text { DIRECTION - (degrees), relative to north }
\end{aligned}
$$


2) MOORING STATISTICS - SUMMARY - Listing on a single page of the composition of a mooring, starting at the top component, and the basic data required to evaluate its performance and configuration.

\begin{tabular}{cccccccccc}
\multicolumn{10}{c}{ MOORING STATISTICS - SUMMARY } \\
COMP & TYPE & LENGTH & WEIGHT & DEPTH & INCLIN & TENSION & EXCUR & DRAG & BACK-UP \\
$\mathbf{x x}$ & $\mathbf{x x}$ & $\mathbf{x} \cdot \mathbf{x}$ & $\mathbf{x} \cdot \mathbf{x}$ & $\mathbf{x} \cdot \mathbf{x}$ & $\mathbf{x} \cdot \mathbf{x}$ & $\mathbf{x} \cdot \mathbf{x}$ & $\mathbf{x} \cdot \mathbf{x}$ & $\mathbf{x} \cdot \mathbf{x}$ & $\mathbf{x} \cdot \mathbf{x}$
\end{tabular}
a) COMP - sequential number of component
b) TYPE - code designating the component type (refer Appendix $c$ )
c) LENGTH - (meters), the measured or unstretched length of the component
d) WEIGHT - (pounds), the total immersed buoyancy of the component
e) DEPTH - (meters), the depth of the lower termination of a component below the surface
f) INCLIN - (degrees), inclination of the lower end of a component from the vertical (in components with $>1$ segment, the inclination of the lowest segment)
g) TENSION - (pounds), axial tension at the lower termination of each component
h) EXCUR - (meters), vector magnitude of the horizontal displace- ment from the anchor of the top of the component
i) DRAG - (pounds), that component of the drag forces acting to incline the component (accumulative)
j) BACK-UP - (pounds), reserve buoyancy of the mooring below the component (the weight of the components below the release is neglected) 
3) SUPPLEMENTAL STATISTICS - Listing of additional statistics of the mooring useful for evaluating its performance.

SUPPLEMENTAL STATISTICS

COMP TYPE CD(N) AREA STR.LT PERC.STR S.F. XEXCUR YEXCUR LAUNCH TENS

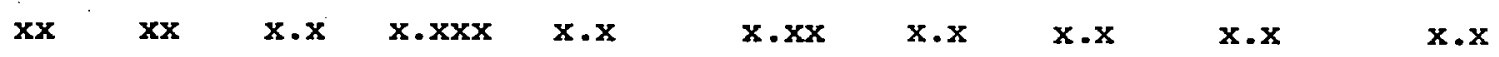
a) $\mathrm{COMP}$
- sequential number of component
b) TYPE
- code designating the component type (refer Appendix C)
c) $\mathrm{CD}(\mathrm{N})$
- (dimensionless), normal drag coefficient applicable to the component
d) AREA - $\left(\right.$ meters $\left.{ }^{2}\right)$, total profile area of the component
e) STR.LT - (meters), stretch length of component
f) PERC.STR - (pph), percent stretch of measured length of component,
g) S.F. - (RBS/tension), safety factor
h) XEXCUR - (meters), horizontal displacement in the $\mathrm{x}$ direction of the top of the component from the anchor ( $+=$ north)
i) YEXCUR - (meters), horizontal displacement in the Y direction of the top of the component from the anchor $(+=$ east)
j) LAUNCH.TENS - (pounds), axial tension at the lower termination of the component during free-fall anchor launch. 
4) SEGMENT STATISTICS - Listing in order from the top of the mooring, the configuration of each segment and the resistive forces acting upon it.

SEGMENT STATISTICS

$\begin{array}{cccccccccccc}\text { COMP } & \text { TYPE } & \text { LENGTH } & \text { INCI } & \text { XEXC } & \text { YEXC } & \text { C.SPD } & \text { C.DIR } & \text { M.AZI } & \text { UDRAG } & \text { VDRAG } & \text { TDRAG } \\ \mathbf{x x} & \mathbf{x x} & \mathbf{x} \cdot \mathbf{x} & \mathbf{x} \cdot \mathbf{x} & \mathbf{x} \cdot \mathbf{x} & \mathbf{x} \cdot \mathbf{x} & \mathbf{x} \cdot \mathbf{x} & \mathbf{x} \cdot \mathbf{x} & \mathbf{x} \cdot \mathbf{x} & \mathbf{x} \cdot \mathbf{x x} & \mathbf{x} \cdot \mathbf{x} \mathbf{x} & . \mathbf{x} \times \mathbf{x} \times \mathbf{x}\end{array}$

a) COMP - sequential number of component

b) TYPE - code designating the component type (refer Appendix C)

c) LENGTH - (meters), unstretched length of segment, termination length added as appropriate

d) INCL - (degrees), inclination of the segment to the vertical

e) XEXC - (meters), horizontal displacement in the X direction of the top of the segment from the bottom of the segment

f) YEXC - (meters), horizontal displacement in the $Y$ direction of the top of the segment from the bottom of the segment

g) C.SPD - (cm/sec), speed of the current acting at the mid-point of the segment

h) C.DIR - (degrees), direction of the current acting at the midpoint of the segment

i) M.AZI - (degrees), orientation of the segment in azimuth relative to north

j) UDRAG - (pounds), normal drag force acting on the segment tending to incline (not accumulative)

k) VDRAG - (pounds), normal drag force acting on the segment tending to rotate (not accumulative)

1) TDRAG - (pounds), tangential drag force acting on the segment (not accumulative) 
5) COMPONENT CHARACTERISTICS - Listing of the composition of the mooring by components with their associated characteristics. Also the constants used in calculating total elongation.

COMPONENT CHARACTERISTICS

\begin{tabular}{|c|c|c|c|c|c|c|}
\hline COMP & TYPE & LENGTH & $A(I)$ & $W(I)$ & $\operatorname{RBS}(I)$ & $\mathrm{AW}(I)$ \\
\hline $\mathbf{x} \mathbf{x}$ & $\mathbf{x x}$ & $x \cdot x$ & $. \operatorname{xxx} \times x \times x$ & $\mathrm{x} \cdot \mathrm{x} \times \mathrm{xxx}$ & $x \cdot x$ & . $\mathrm{x} \times \mathrm{xx} \times \mathrm{x}$ \\
\hline
\end{tabular}

STRETCH CONSTANTS

COMP

$(1-5)$

$(6-10)$

$(11-15)$

$(16-20)$

a) $\mathrm{COMP}$

b) TYPE

c) LENGTH

d) $A(I)$

e) W(I)

f) $\mathrm{RBS}(\mathrm{I})$

g) $A W(I)$

h) STRETCH CONSTANTS
(1)

. $\mathrm{xxxxxE+xx}$

$"$

"

"
(2)

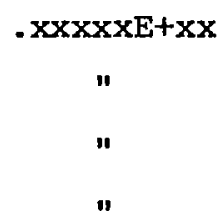

(3)

. $\mathrm{XXXXXE+xx}$

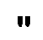

$n$

"
(4)

$. \mathrm{xx} \times \mathrm{xxE}+\mathrm{xx}$

"1

1

n

- sequential number of component

- code designating the component type (refer Appendix C)

- (meters), the measured or unstretched length of the component as input

- $\left(\mathrm{m}^{2} / \mathrm{m}\right)$, area per unit length

- $(1 \mathrm{bs} / \mathrm{m})$, buoyancy per unit length

- (pounds), rated breaking strength

- $\left(\right.$ inches $\left.{ }^{2}\right)$, cross-sectional metallic area of wire

- (dimensionless), values stored in array E(1-16) used as constants in the calculation of component elongation. Four values are assigned to each type component. Components 21 through 42 do not elongate.
i) $\operatorname{COMP}(1-5)$
- components 1 to 5, wire
j) $\operatorname{COMP}(6-10)$
6 to 10 , dacron
k) COMP (II - 15)
11 to 15 , nylon
1) $\operatorname{COMP}(16-20)$
I
16 to 20 , unspecified 
APPENDIX F

SAMPLE RUN

The accompanying computer run is intended to illustrate program instructions, the operator input, and the resulting hard copy output for a typical W.H.O.I. intermediate mooring. Certain component characteristics, stretch constants, drag coefficients, and termination constants were modified solely to demonstrate the processes involved. A subsequent run with an altered current profile is included to demonstrate the use of a change option. The first run is made with sense switches $1,2,3,4$, and $5-O N$ and the second run with sense switches 1 and 4 - ON.

The machine generated instructions are normally displayed on the soft copy device.

The sample mooring is composed of thirteen individual components. In order from the top of the mooring, they are:

radio float

$1 / 2$ " chain (2 meters)

main buoyancy (20 glass spheres)

instrument (VACM)

$3 / 16 "$ wire (1000 meters)

intermediate buoyancy ( 2 glass spheres)

instrument $(850-\mathrm{CM})$

3/8" dacron line (1000 meters)

backup buoyancy ( 8 glass spheres)

release

$1 / 2$ " chain (5 meters)

$3 / 4 "$ nylon line (20 meters)

$1 / 2$ " chain ( 3 meters) 
ENTER FIVE I/O DEVICES

SOFT COPY,HARD COPY,PAPER PUNCH,KEYBOARD, PAPER READER

STANDARD URN ARE:

$2,6,4,1,5$

$2,6,4,1,5$

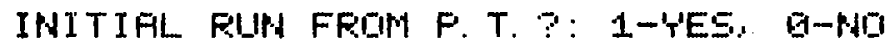

0

CHANGE CONF. CONETANTS?: 1-YES. G-ND

1

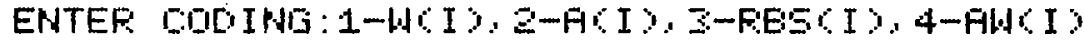

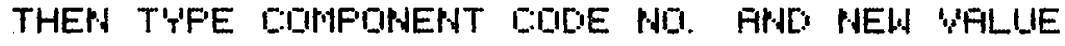

$$
1,23,-8.5
$$

NEYT OF 99

$$
2,23,0.46
$$

NEXT DIF 99

99

CHANGE STFETLH DHFFATTEFISTICST: 1-TES. D-NI

1

ENTEF: 1-WIFE. Z-DFCFON. Z-N'TLON. 4-UNSFEL.

3

NOW ENTEF: THE 4 CONETANTS

$1.5 \mathrm{E}+05,0.52,1.33 \mathrm{E}+05,0.54$

NEXT DF: 99

99

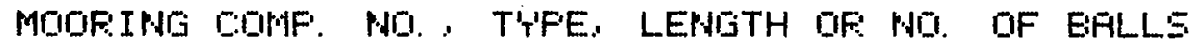

$$
\begin{aligned}
& \text { NEYT TIF } 99 \\
& 2,23,2 \\
& \text { NEXT DF: } 99 \\
& 3,40,20 \\
& \text { NEXT DFE } 99 \\
& 4,25,1.9 \\
& \text { NEST DE: } 99 \\
& 5,1,1000 \\
& \text { NEXT DIF } 99 \\
& 6,40,2 \\
& \text { NEYT DF: } 99 \\
& 7,26,1.8 \\
& \text { NE'XT DF: } 99 \\
& 8,6,1000 \\
& \text { NEXT DIF } 99 \\
& 9,40,8 \\
& \text { NEXT DIF } 99 \\
& 10,35,1.8
\end{aligned}
$$


NEXT OR 99

$11,23,5$
NEKT QF 99
$12,15,20$
NEXT GF 99
$13,23,3$
NEXT GF: 99

99

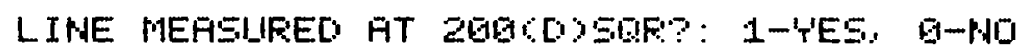

1

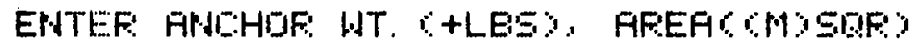

$2500,1.0$

ENTEF: COMMENTS - 1 LINE MFY.

SAMPLE RUN OF TYPICAL WHOI SUBSURFACE MOORING - OCT 1975

ENTEF: DEFTH OF HATEF: MUETEF:

3000

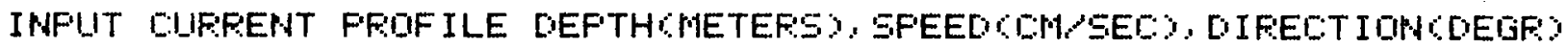

$0,30,90$

$1000,30,90$

$1500,20,180$

$2000,15,135$

$3000,10,90$

CHANGE STANOAFD CD?: 1-YES. Q-NO

1

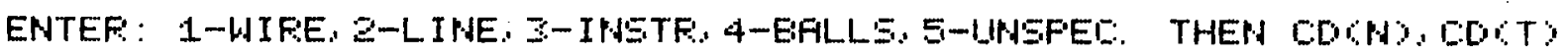
$4,0.5,0.5$

HEYT DF: 99

99

SEGMFNT LEMIITHCMETEFSY

100

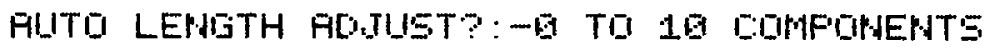

2

ENTEF: COFITICFL DOMF. DESIFED DEFTH. FDIUST. COHF.

$4,900,5$

$7,1900,8$

ENTEF: MAISNITLDE. INCLINATION, FZIMUTH DF F. F.

$0,0,0$

CHANGE IN TEFNINATION EONSTAMTS?: 1-'T'ES: 9-NO

1

ENTEF: TEFM. LENISTHCMETERS. HT. CLESO

$0.2,-2.2$

GO? - 699: GF DFTIIA? - 1 TO 1E)

9

SEIMUNT LENIITHCMETEFSY?

50

G0\% - 699\% QF DFTIDW - 1 TO 1E? 


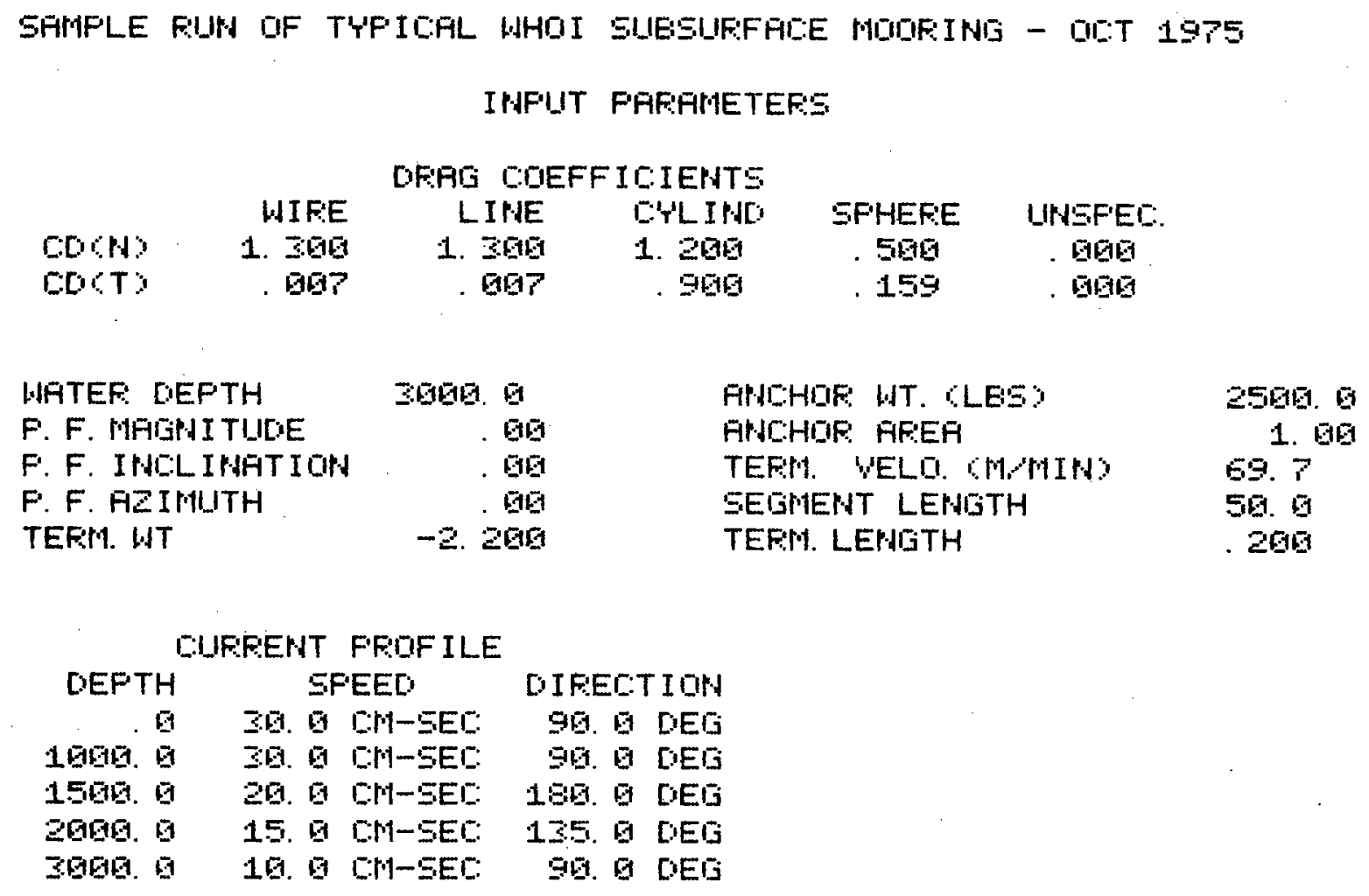




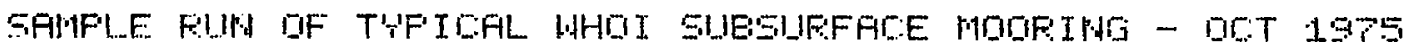

SEIDNENT STATTSTICS

\begin{tabular}{|c|c|c|c|c|c|c|c|c|c|c|c|}
\hline ronif & T'T'FE & LEHVITH & TPICL & KEAC: & 'T'EY: & 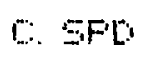 & C: OUF & M. $\mathrm{FII}$ & DIOFEAFII & WDFAC & TLEAHS \\
\hline 1 & 39 & 1. 2 & 2.4 & -0 & .1 & 301 & 96.0 & 91.6 & 1. $E$ & . 01 & .09205 \\
\hline 2 & 2 & 22 & 577 & -.9 & 1. 2 & 30.0 & 90.9 & 90.9 & 3.54 & 89 & 97121 \\
\hline 3 & 40 & 20.2 & 2.0 & -0 & 7 & 29.8 & 90.0 & 50.0 & 28.3 & 80 & 05554 \\
\hline 4 & 25 & 2.1 & 2. 4 & -0 & 1 & 20.9 & 90.8 & 90.9 & 4. 14 & 85 & 01747 \\
\hline 5 & 1 & 50.9 & 27 & -.9 & 2. 4 & 50.0 & 90.9 & 90.0 & 4. 45 & 00 & GEDA 7 \\
\hline 5 & 1 & 50.9 & 29 & -0 & 2. $E$ & 30.0 & 90.0 & 90.0 & 4.45 & 90 & OE1120 \\
\hline 5 & 1 & 50.9 & 33 & -9 & 2. 8 & 29.4 & 95.5 & 90.6 & 4. 22 & 54 & 0992 \\
\hline 5 & 1 & 50.9 & 3.5 & -.9 & 3.1 & 20.4 & 104.7 & 9013 & 372 & 25 & 00124 \\
\hline 5 & 1 & 50.9 & 37 & -0 & 33 & 27.3 & 114.6 & 90.9 & $\exists 12$ & 57 & 99922 \\
\hline 5 & 1 & 50.9 & 39 & -.1 & 3.4 & $2 E$. & $122=$ & 91.7 & 243 & 93 & 00919 \\
\hline 5 & 1 & 50.0 & 4. 9 & -.2 & 3.5 & 25.2 & 1324 & 92.9 & 1. 80 & 1. 29 & ODGLE \\
\hline 5 & 1 & 50.9 & 4. 2 & -.3 & $3 E$ & 24.3 & 141.6 & 94.2 & 1.3 & 1. 58 & 50012 \\
\hline 5 & 1 & 50.8 & 4. 2 & -.4 & 37 & 232 & 150.9 & 95.7 & .87 & 1.90 & DEg9s \\
\hline 5 & 1 & 50.9 & 4.3 & -.5 & 37 & 22.2 & $1 E A .1$ & 97.4 & 51 & 1. 98 & 019005 \\
\hline 5 & 1 & 56.9 & 4. 4 & $-E$ & 3. & 21.2 & 1Eg $\Xi$ & 99 & .25 & 1. 97 & 90992 \\
\hline 5 & 1 & 50.6 & 4. 4 & -7 & 3. & 29.2 & $179 . E$ & 106. & 69 & 1. 9 & 00001 \\
\hline 5 & 1 & 50.9 & 4. 5 & -.8 & Z : & 195 & 17E. 1 & 1020 & .14 & 1. 75 & 9999: \\
\hline 5 & 1 & 59.9 & 4.5 & -.9 & $\Xi:$ & 131 & 171.5 & 1023 & 25 & 1. 55 & 090109 \\
\hline 5 & $\perp$ & 50.9 & 4. $\theta$ & -1.0 & 39 & 18.5 & $1 E \theta 9$ & 194.4 & $\Xi E$ & -1. 24 & 909514 \\
\hline 5 & 1 & 50.9 & 4. $E$ & -1.1 & 39 & 18.9 & 1623 & 105. & 49 & 1. 12 & Q01965 \\
\hline 5 & 1 & 50.0 & 4.7 & -1.1 & 4. 9 & 17.5 & 157.6 & 100.1 & 50 & .98 & 90997 \\
\hline 5 & 1 & 50.9 & 4. 3 & -1.2 & 4. 9 & 17.9 & 1500 & 1EE. 7 & $\theta \theta$ & 75 & 000日5 \\
\hline 5 & 1 & 56.9 & 4.9 & -1.5 & 4. 1 & $1 E .5$ & 148.4 & 107.2 & $7 E$ & 59 & 50069 \\
\hline 5 & 1 & 45.2 & 5.0 & -1.2 & 3.5 & 15.0 & 144.0 & 107.5 & .74 & 41 & E9619 \\
\hline 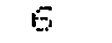 & 40 & 2.2 & 4. 5 & -1 & $\therefore$ & 15.0 & $141 . \theta$ & 197.7 & .58 & 27 & 00259 \\
\hline 7 & 26 & 2.0 & 4. 8 & -.1 & 2 & 15.7 & 141.6 & 1EG. & 85 & 8 & 01286 \\
\hline$\theta$ & $E$ & 56.9 & 4. $\theta$ & -1.4 & 4.2 & 15.5 & $123=$ & $106 .=$ & 1. 17 & 42 & 59914 \\
\hline 8 & $E$ & 50.0 & 4. 9 & -1.4 & 4. 3 & 15.9 & 154.8 & 19日. 5 & 1. 20 & 29 & 001515 \\
\hline$\theta$ & $E$ & 50.9 & 5.5 & -1.5 & 4. 4 & 14.7 & 132.5 & 109.7 & 1. 21 & 24 & GQ1010 \\
\hline 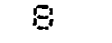 & $E$ & 50.9 & 5. 1 & -1.5 & 4. 5 & 14.5 & 130. & 100.8 & 1. 21 & 19 & 00015 \\
\hline$\theta$ & $E$ & 50.9 & 5.2 & $-1 . \theta$ & 4. 5 & 14.2 & 127.9 & 1EO & 1. 20 & 14 & 91901: \\
\hline 8 & $E$ & 50.9 & 5.2 & $-1 . E$ & 4. $E$ & 14.8 & 125.6 & 150.0 & 1. 19 & 11 & 91017 \\
\hline$\theta$ & $E$ & 50.9 & 5.4 & $-1 . E$ & 4. $\vec{r}$ & 137 & 122. & 199.:L & 1. 17 & 98 & 0917 \\
\hline 8 & $E$ & 50.9 & 5.5 & $-1 . E$ & 4. 7 & 134 & $1 \geq 1.0$ & 1951 & 1.15 & 155 & 09917 \\
\hline 8 & $\Xi$ & 560 & 5.5 & $\cdots 1.7$ & 4.8 & 132 & $\angle \perp B . E$ & 109.1 & 1. 12 & 92 & 99817 \\
\hline$a$ & 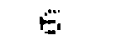 & 50.0 & 5.6 & $-1 . \vec{r}$ & 4. 9 & 12.9 & 11E. $Z$ & 1591 & 1. 09 & 92 & 95B17 \\
\hline 9 & $\theta$ & 56.9 & 5.7 & -1.7 & 5. 9 & 127 & 114.6 & $105=$ & 土. $9 E$ & 81 & 1961\% \\
\hline 5 & $E$ & 59.9 & 5.8 & -1.7 & 5.9 & 124 & 1117 & 199. 2 & 1. 92 & 90 & Q0017 \\
\hline 8 & 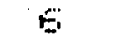 & 50.9 & 5.9 & -1.8 & 5.1 & 12.2 & 1094 & 159.2 & .98 & .89 & 89917 \\
\hline 8 & $E$ & 56.9 & 5.9 & -1.5 & 5.2 & 11.9 & 187.1 & 109 & .94 & … & 9ES17 \\
\hline$\theta$ & 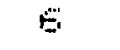 & 59.9 & 60 & -1.9 & 5.2 & $11 . E$ & 184.8 & 1619 & .89 & -.91 & GQFLE \\
\hline 8 & $E$ & 56.9 & E. 1 & -1.6 & 5. & 11.4 & 105 & 19G. 1 & .85 & -01 & GGOLE \\
\hline$\Xi$ & $E$ & 5018 & 6.1 & -1.9 & 5.5 & 11. 1 & 1EQ 2 & 159.1 & .80 & -.5 & 09015 \\
\hline$\theta$ & $E$ & 50.9 & E. 2 & -1.9 & 5.4 & 10.9 & 97.9 & 159.1 & .75 & -15 & 60015 \\
\hline$\Xi$ & 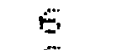 & 50.9 & E. & -1.9 & 5.4 & 10. & 95.6 & 169.1 & .71 & -94 & 00014 \\
\hline$\theta$ & $E$ & 50.9 & E. 3 & -1.9 & 5.5 & 19.4 & 93. & 1E9.1 & $E E$ & -.95 & 91913 \\
\hline$\theta$ & $E$ & $E .9$ & E. 3 & -.5 & 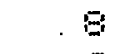 & 19.2 & 92.9 & 109.0 & .99 & -.81 & DEDEZ \\
\hline 9 & 49 & $\theta 2$ & 4. 3 & -.2 & $E$ & 10.2 & $91 . E$ & 159.0 & 1. 20 & -12 & Q166- \\
\hline 10 & 25 & 2.9 & 4. $E$ & -.1 & 2 & 10.2 & 91.4 & 199.9 & .39 & -.84 & EQ159 \\
\hline 11 & 22 & 5.2 & 5. 9 & -.1 & .4 & 10.1 & 91.2 & $10 \%$. & 324 & -54 & 00045 \\
\hline 12 & 1.5 & 20.2 & 5.9 & -.6 & 1. 9 & 10.1 & 50.6 & 1.19. 7 & .49 & -.95 & EOADEE \\
\hline 13 & 23 & 2.2 & 5.2 & -1 & .5 & 10.0 & 90.1 & ISE. $=$ & 1. 99 & -22 & DELOE \\
\hline
\end{tabular}




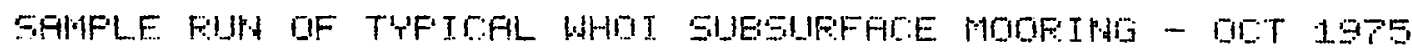
MOOFIMIS STATISTIES - SUMMFF'T

\begin{tabular}{|c|c|c|c|c|c|c|c|c|c|}
\hline CMF & $T^{\prime} T^{\prime} F^{\prime} E$. & LEHISTH & WEI IIHT & DEF'TH & IHACL ISP & TEHSI IN & ENIIIF & DFFA & EFE: - LF \\
\hline 1 & 30 & 10 & 410 & 875.7 & 2. 4 & 28.8 & $1 E: E$ & 1. $E$ & 11ER \\
\hline$z$ & 23 & 20 & -17.0 & $\theta 7 \%$ & 27.7 & $L F=$ & 1804 & 11.1 & 1196 \\
\hline 3 & 49 & 29.9 & IEEO 0 & 997.9 & 20 & $10 \% 1.9$ & 1797 & 39.5 & 128 \\
\hline 4 & 25 & 1. 9 & -75.9 & 893.6 & 2.4 & 994.7 & 1797 & 43.5 & 205 \\
\hline 5 & 1 & 935.1 & $-158 z$ & 1895.5 & 5.9 & 899 & 1084 & 75.9 & 81 \\
\hline$\epsilon$ & 40 & 20 & 100.0 & 1997. & 4.5 & 945.9 & 1.95 .2 & 75. & 257 \\
\hline 7 & 25 & 1. $\theta$ & -40.6 & 1999.7 & 4. $:$ & 961.0 & 1EE. & PE. 4 & $29=4$ \\
\hline$\theta$ & $E$ & 1916E. 7 & $-2 . \Xi$ & 2959.5 & E. 3 & $96 \mathrm{~L} 2$ & 3.5 & 95.9 & 38 \\
\hline 9 & 40 & E. $\theta$ & 424.0 & 2960.6 & 4. 3 & 1201.2 & 29 & 98.1 & -62 \\
\hline 10 & 35 & 1. $\theta$ & -80.0 & 2909.6 & 4. 6 & $1199=$ & 27 & 98.5 & \\
\hline 11 & 23 & 5.9 & -42.5 & 2974.9 & 5. 9 & 1154.6 & 23 & 101 & \\
\hline 12 & 15 & 20.9 & $\cdots .9$ & 2996.8 & 5. 8 & 1151.7 & 3 & 1E12. & \\
\hline 13 & 28 & 30 & -25.5 & ZEGE 8 & 5.2 & $11 \geq 4.1$ & $\theta$ & 194. $:$ & \\
\hline
\end{tabular}




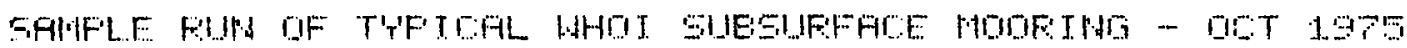

DIJFLENEPTFI. STHTTSTTCS

\begin{tabular}{|c|c|c|c|c|c|c|c|c|c|c|}
\hline ECINAF & T'T'F'E & C:[1] & FIFEA & $\Xi T F . L T$ & FEFE: & STR & $=F$. & YEOEIIF & 'TE:MIIF: & LAHBWAH TEHS \\
\hline 1 & 3 &. & 209 & 1. 9 & & 99 & 0 & -40.7 & 175.5 & 59 \\
\hline 2 & 23 & 1. $\Xi$ & .920 & 20 & & 80 & $=7$ & $\cdots 407$ & 174.2 & 43.1 \\
\hline$\Xi$ & 49 & .5 & 5.392 & 29.0 & & 80 & 9 & $-4 \pi 7$ & 1725 & 15230 \\
\hline 4 & 25 & 2 & .301 & 1. 9 & & 89 & $\theta$ & $-4 E .7$ & 1735 & $1061 . E$ \\
\hline 5 & 1 & 3 & E. 545 & 9982 & & 31 & 4. 9 & -35. & 102.5 & 14697 \\
\hline$F$ & 49 & 5 & .59 & 20 & & 09 & Q & -35.2 & 192.2 & 1914.7 \\
\hline 7 & 26 & 1. 2 & .328 & 1. $\theta$ & & 89 & . & -35.2 & 1921 & 17452 \\
\hline 9 & $E$ & 1. 3 & 9. 9E & 10599 & 5 & $6 \theta$ & $E$. & -1.1 & 3 & 17341 \\
\hline 9 & 49 & 5 & $\because 157$ & 8. 0 & & 00 & 8 & $\cdots .9$ & 2. & 204.9 \\
\hline 19 & 3 & 1. 2 & 270 & 1. 8 & & $\mathrm{EtS}$ & $\theta$ & -.9 & 2. $E$ & 281.0 \\
\hline 11 & 25 & 1. 2 & 2200 & 5.9 & & 80 & 13.0 &.$- \vec{r}$ & 2.2 & 2844.9 \\
\hline 1.2 & 15 & 1. 3 & . 5 & 227 & 13 & $\theta \theta$ & 123 & -1 & - & 28429 \\
\hline 13 & 22 & 1. 2 & 1. 280 & 30 & & 8E & 19. & 9 & 9 & 280.9 \\
\hline
\end{tabular}




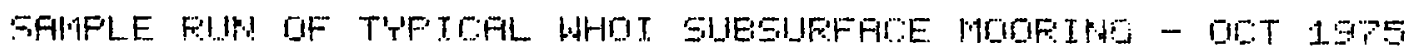

\section{DOMFOPEAT CHAFACTEFISTIOS}

\begin{tabular}{|c|c|c|c|c|c|c|c|}
\hline CONAF & T'T'FE & LEPASTH & FICI & WI & FEESCI & & FHSI \\
\hline 1. & 3 & 1. 9 & 2001000 & 41. 00109 & & 0 & G0199E \\
\hline 2 & 23 & 29 & 4590100 & -9.5000 & 21001 & 9 & $9090 \mathrm{~g}$ \\
\hline 3 & 49 & 20.9 & 2695200 & 5.9000 & & $\theta$ & 960EEA \\
\hline 4 & 25 & 1. 9 & 1579600 & -39.474 & & $\Xi$ & 909090 \\
\hline 5 & 1 & 995.1 & 9E65786 & -15450 & $400 \mathrm{a}$. & Q & 016110 \\
\hline$E$ & 40 & 20 & 2690209 & 5.9000 & & 9 & $9900 \mathrm{DE}$ \\
\hline 7 & $\Xi E$ & 1. 8 & 1791799 & -22.222 & & 9 & 090000 \\
\hline$\theta$ & $E$ & 1015.7 & 0099659 & -.98756 & 5791 & 9 & 900919 \\
\hline 9 & 40 & e. 9 & 2896200 & 52.0000 & & 9 & EDEGIEA \\
\hline 10 & 35 & 1.8 & 1499000 & -44.444 & & 9 & 0010901 \\
\hline 11 & 28 & 5.9 & 46000100 & -6.5000 & 2LEOS & $\theta$ & 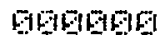 \\
\hline 12 & 15 & 20.9 & 9178119 & -.94570 & 14209 & 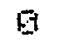 & 90: \\
\hline 13 & 23 & 20 & 4601909 & -9.5000 & 21000 & 9 & G199EG \\
\hline
\end{tabular}

\begin{tabular}{|c|c|c|c|c|}
\hline \multicolumn{5}{|c|}{ STFETCH CIRUSAMTS } \\
\hline EnMF. & 13 & 83 & 0 & $64 y$ \\
\hline $1-5$ & $1428 E-62$ & $29598 E+98$ & $\triangle Q G Q B E+E G$ & GEQGOE+GE \\
\hline $6 E-16$ & $2019 \mathrm{EE}+97$ & GOTOEE+DQ & З9SGGE & $74900 E+910$ \\
\hline $611-15$ & $15 E 00 E+95$ & $52090 E+90$ & $12390 E+9 E$ & $54909 E+Q 9$ \\
\hline $616-20$ & QGG10EE+QIE & 99900E+6פ & GQGGQE+QBG & Q19099E+Q19 \\
\hline
\end{tabular}


DHARIJE DFTIOHA

1 EOHF. CHAF:

2 ETFETCH EHAF

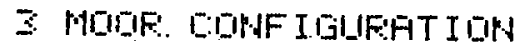

4 2GE D DGF MEASUIFE

5 ARILHIF: WT.

5 WFTEF: DEFTH

7 CIIFEFENT FFIOFILE

G OFAL ODEFF

9 SEGMENT LEHIGTH

19 FLITO FD,TLET STATIE

11 F. F. AT TOF

12 TEFI CONST.

12: DONHENTS

14 CONTINIE WO FELFLE

15 IPAFIT MOIF FROM FTF:

1E DUTFUIT MIOF. TO FF

\section{7}

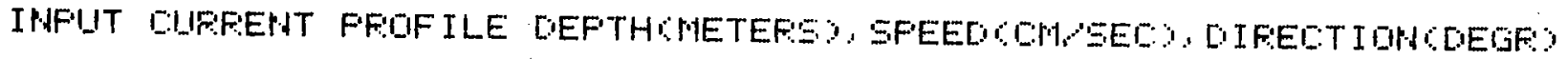
$0,0,0$

$3000,0,0$

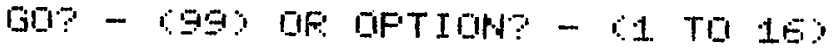

99 


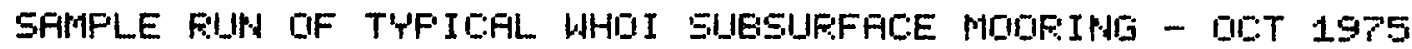

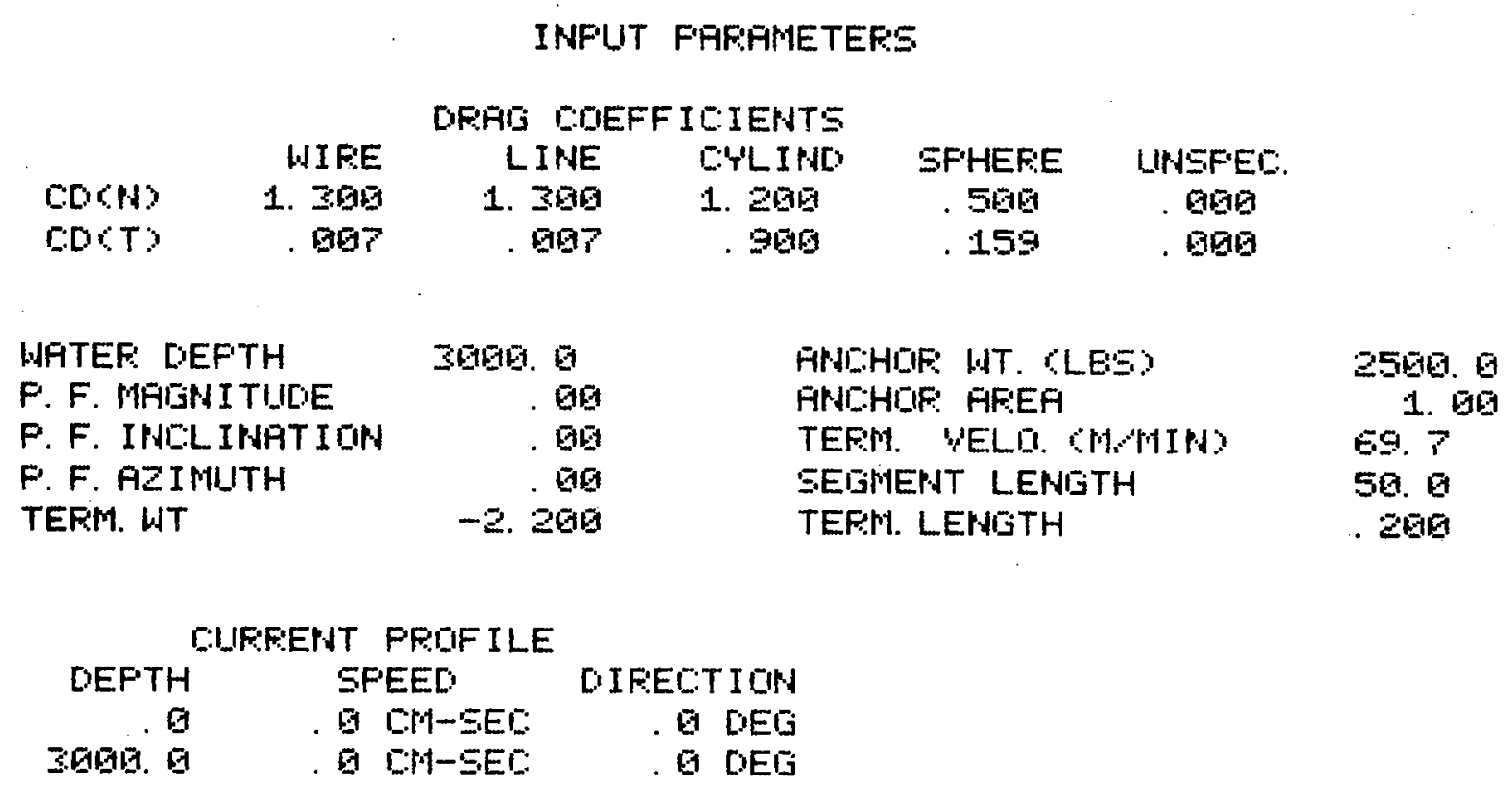




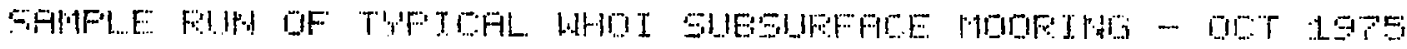

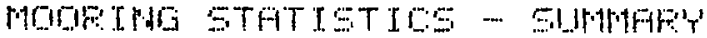

\begin{tabular}{|c|c|c|c|c|c|c|c|c|c|}
\hline EOMlF & T'S'PE & LEPAITH & HEI IOHT & GEF'TH & IPACLE THA & TEHSION & ENOUY: & DFAOA & $B F \mid 1-1,1 F$ \\
\hline 1 & 28 & 1. 9 & 410 & घE. 2 & .0 & 30. & $\ddot{\theta}$ & 9 & 1199 \\
\hline$z$ & 28 & 2.0 & -17.0 & $8 \theta=4$ & 0 & 19.6 & 9 & 9 & $11 E=$ \\
\hline 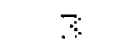 & 49 & 200 & 1000. & 690. & .8 & 1977 & 0 & 9 & 128 \\
\hline 4 & 25 & 1.9 & -75.0 & 991.7 & 0 & 19E19: $=$ & 5 & 8 & 205. \\
\hline 5 & 1 & 9551 & -158.2 & 1990.1 & 9 & 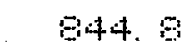 & 9 & 0 & 381 \\
\hline$E$ & 49 & 2.9 & 196.0 & 1902.5 & 9 & 945.6 & 9 & 9 & 25 \\
\hline 7 & $2 E$ & 1. $\theta$ & -40.0 & 1994.3 & $\mathrm{G}$ & gाह 4 & 9 & 9 & 299 \\
\hline 5 & $E$ & समEब 7 & -78 & 2958.5 & 5 & $B E B$ & $\theta$ & $\theta$ & 30 \\
\hline 9 & 40 & a. & 424.6 & Q9EE. 7 & 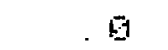 & 1290.2 & 9 & 8 & -82 \\
\hline 19 & 5 & 1. 8 & -80.6 & 2SEE. $P$ & g & 1200.6 & 6 & 9 & \\
\hline 11. & 23 & 5.9 & -425 & 29795 & Q & 11012 & E & 9 & \\
\hline 12 & 15 & 20.9 & -.9 & 2996.8 & 9 & 11502 & 9 & $\theta$ & \\
\hline 1.3 & 23 & 3.9 & -25.5 & S9G0. 0 & 9 & 1130.5 & 9 & $\theta$ & \\
\hline
\end{tabular}




\section{APPENDIX G}

\section{GLOSSARY - PROGRAM VARIABLES}

A

ANCR wet weight of anchor in positive pounds

ANCRA effective area of anchor $\left(\mathrm{m}^{2}\right)$

ANINC angular difference of inclination between adjacent segments $\left(\phi_{n}-\phi_{n-1}\right)$.

AW array, 5 wire components, characteristic of cross-sectional metallic area (inches ${ }^{2}$ ).

BKUP reserve or back-up buoyancy at top of each component (lbs)

CALC subroutine, calculate mooring configuration

CDN array, 5 normal drag coefficients

CDT array, 5 tangential drag coefficients

CLI length of segment $n$ (meters)

CLIN inclination of segment $\mathrm{n}-1$ (radians)

CONST subroutine, standard component characteristics

CP array, current profile, speed (cm/sec)

$\mathrm{CPK}$ conversion constant $(\mathrm{cm} / \mathrm{sec})^{2}$ to $(\mathrm{ft} / \mathrm{sec})^{2}$

DB array, selected depths for critical components in auto adjust feature (meters)

DCP array, depths of current profile points (meters)

DN estimated depth of mid-point of segment $n$ (meters)

DONE output flag when set $>1$, indicates start of output sequence

DPT water depth (meters)

DRAG accumulative normal drag acting to incline the mooring (pounds)

DRGT tangential drag force (pounds)

D200 stretch factor, dacron line, compensate stretched length for slack line measurement 


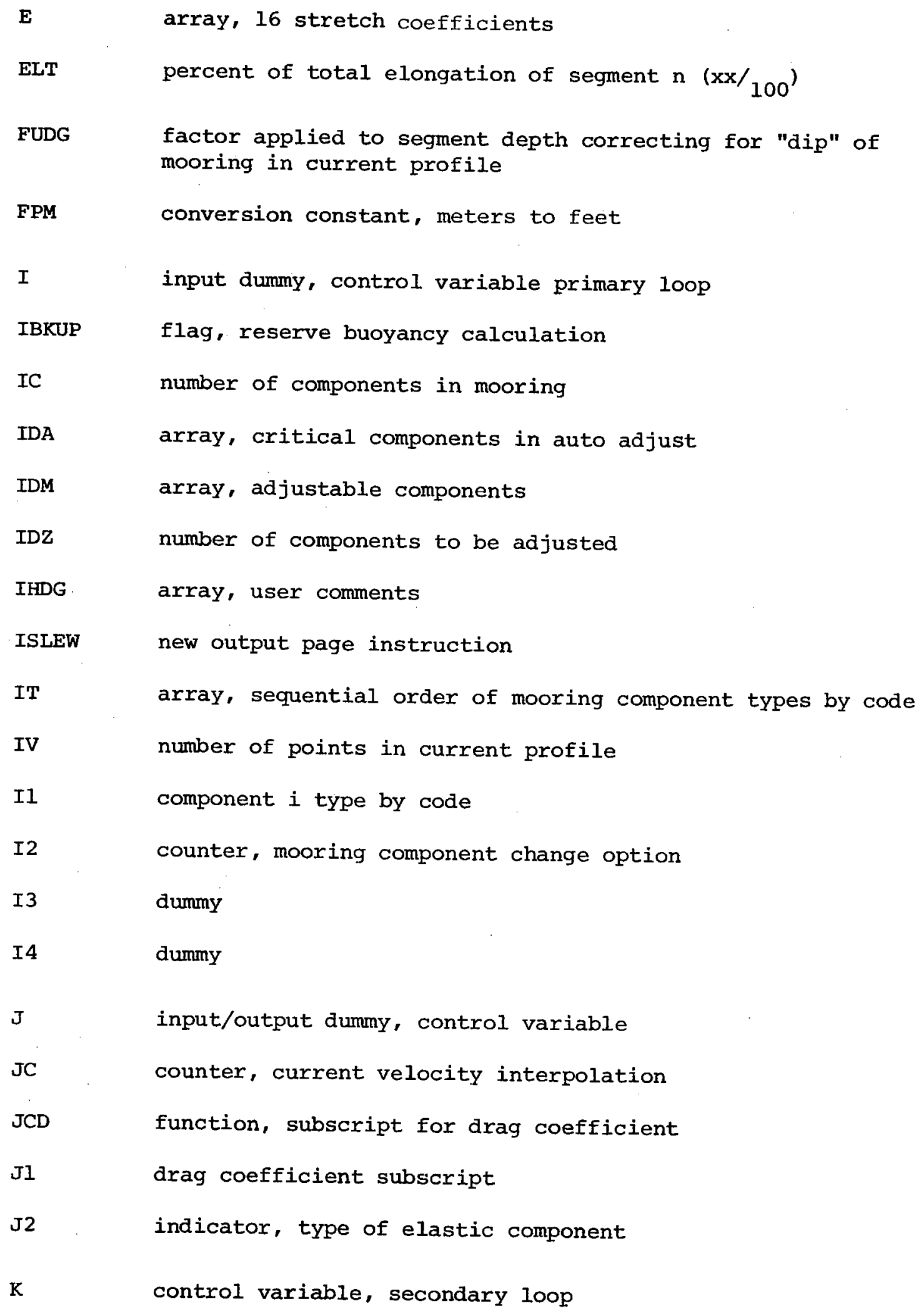




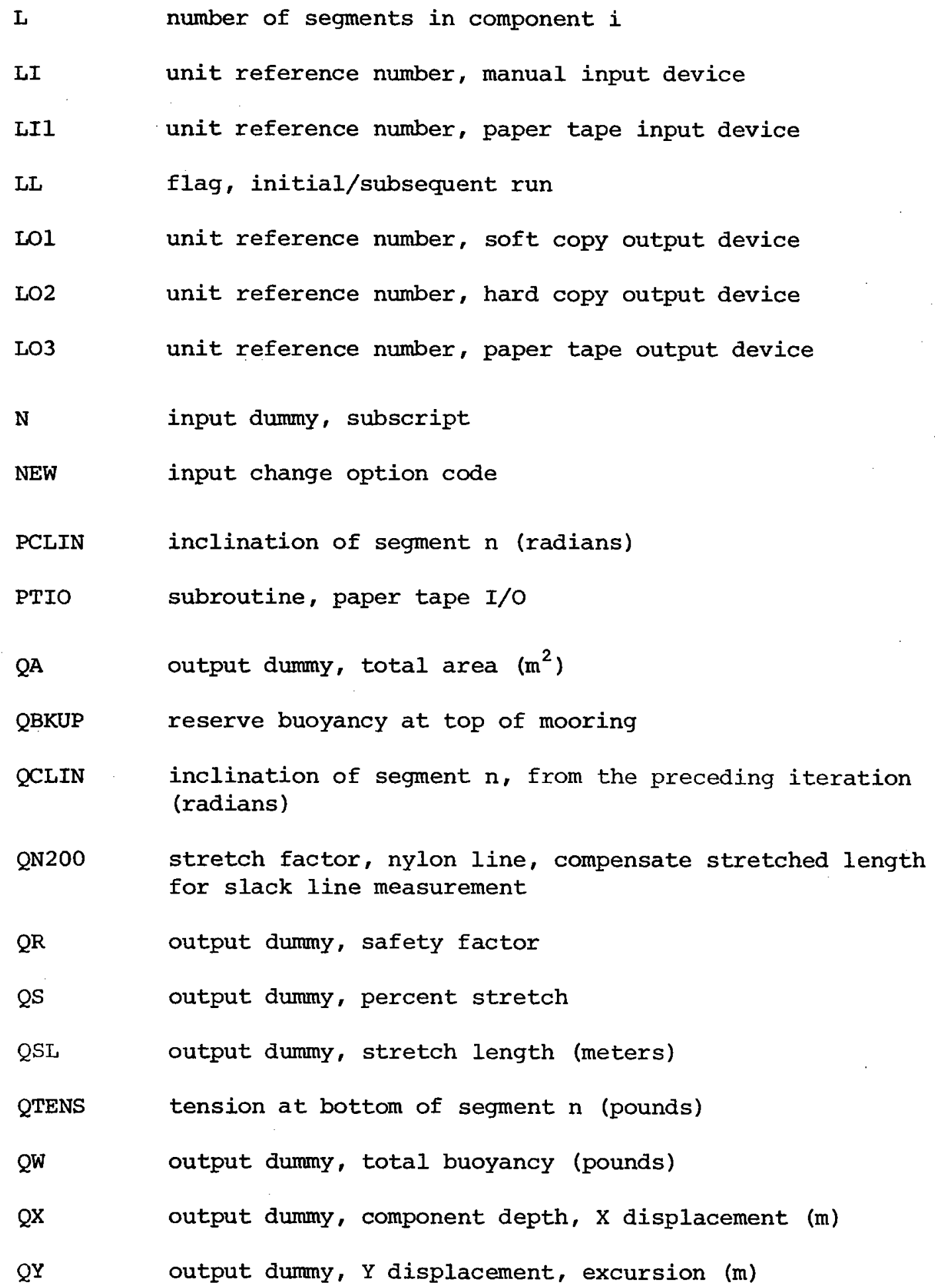




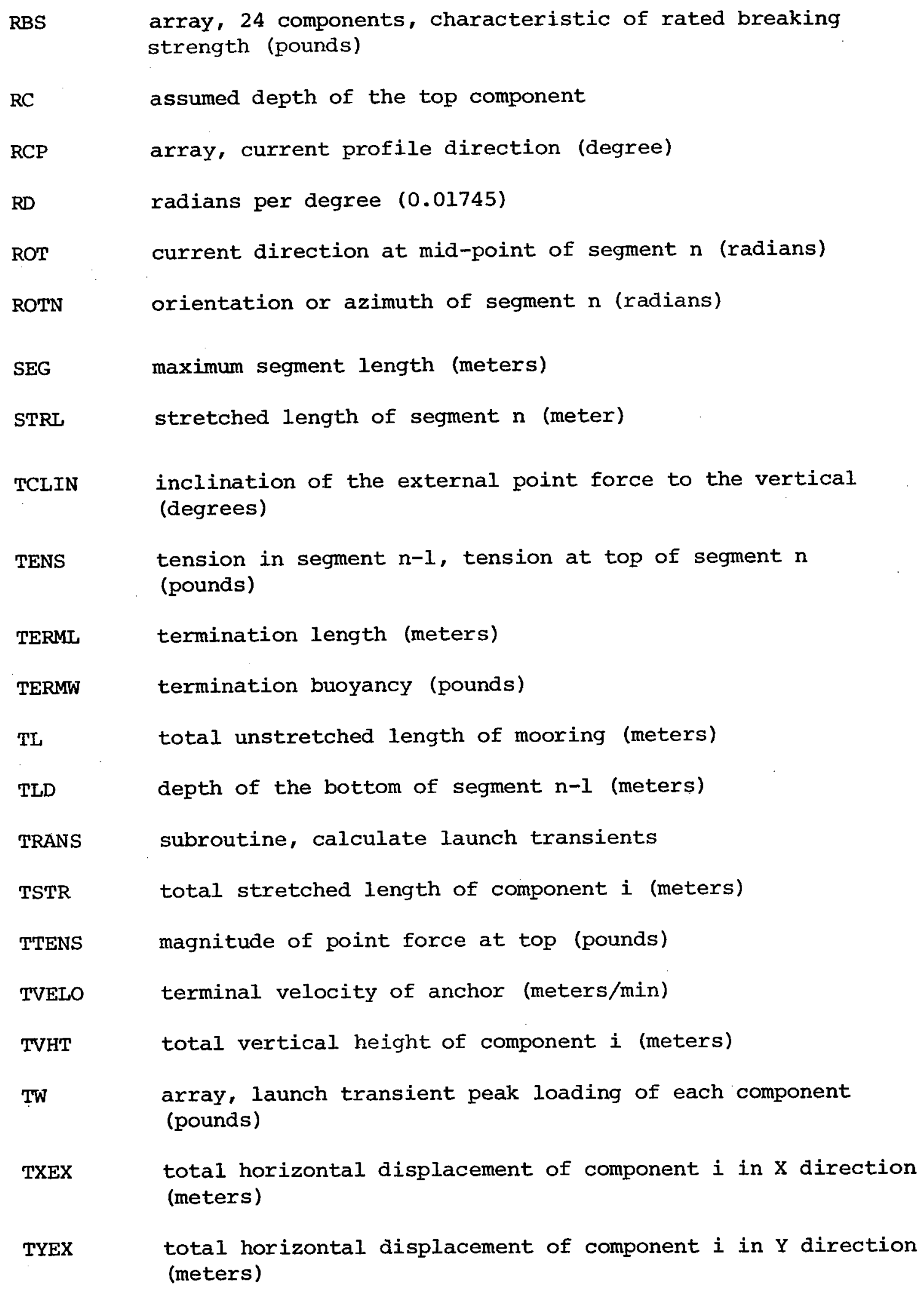




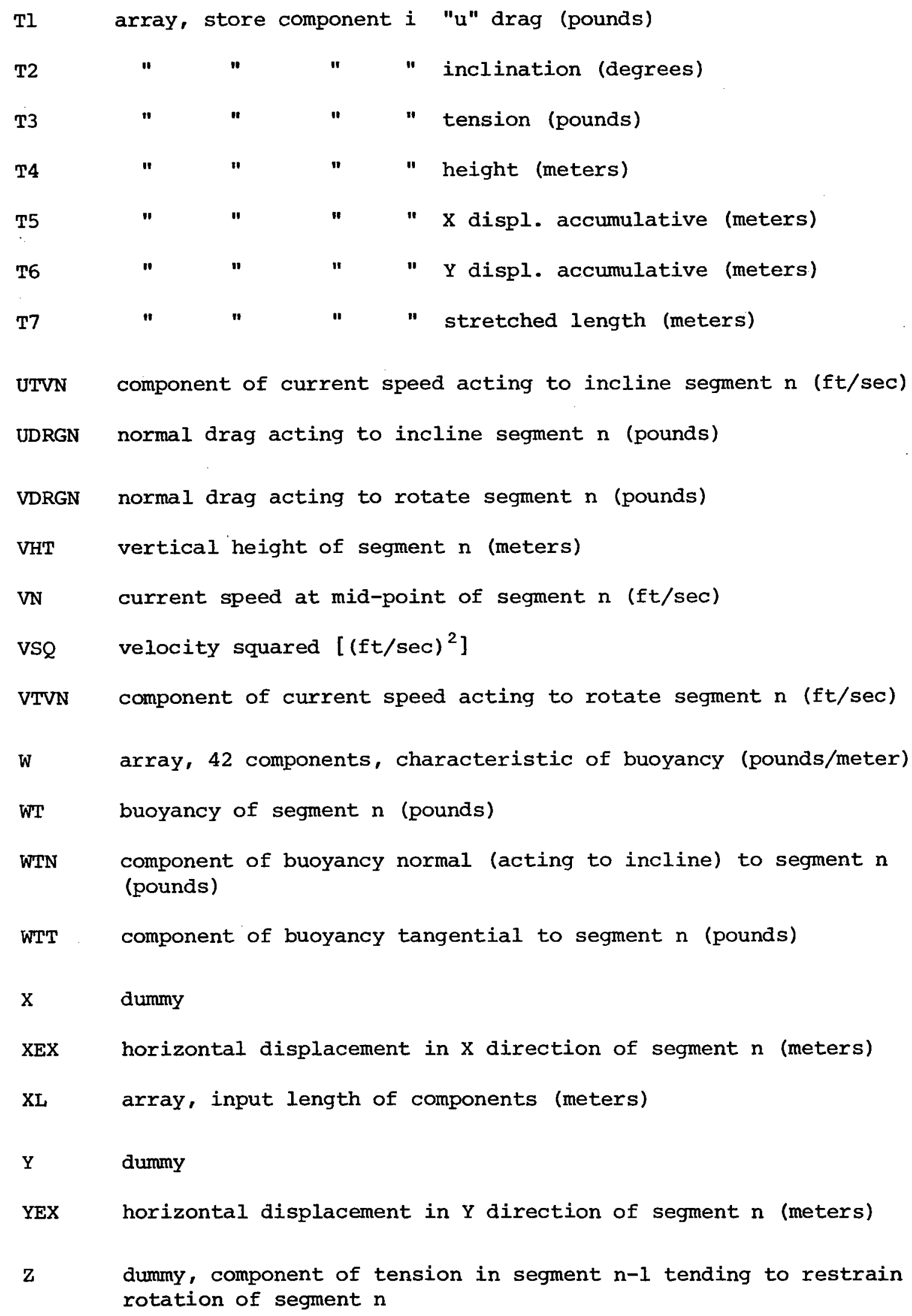


APPENDIX H

PROGRAM LISTING

The following is the listing of the source programs, subroutines, and functions of NOYFB, Rev. 9.1, March 1975.

The language is Fortran II as listed in Hewlett-Packard manual "A Pocket Guide to the 2100 Computer."

The listing includes in order:

1) Program NOYFB

2) Subroutine CALC

3) " CONST

4) " TRANS

5) " PTIO

6) Function JCD 
it

E101

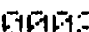

Q1E1E

EDE

멈ㄷㄴ

GESE:

므메국

EDET:

DEDS

EIF16

E1511

EQ10

Q91512

ज्ञ1 4

Q1515

EEA 1 -

0817

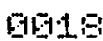

5919

퍼요

ज्ञात-1

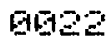

시눙

जEE4

ज15:5

Q1E2:

जㅡ룽

D15:

미를

보는

Fin 1

티을

E15

드년

페드

슬

ज्ञ궁

196

ज19

Q194

6041

E1042

जEF4

터뎐혀

준도

E154E

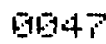

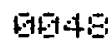

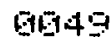

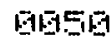

Q015.1

테동

피도

미두

부도

Ge15:

버닥

005
FFIIIGFHFI RII'T'FE

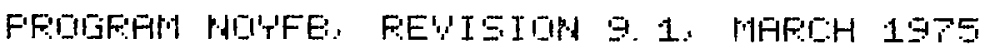

FFILIFEFMHEF: HILLEF: OF H. H. OI. I.

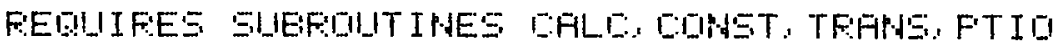

FEEUIFES FIPRITILW JTL

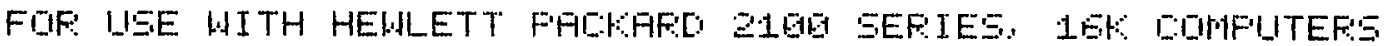

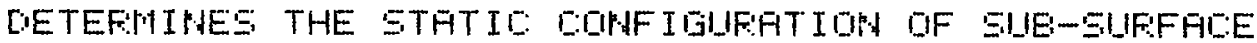

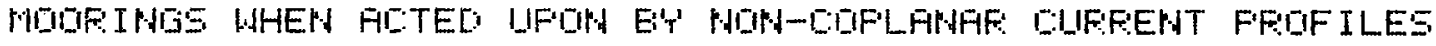

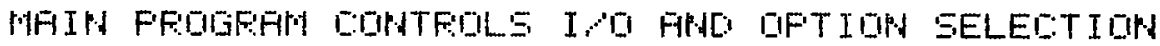

SENSE SWITLH DIFTIDNS AFE:

S. S. - 1 - QNA - LIST INAFUT FFFHIIETEFE

" - 2 - DN - DIITFIT SELINEHT ETHTS.

$" \quad-\Xi-$ DH - DITFIUT SIIFFLEMENTFL STATS.

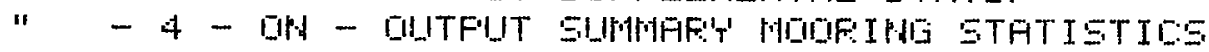

" - 5 - OW - DUTFUT CONFGNEHT CHAFAITEFISTILS

" -19 - OW - OLITFUT TO SOFT EOF'T' DEYILE

" - 1 - DFF- DIITFUT TO HAFE DIF'T OEYIEE

"-14 - OW - AEIFT FILH - GO TQ "FFHSE"

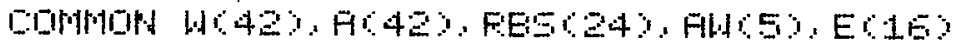

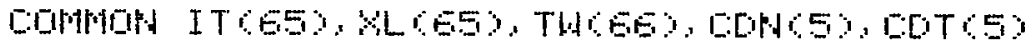

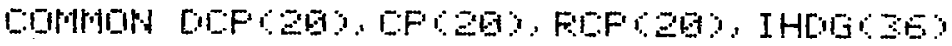

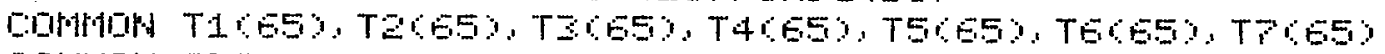

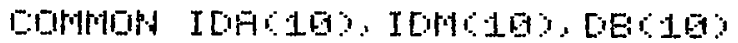

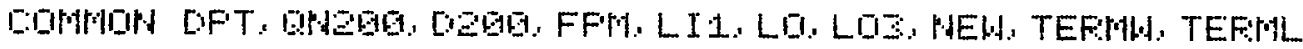

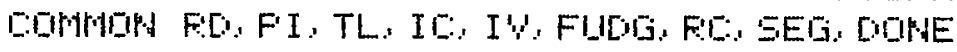

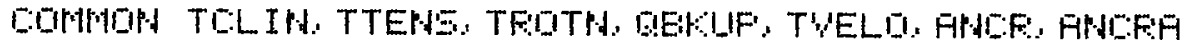

$L L=G$

$I E=0$

NEW $=15$

$I \Xi L E M=14 E$

L:

E:

$E$

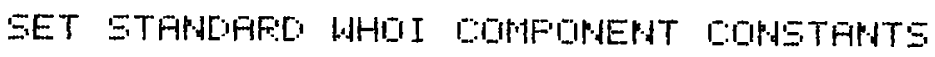

EALL COURST

C:

E.

t:

C.

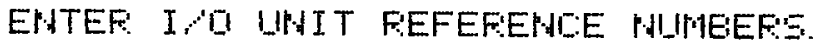

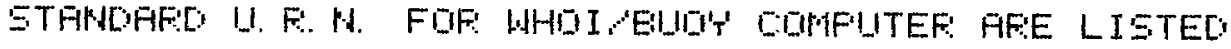

WFIT ITE 21 :

1 FDFWHT CZHEPTEF FIUE IO DEYIDES

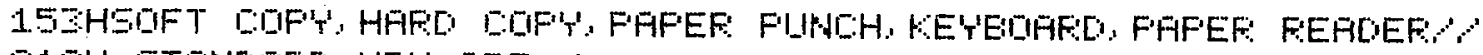
ZIEH STAKIOFFO LIFH RFE :

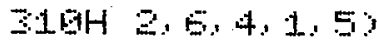

FEFO C1. : L LO1. LOE. LOS. LI. LII

WFITE LOL. 40

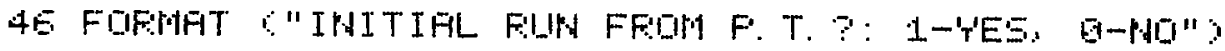

FEFO CLI, : $Y$ I

IF $(I-1) 59,55$

5

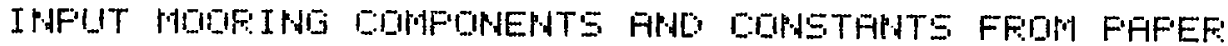

TFFE DF: DTHEF: SDUIFIE

55 CFILL FTIG 


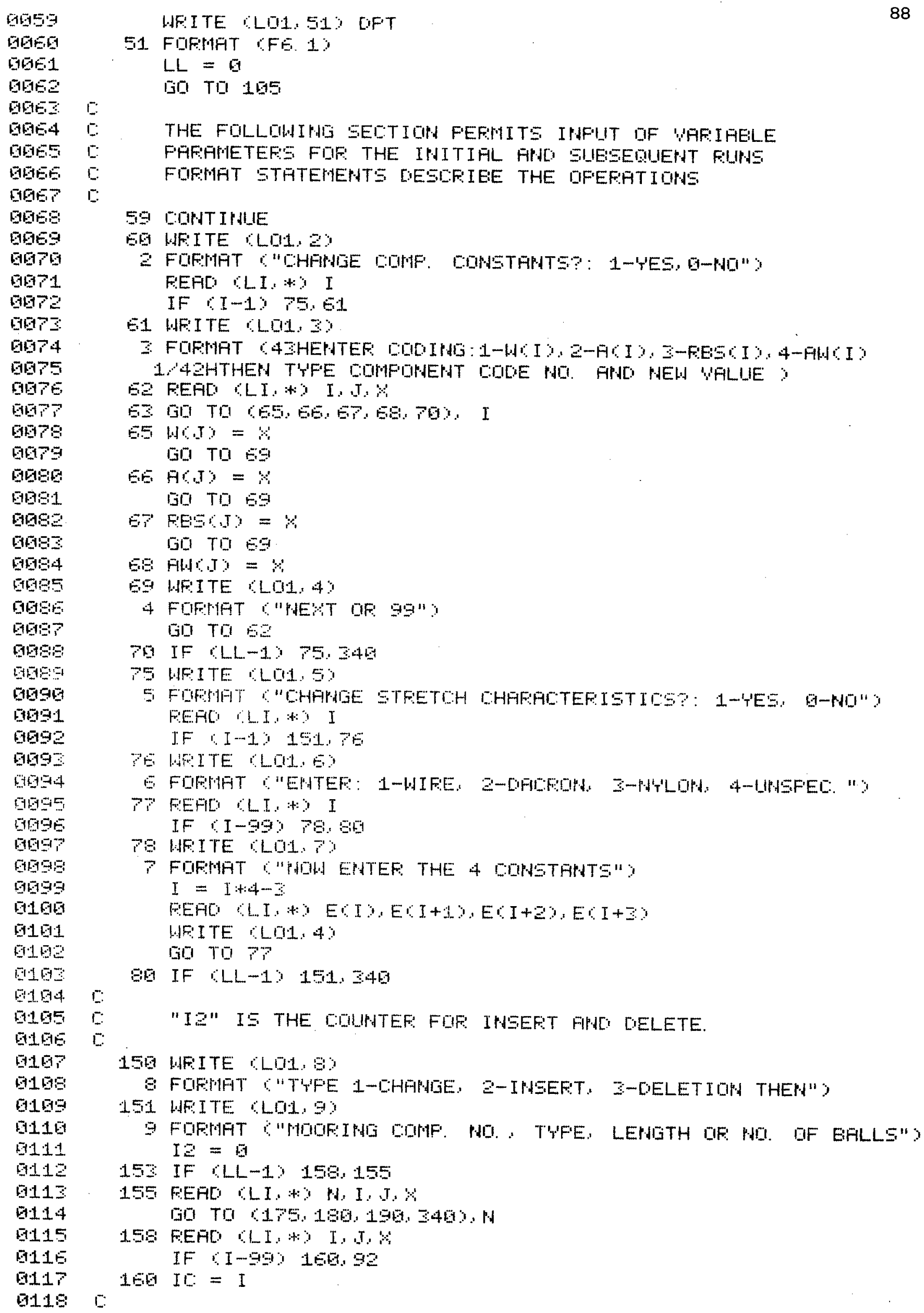




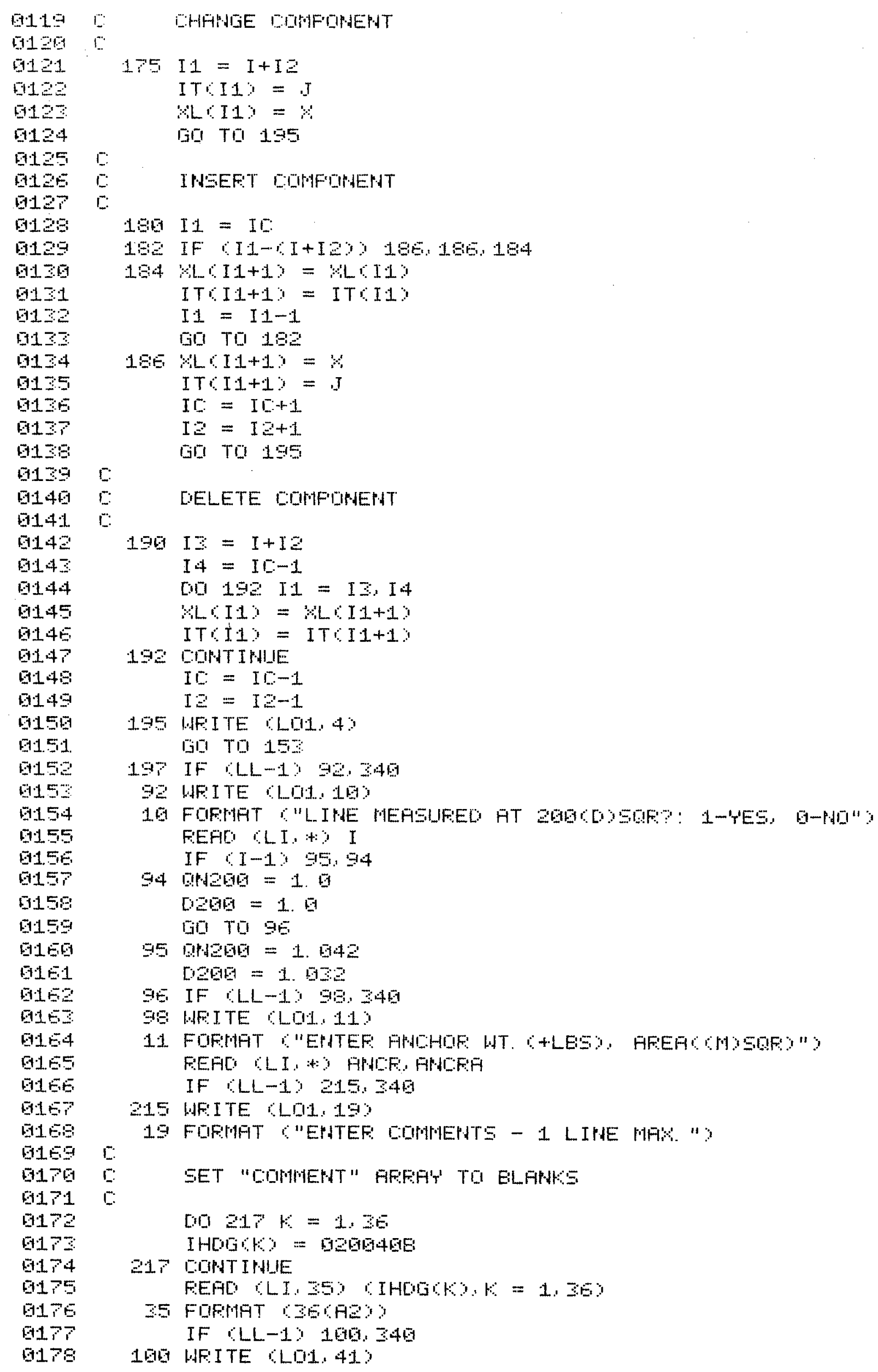




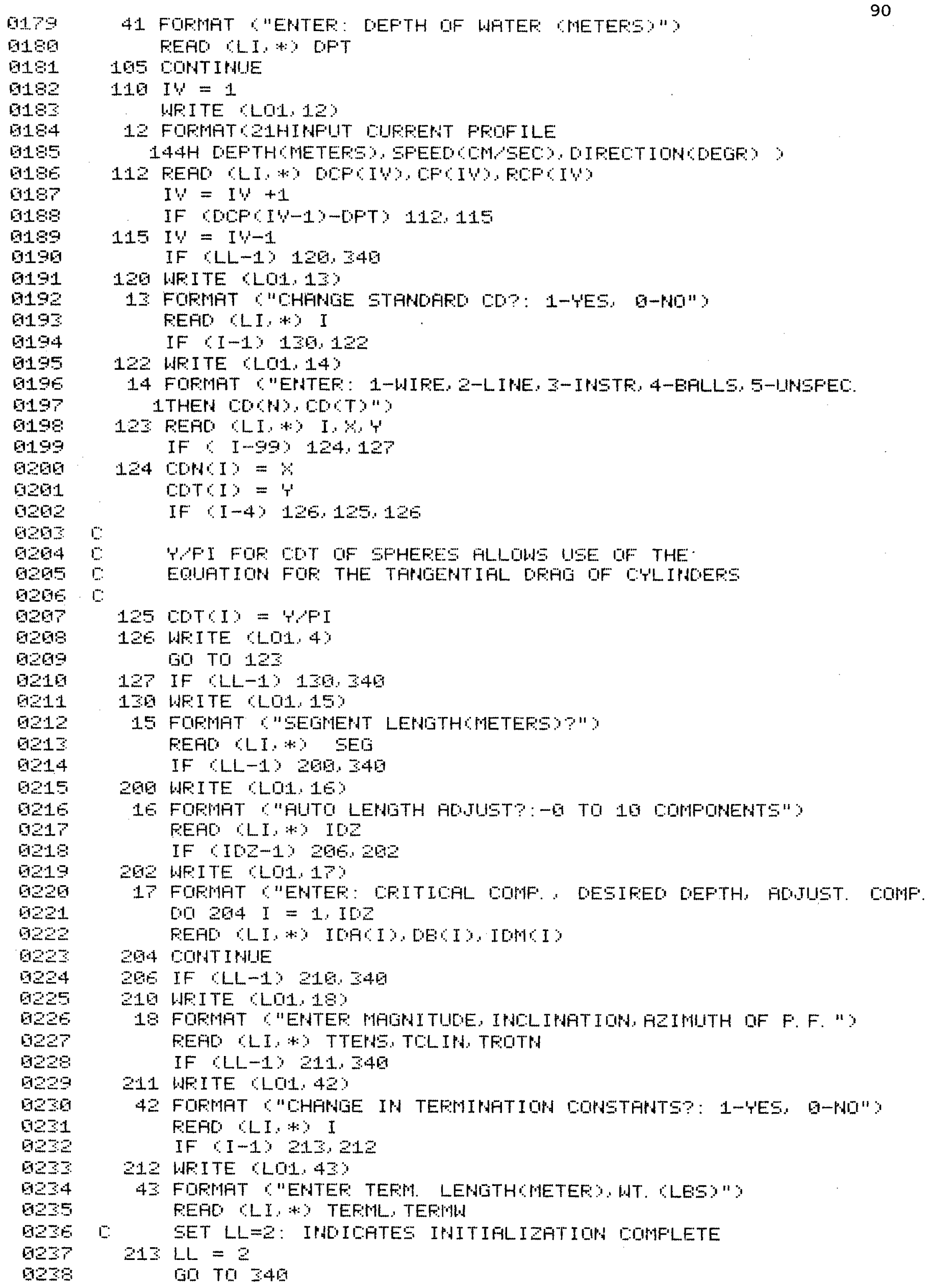




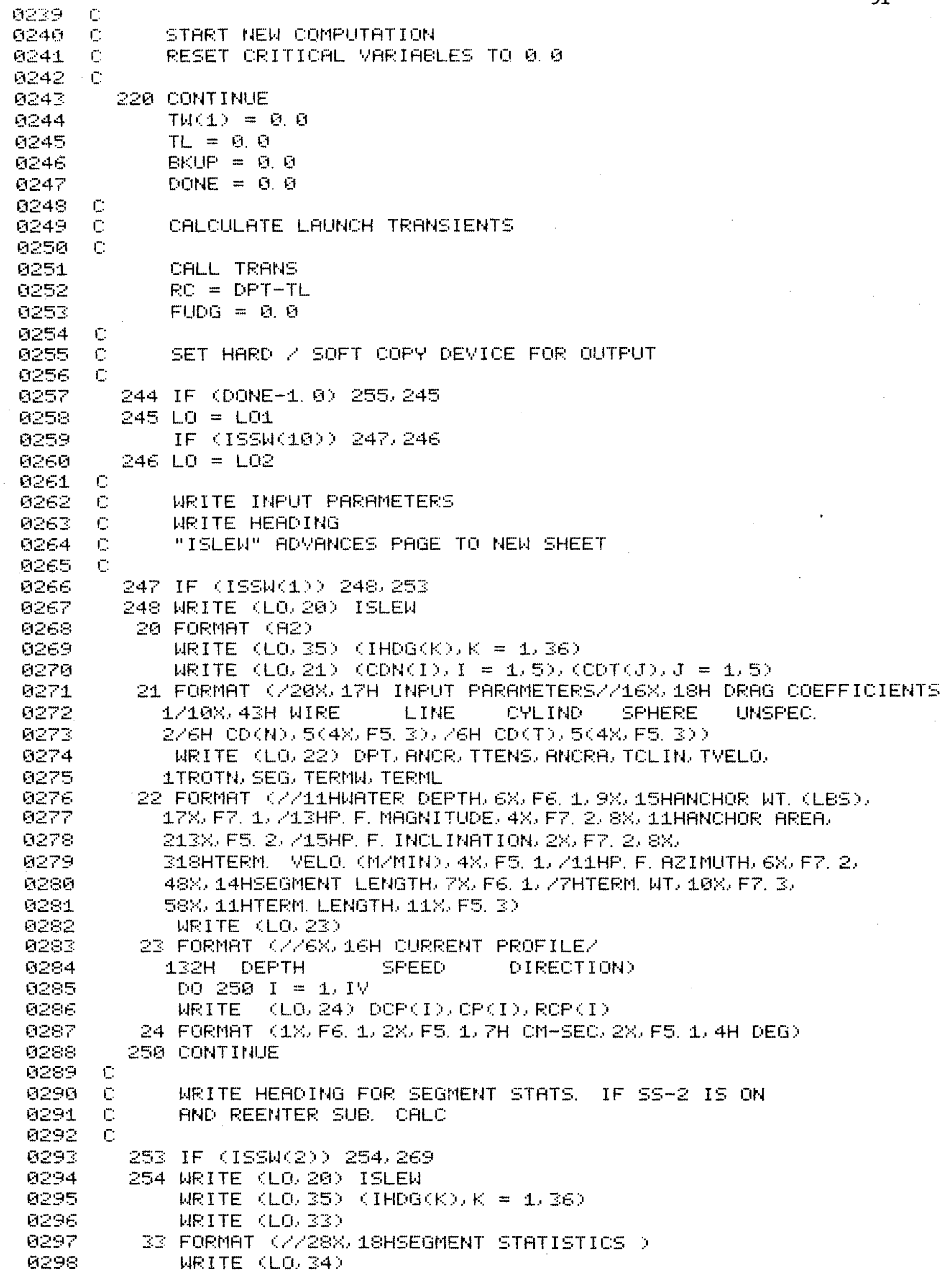




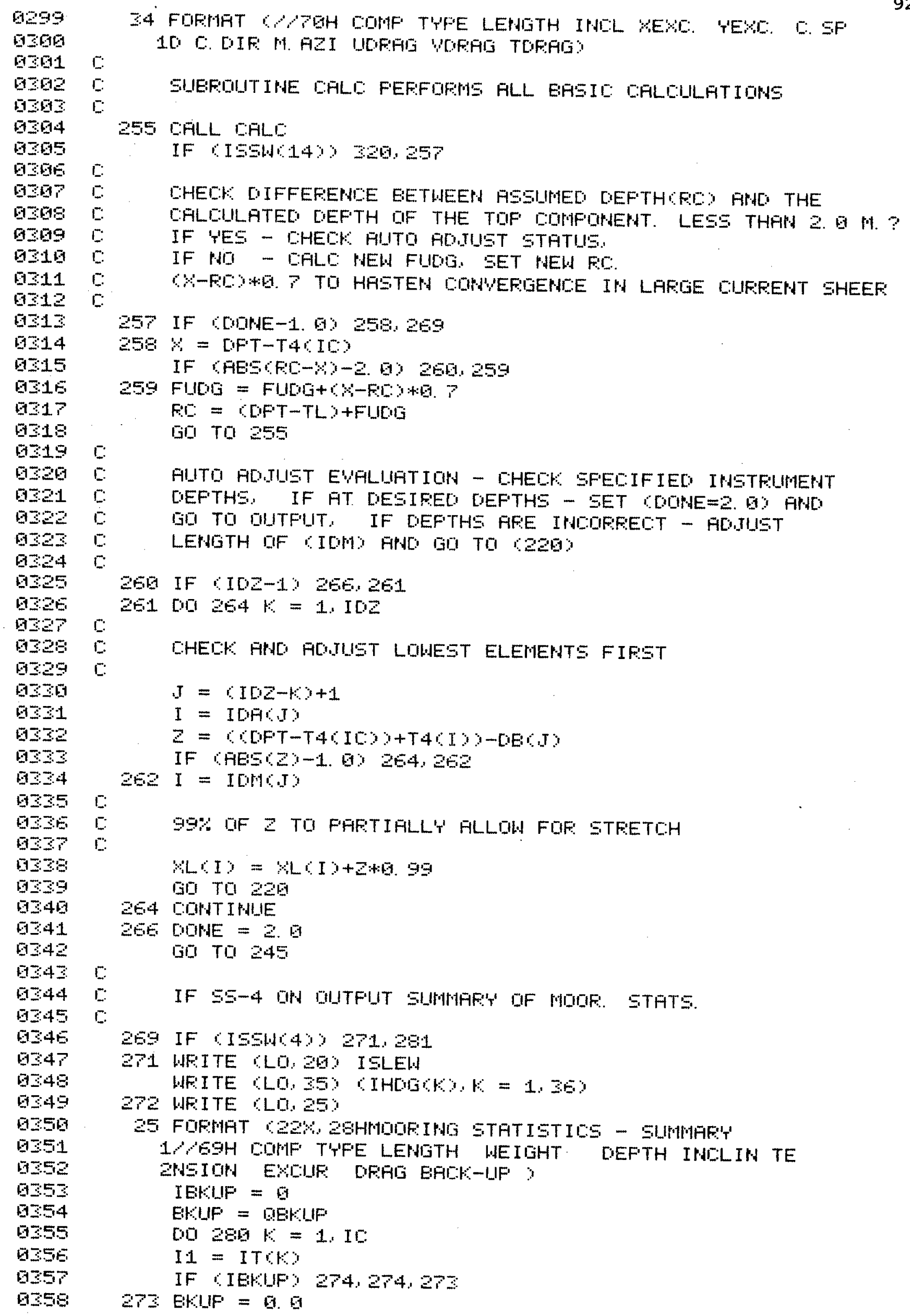

0328

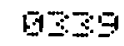

0340

034

0242

0134

634

0245

0345

0347

0349

0549

0856

0.51

1952

025

0.54

0755

025

0257

025

L: 


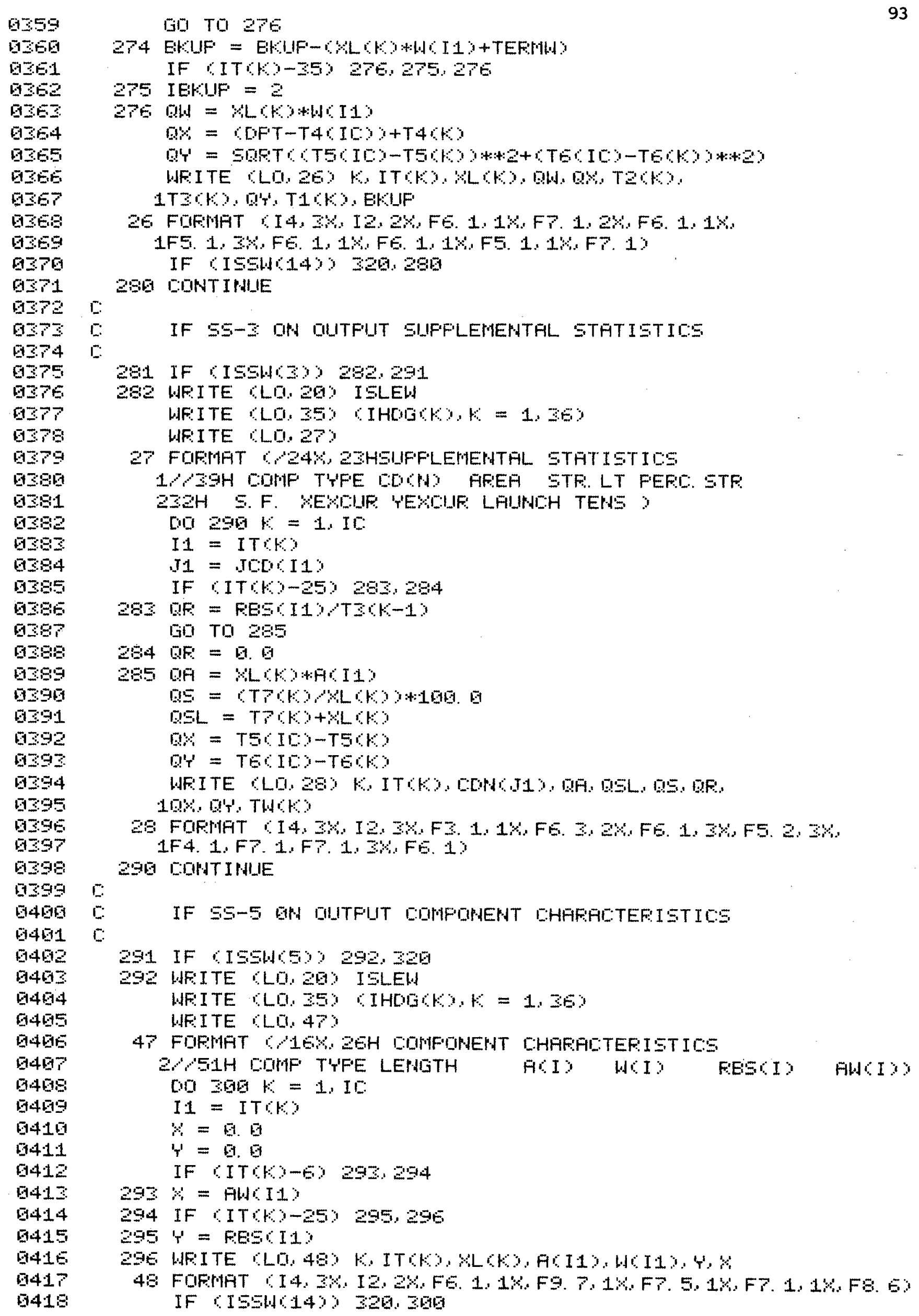

브군

0153

몬

9175

0376

0국

037

모을

Q 980

GIS1

- 1282

01582

0384

0355

0286

0387

9289

0289

0890

0291

0192

0392

0394

0185

0296

0397

0398

01399

c:

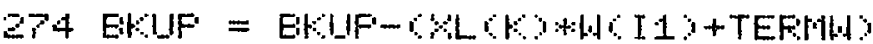

IF $(I T C)-35) 270,275,276$

275 IEHUF $=2$

27E OW = KLOH+WI1?

$Q \%=C D F T-T 4 C I C Y+T 4 C K$

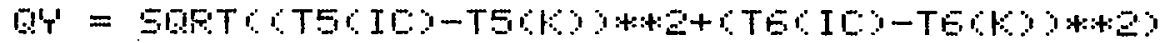

WFITE CLO 2E H ITCKO YLCO DW OW, TZCKO

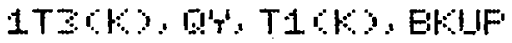

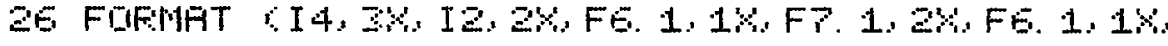

1F5. 1. $2 \%$ FE. 1, $1 \%$ FE 1. 1\% F5. 1. 1\%FP. 1 \%

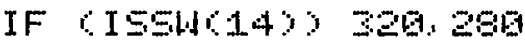

280 CDNT IHUIE

ᄃ:

I:

IF $\Xi \Xi-3$ ONA DUITFUT SILFFLMENTHL STFTISTICS

281 IF ISSW63) 282.291

282 WFITE CLQ. $20 \%$ ISLEW

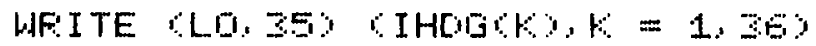

WFITE UL. 27

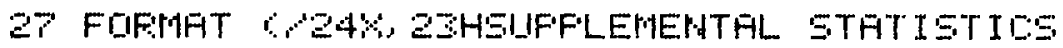

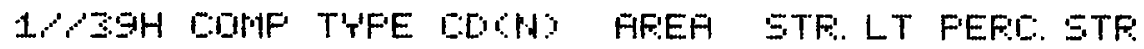

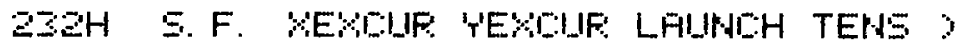

00 $290 \mathrm{r}=1.1 \mathrm{C}$

$I 1=I T C H$

$.11=\operatorname{TLO}[113$

IF IT $16-25 \% 203294$

282 OF: = FESTISTSC-1)

GO TO 285

284 QR: $=0.6$

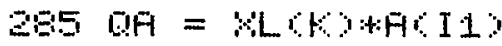

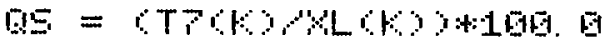

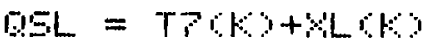

$Q \%=T S C I C Y-T S C \%$

$D^{\prime} T^{\prime}=T E C I D Y-T E C O$

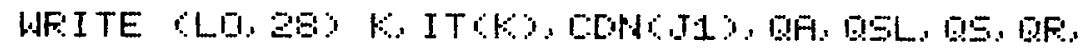

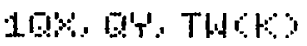

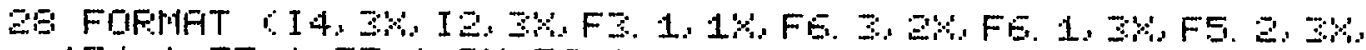

1F4. 1. FP. 1. FP. 1. 2\% FE. 1 ?

290 COLHTINIE

Q 14901

04010

0402

0463

마여

0495

9406

마이

0408

5409

0410

0411

6412

9413

5414

0415

9415

9417

9418

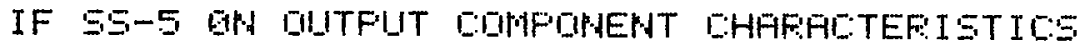

291 IF $\quad$ I 594659292.20

292 WFITE CLO. 20 O ISLEW

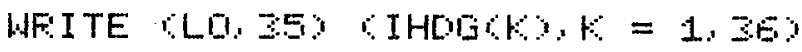

WFI ITE LQU, $47 \%$

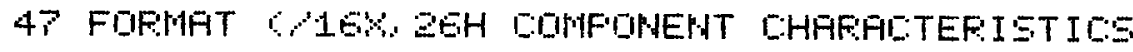

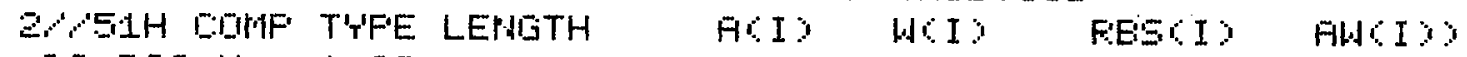

$00300=1.1 \mathrm{C}$

$I 1=I T C K$

$x=\theta$

$' T '=\theta$

IF ITCKO-6) 298,294

$292 \%=\mathrm{FW}(\mathrm{I} 1)$

294 IF IT IF-25) 295, 296

$295 \mathrm{~T}^{\prime}=\mathrm{FEECIIY}$

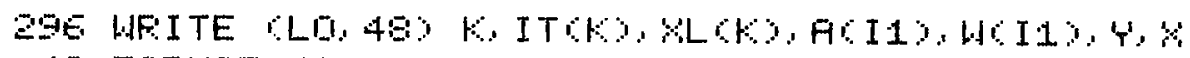

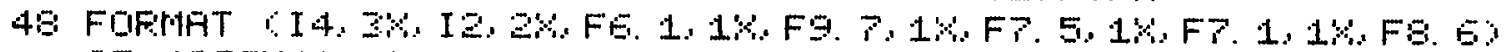
IF ISSHC14) 320.30 


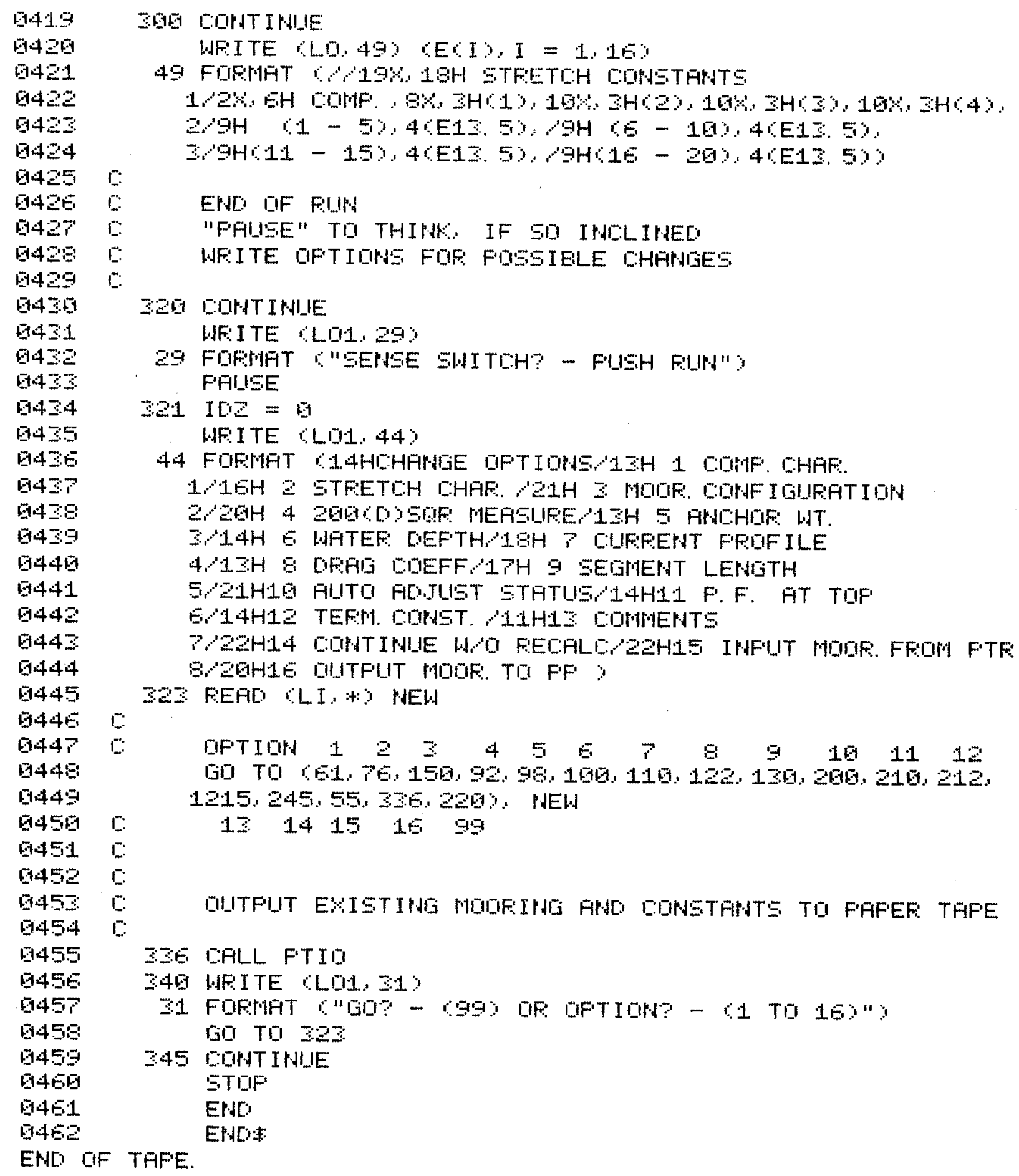




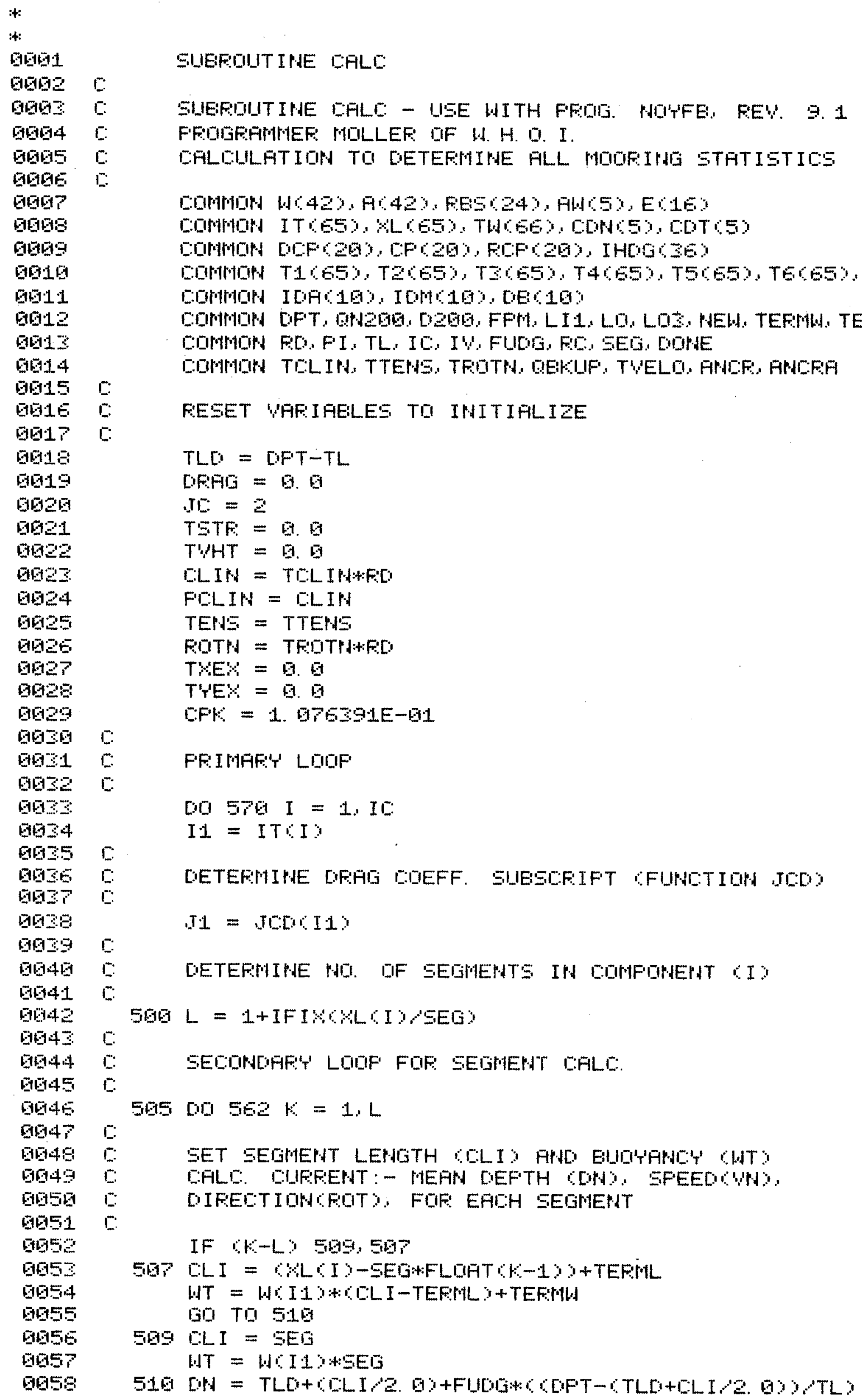

E: 
0650

0600

G日E 1

0062

gates

Q1064

0065

906

Q

머의

0069

50170

면 1

0972

미고

01074

01075

0975

믹ㄱ

096?

0079

006

0051

as.

nase

0094

0695

0065

뜨묵

genes

5009

0095

9691

0992

0093

0694

0095

0095

6097

E1999

0099

Q1日1

Q101

G192

Q102

버단

0195

Q1e

Q19?

0198

ㅁ.169

0110

0111

Q112?

Q113

0114

0115

9115

9117

Q115 $\because$

$E$

$E$

IF CON-[OFTY 514.512

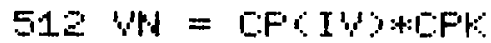

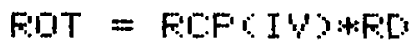

[ii) TO 519

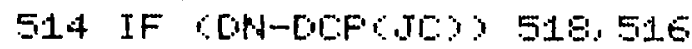

$515 . \mathrm{I}:=. \mathrm{I}:+1$

III TE 514

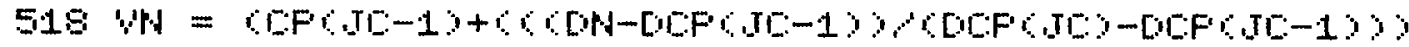

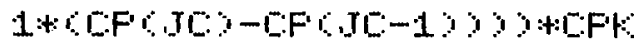

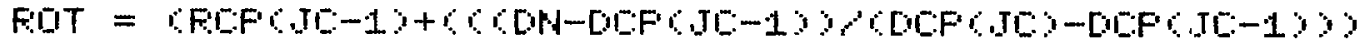

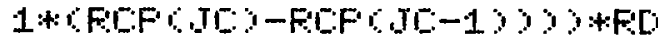

E:

E: GET FITTH=FOT WHEN TEHSILW = EI

E.

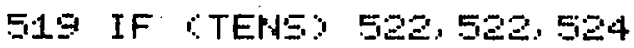

52 FOOTP = FOTT

E:

I:

I.

E:

I.:

E

524 $\%=$ FIITH

' $r$ ' = FiITH

$Z=$ TENS:EIHCLLINS

S2E GILLIN = FULLIN

AHIINI: = DI:LIPIELIN

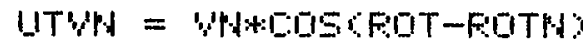

WTW = w

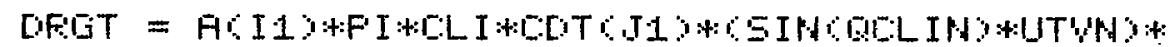

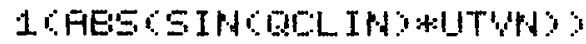

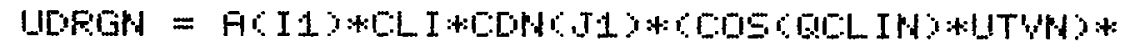

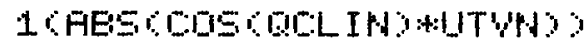

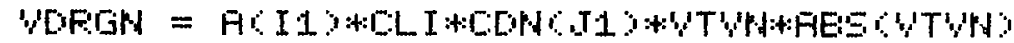

WTT = HT:LDESELLIPO

WTH = WT:A:EINGELLINS

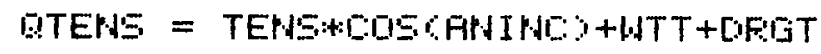

I:

I:

E.

$E$

I:

I:

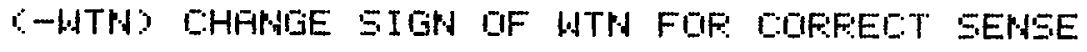

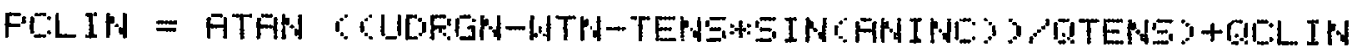

FHIID AB. 9 IH

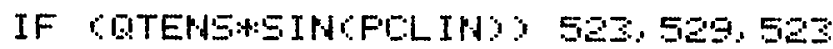

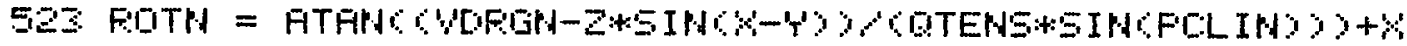

529 IF $15.6143 \%$ IPE, 525

$E$

E:

I:

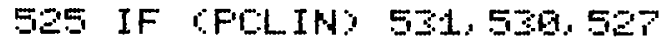

E:

I.:

E.

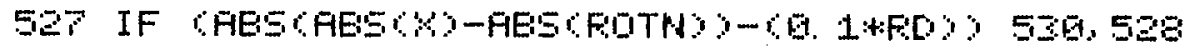

$520 \%=\mathrm{ROTN}$

60 TO 526 


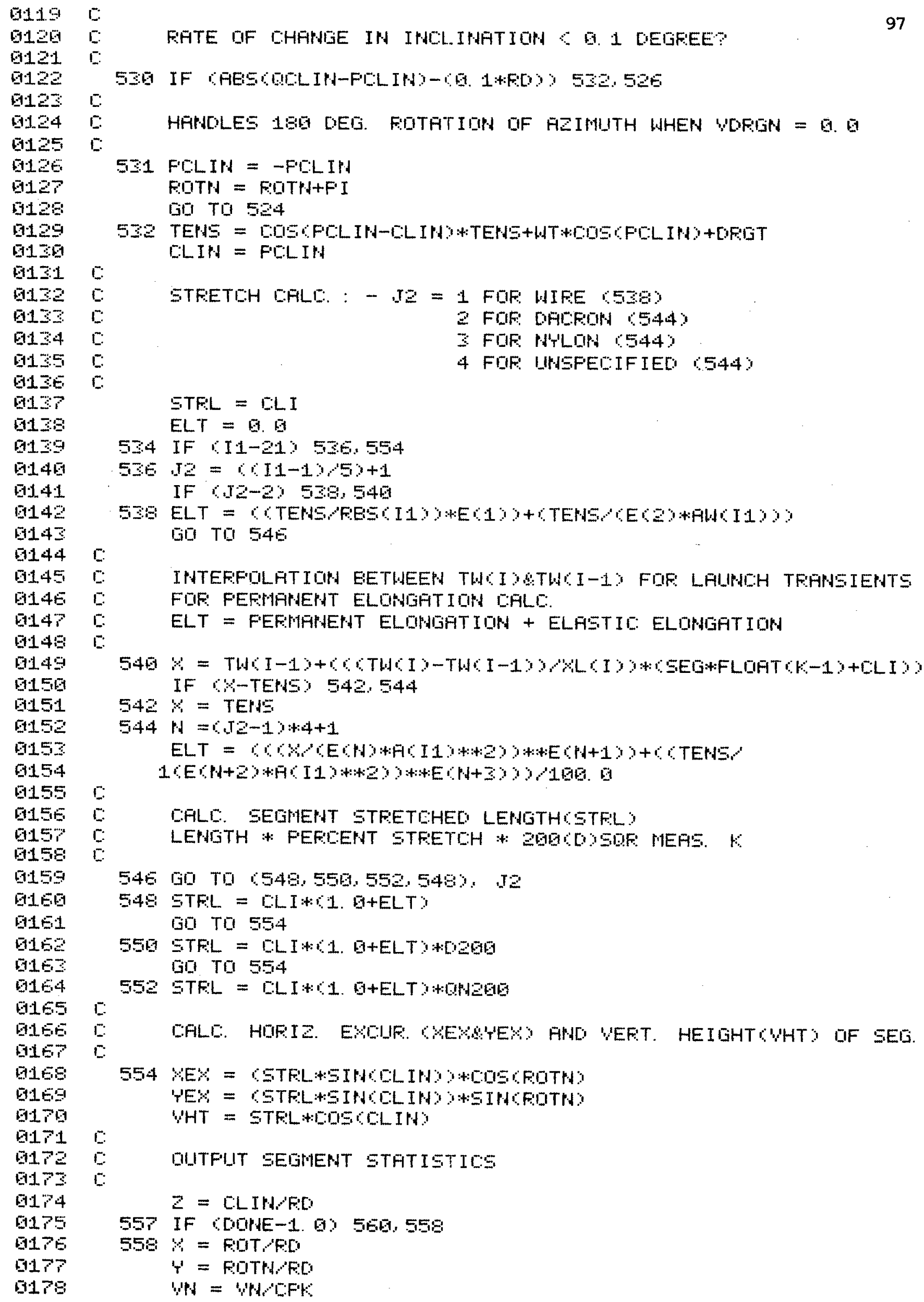

1943

6144

5145

Q14E

0147

0145

0149

0150

ㅁ151

4152

0152

0154

0155

0156

$015 \%$

0158

6159

Q150

Q1e1

G1E2

Q1E:

0164

0165

QLEE

말

Q169

0109

9170

․171

ㅁ172

ㅂ.173

Q11\%4

0175

․176

ㅌ.177

0178

E:

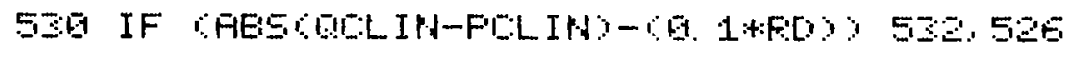

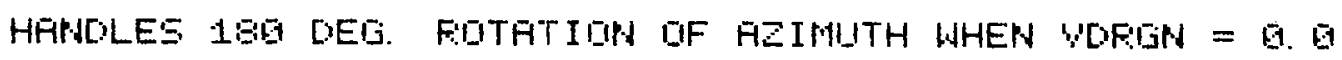

51 FCLIH $=-F^{\prime}$ LLIPA

FIOTN = FOTP.

G0 TO 504

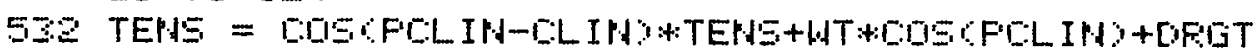
CLIH = FLLIH

STFETLH LFLE: : - IZ = 1 FGF HIFE 6589

2 FOF: ORIERON 644 ?

¿ FOF: H'TLOA (544)

4 FQF: LIFAFELIFIED 644 \%

STFL = ILI

$E L T=9.9$

53 IF $(11-21) 556.54$

$5 \mathrm{SE} \mathrm{I} 2=0 \mathrm{I} 1-135 \mathrm{y}+1$

IF $0,2-23 \quad 520,540$

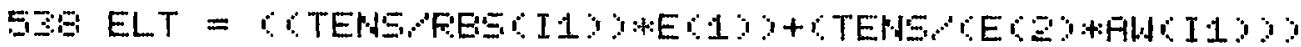
GD TQ 540

C:

E:

E

E

E

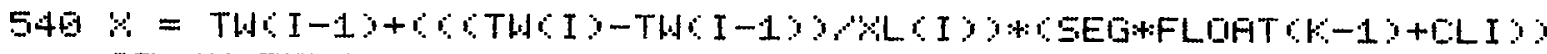
IF 6 Y-TENSY 542,544

$542 \%=$ TENS

544 id $=6.2-1): 44+1$

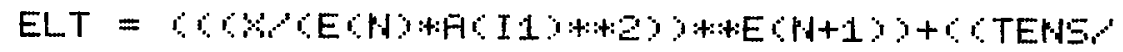

C:

E

E

E:

54500 TO $549,550,552,548 \%, 02$

549 STFL = CLI:A1. QTELT)

00 TO 554

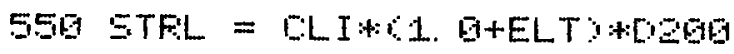
[10 TO 554

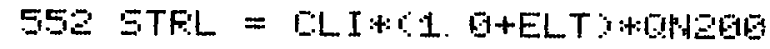

E:

E:

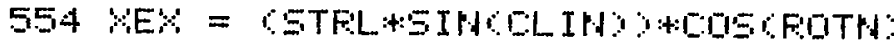

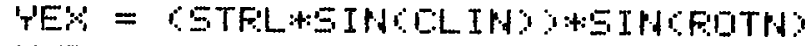

YHT = STFL:TLODECOLIPS

c:

E

E 


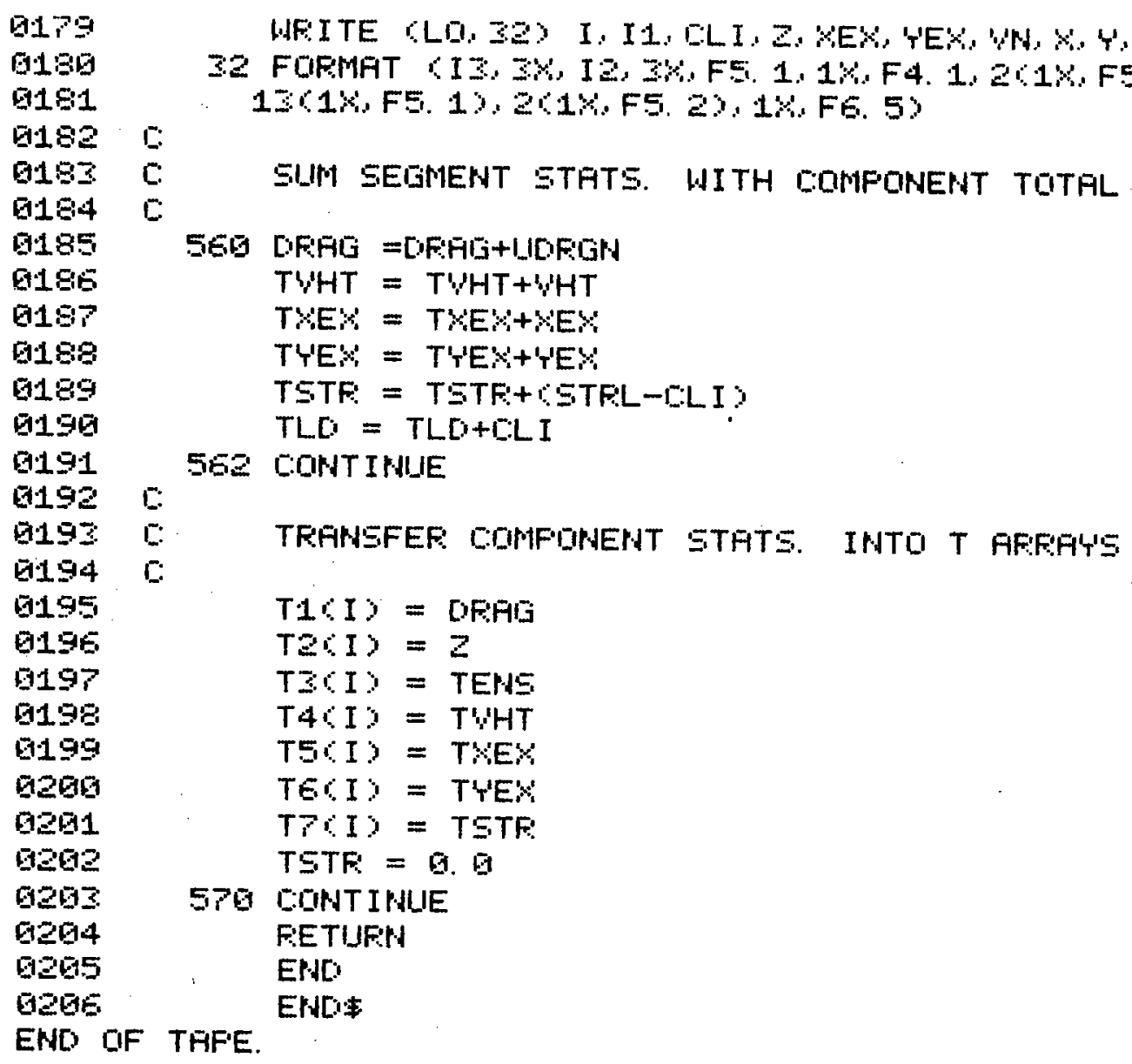


:4:

it:

Gand

9602

096

090145

0905 $C$

G095 :

51907

9919

090

9516

0911

0912

0013

5014

0115 :

G91E :

9017

9015

9019

ด9E0

0921

0922

0923

9924

0625

0925

gae?

9928

0029

9659

9051

6052

9033

9024

0035

age

093

9028

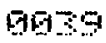

9046

0941

0942

1954:

01544

01045

9945

01947

9949

D149

9059

905:1.

0052

$095:$

$0954 \quad c$

$0055 \mathrm{C}$

Q105e C

9557 :

095a :
GUEROLITINE COPST

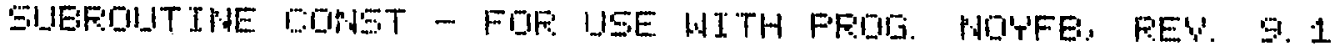

FFOSFATHER MOLLEE: DF H. H. O. I.

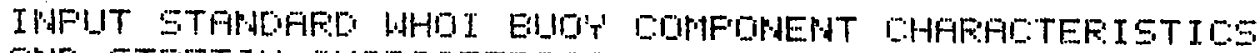

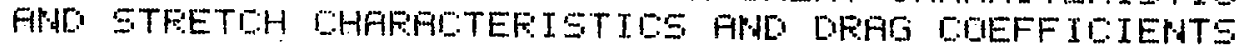

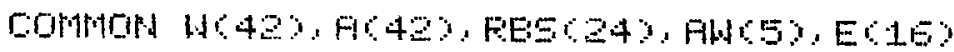

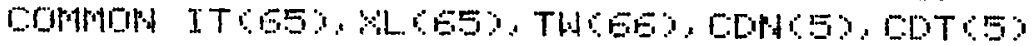

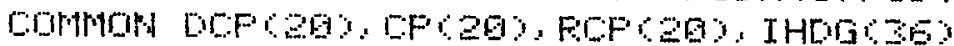

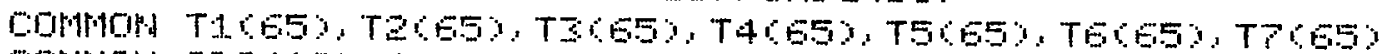

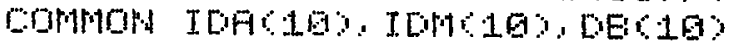

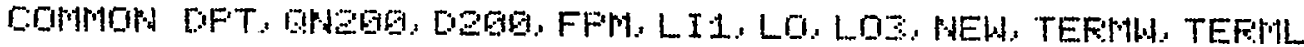

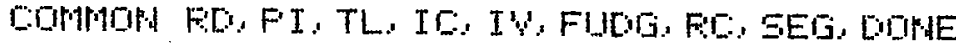

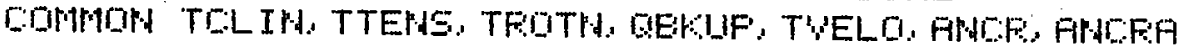

TEFMN $=-219$

TEPHL = 0.20

$\mathrm{FO}=01745293$

$F T=3.14505054$

$\mathrm{FFM}=2.280 \mathrm{E}$

FII - AFEA DF COMF. IM EGE. METEF FEF METEF LEPISTH CLIME, WIFE. CHAIP = DIAMETEF JH METEFS?

HCIO - WEIGHT DF COMF. IH FOUMDS FEF METEF LENIJTH

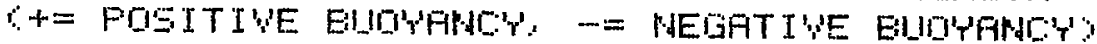

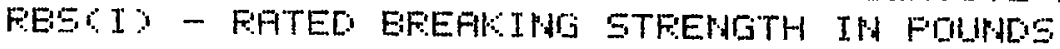

FHCID - CFOSS SECTIOHFL METFL. AFEF OF WIRE IH SQF. IHLHES

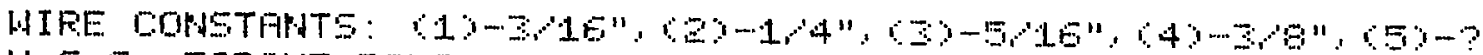
แ. 5.5. TOFIIE RALFMED TALKETED 319 HIFE

$A(1)=E .5 F E-013$

Hi $1=-6.154$

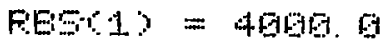

$F H 1 \%=0.01511$

$\mathrm{HCO}=\mathrm{\theta} .256 \mathrm{E}-0 \mathrm{~S}$

HC2 $=-6.28$

PESC2O = 5P59 $\mathrm{Q}$

FHCZ = 0.92720

$A C B=9.9558 E-03$

$4(3)=-941$

FESC $=10300$

FH $C 3=0.9420 \mathrm{E}$

$\mathrm{A}(4)=1.15924 \mathrm{E}-\mathrm{Q} 2$

$464=-0.544$

PES64: = 14800 0

Fll $4=0.06015$

$F(5)=0.0$

$W(5)=0.9$

$F E S C 5=1.9$

$F \mid 15)=1.6$

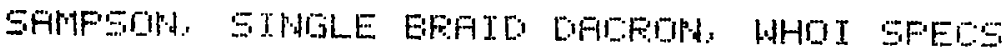

DACFOH LIPE IOHSTFWTS: 60,

$69-91 \theta^{\prime \prime} \cdot 189-54 "$

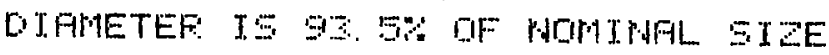




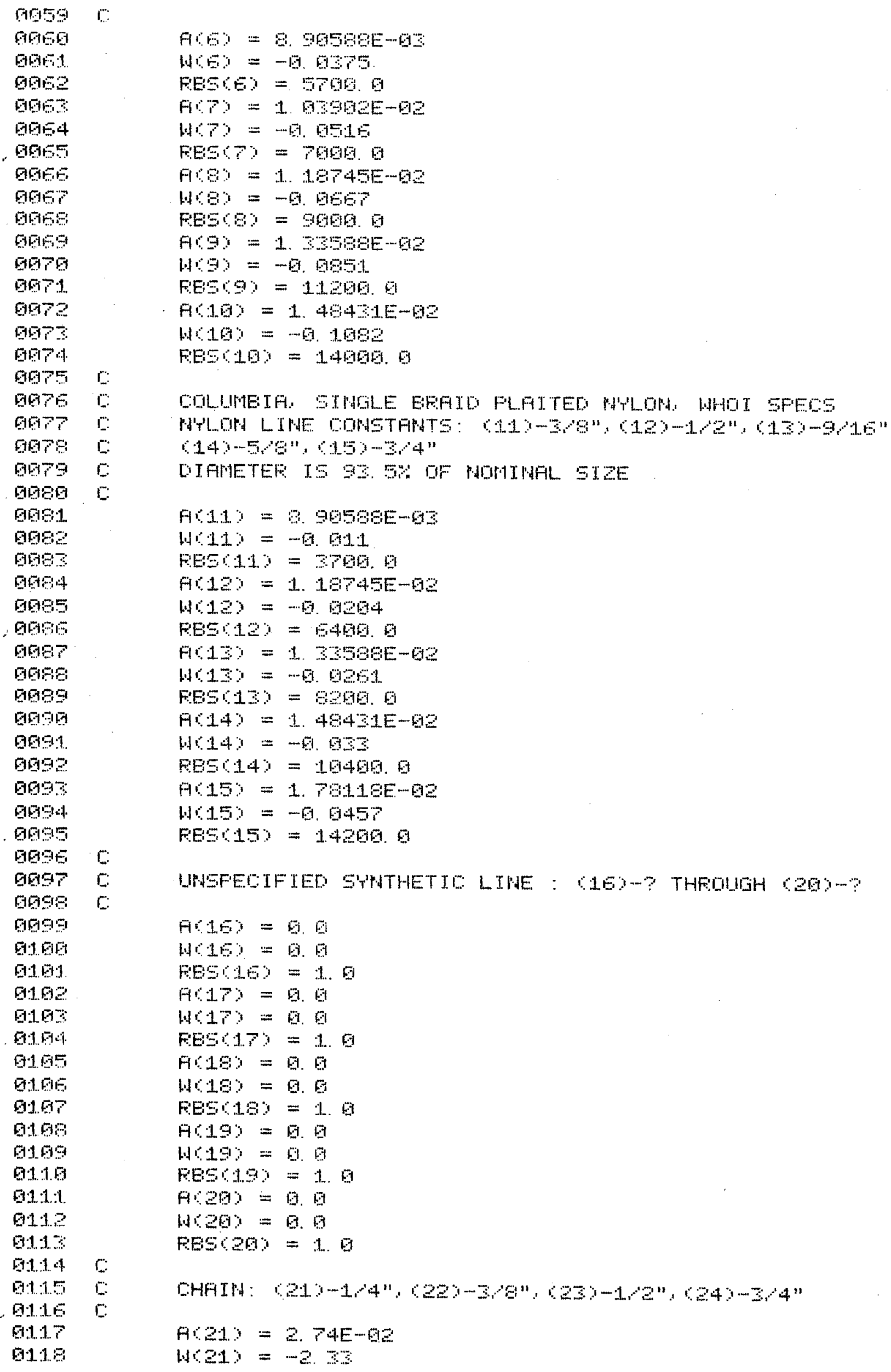




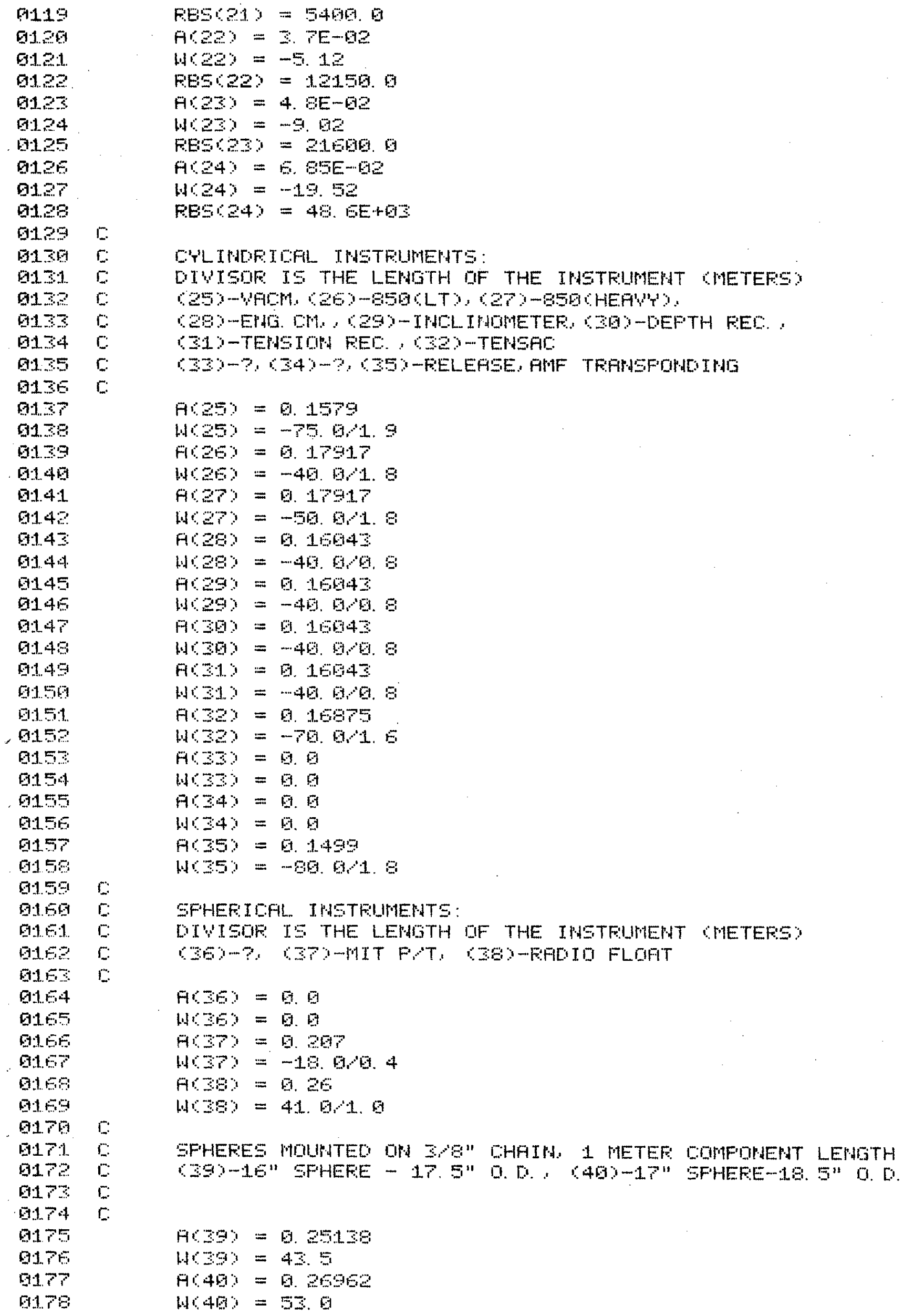




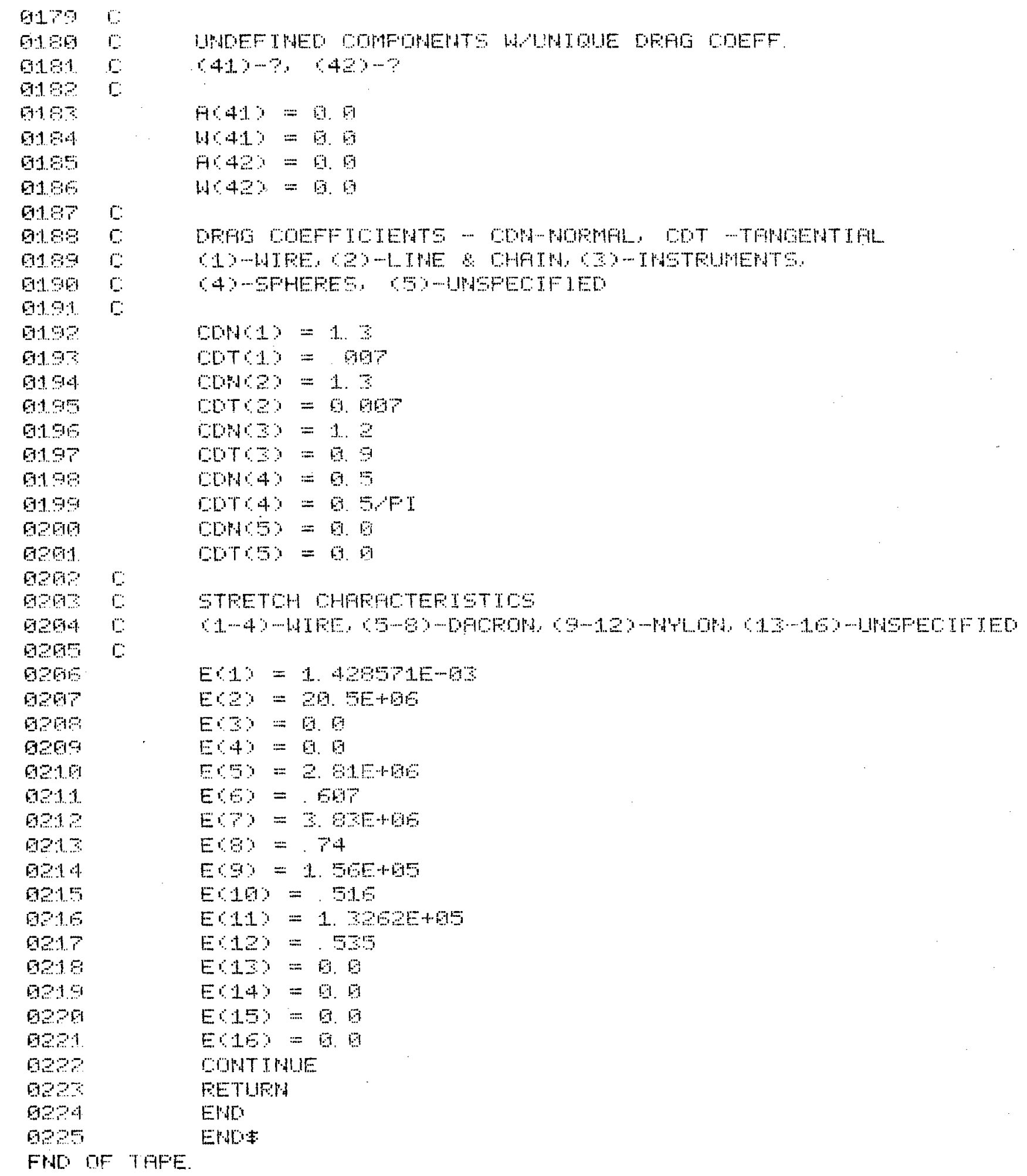


it:

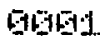

E10182

퍼넌

텀ㄷㅇ

터먿ㅇ

ETES

ज国国?

DIEA

E1615

ज्ञ15

01011

aㅣ를

E1512:

E1614

EN1515

EN1E

E1E17

마모

G519

ज1를

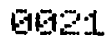

G15:20

테을

먼ㄷㄴ

E162:

GEE

미룽

어릉

머면

먿ㅇ

161 21

ज1:

버월

븐ㄷㄴ

버너든

Eब드

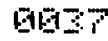

ज1중

E16?

0946

ज1741

ㄷ⽊년

머년

01644

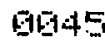

E946

1964?

E6146

gints

095

01051

616.5

0155

$\therefore 0054$

- 0105

G15s

015.57

0195
SIIEFIOIT IHE TFHHS

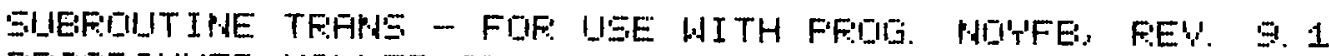

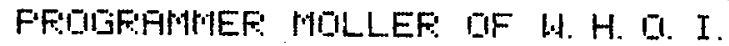

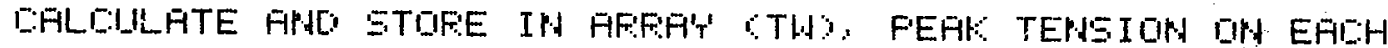

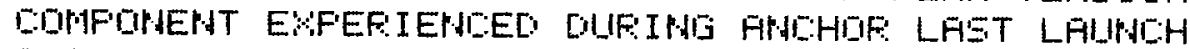

IMITIATES EATH FULA E'T' DETEFMINING TOTHL FELFEED LENGTH CTLY

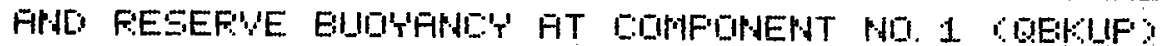

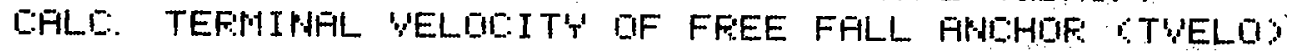

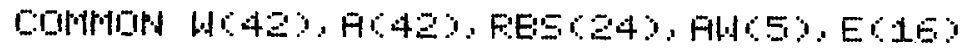

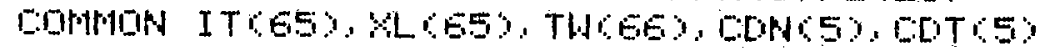

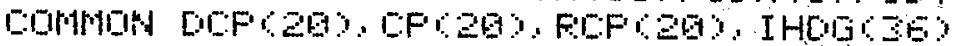

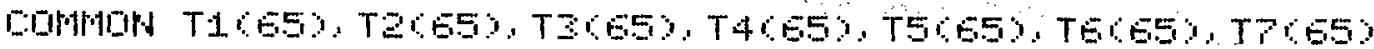

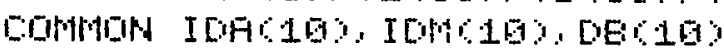

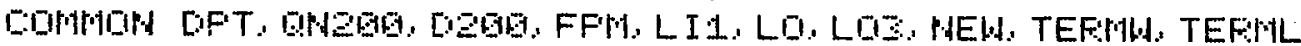

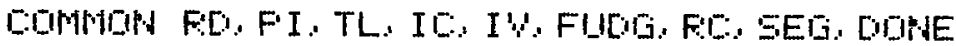

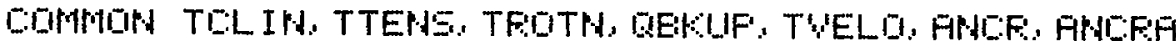

$Y=\theta$

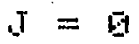

[O] $420 \quad I=1 . \quad I C$

E

$4011=I T C I S$

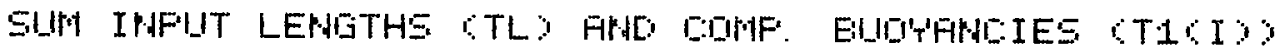

TICI IS USEO FOF TEMFOFFF'T' STIFEAIE

$T L=T L+M L C I Y+T E F H L$

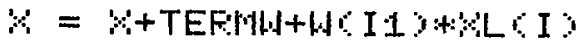

$T \perp C I Y=Y$

I:

E:

5

둔

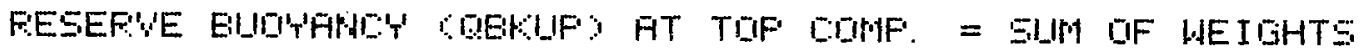

OF FELEFSE CSO FHD FLL COHFOMENTS FEONE IT

IF $(T-1) \quad 402,495$

4 GE GEVIF $=\%$

IF $(1-35) \quad 465,462,465$

E:

$403 \quad T=2$

5

$495 . T 1=\pi[113$

E:

[:

C

E:

L:

I:

C:

C:

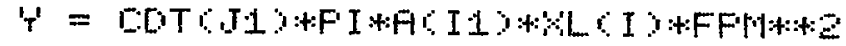

G0 TO $410,410,412,410,412 \%, \mathrm{~J}$

410 THCI+1) = THCIY+'T'

GO TO 420

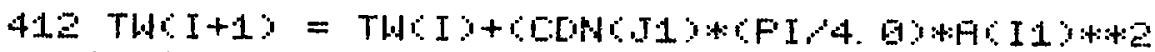

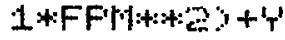

E:

420 CIONTT INHIE

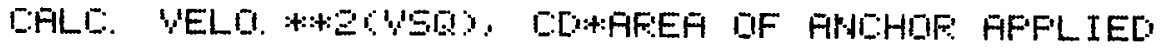




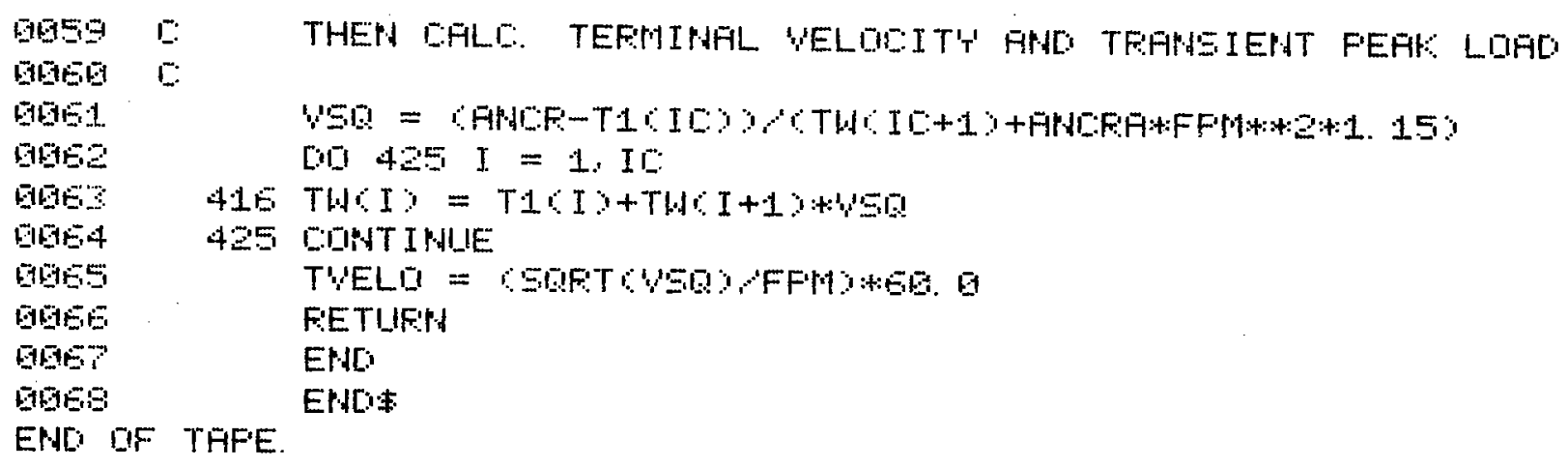

9561

Gete:

E19es

01054

0005

006

598?

DES:

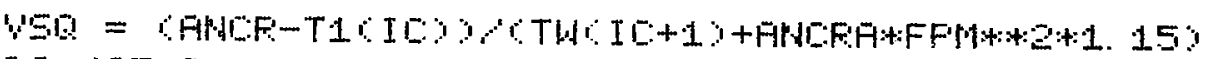

[0] $425 \mathrm{~J}=1 . \mathrm{IC}$

$416 T$ TW I $=T 1(I)+T H C I+1)+40 D$

425 CIOHT IPULE

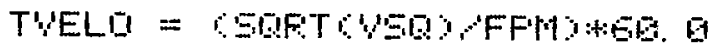

FEETLIFH

ENSO

END OF TAFE. 


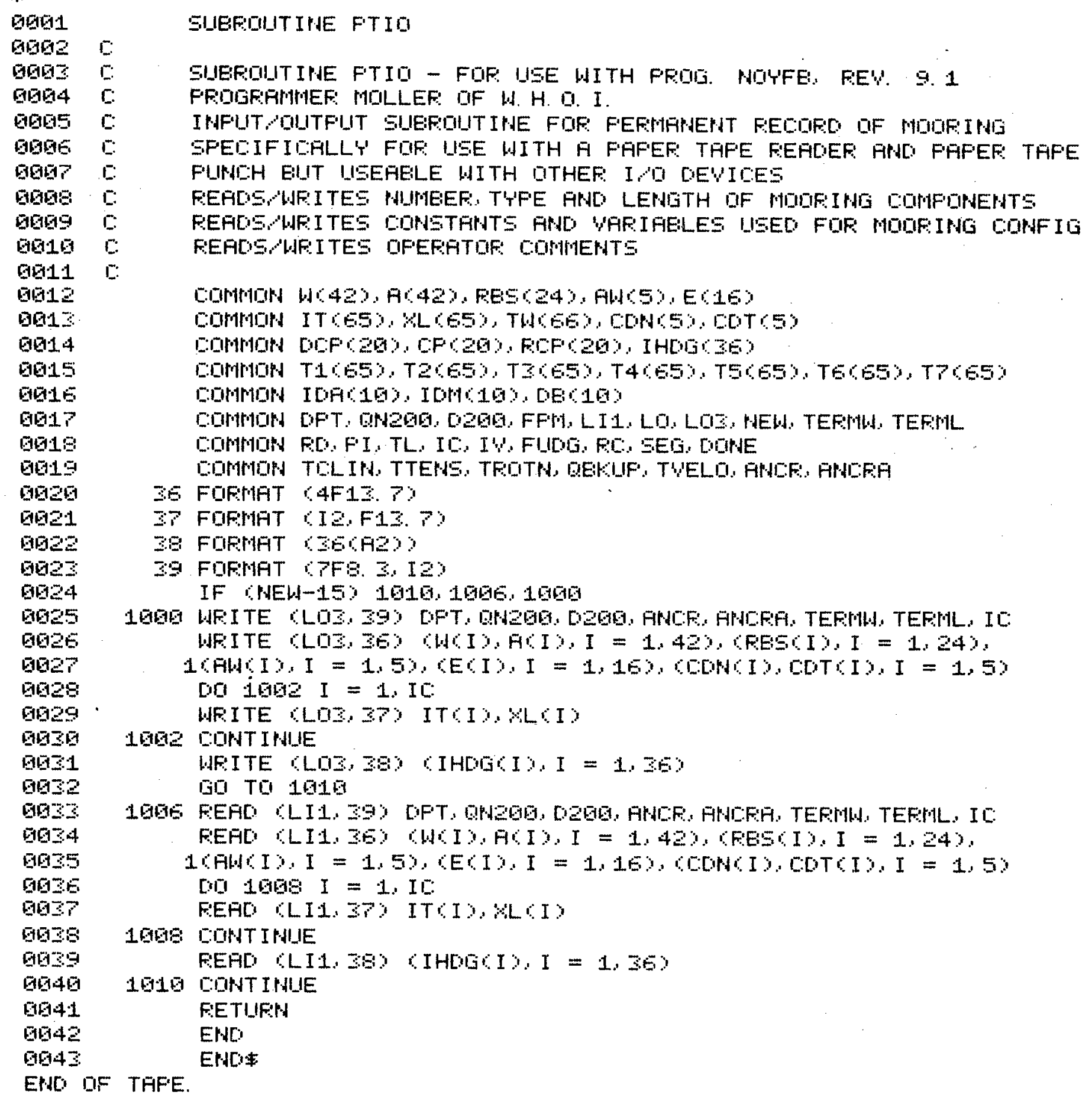


:t:

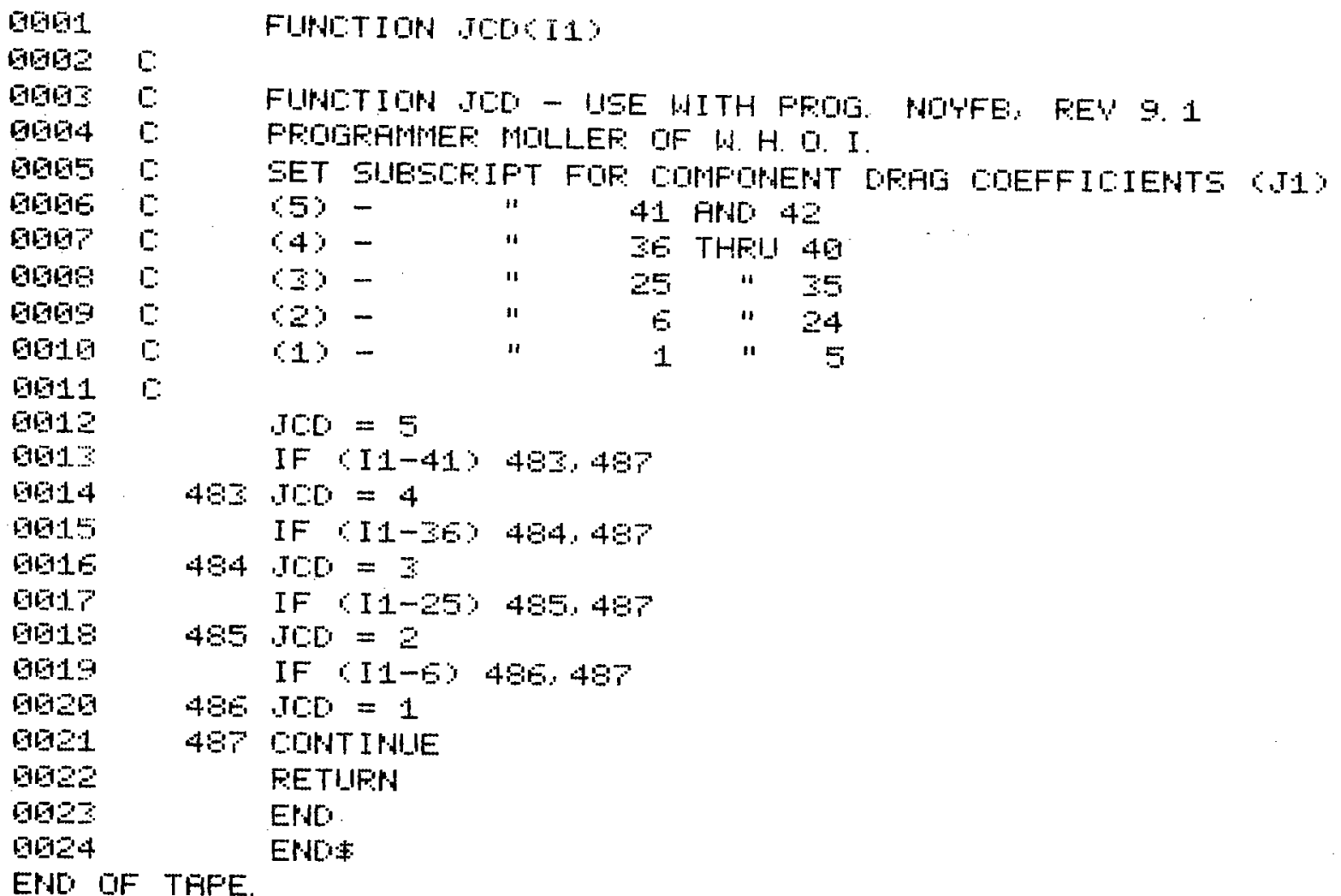




\section{MANDATORY DISTRIBUTION LIST}

FOR UNCIAASSIFIED TECHNICAL REPORTS, REPRINTS, \& FINAL REPORTS PUBLISHED BY OCEANOGRAPHIC CONTRACTORS

OF THE OCEAN SCIENCE AND TECHNOLOGY DIVISION

OF THE OFFICE OF NAVAL RESEARCH (REVISED OCT . 1975)

1 Director of Defense Research and Engineering

Office of the Secretary of Defense Washington, DC 20301

ATTN: Office Assistant Director (Research)

Office of Naval Research

Arlington, VA 22217

3 ATTN: (Code 480)

1 ATTN: (Code 460)

1 ATTN: (Code 102-OS)

6 ATTN: (Code 102IP)

1 ATTN: (Code 200)

1 LCDR David Cacchione, (USN)

ONR Representative

Woods Hole Oceanographic Inst.

Woods Hole, MA 02543

1 Office of Naval Research

Branch Office

495 Summer Street

Boston, MA 02210

Director

Nava1 Research Laboratory

Washington, DC 20375

6 ATTN: Library, Code 2620

1 National Oceanographic Data Center

National Oceanic \& Atmospheric

Administration

Rockville, MD 20852
12 Defense Documentation

Center

Cameron Station

Alexandria, VA 22314

Commander

Naval Oceanographic

Office

Washington, DC

1 ATTN: Code 1640

1 ATTN: Code 70 


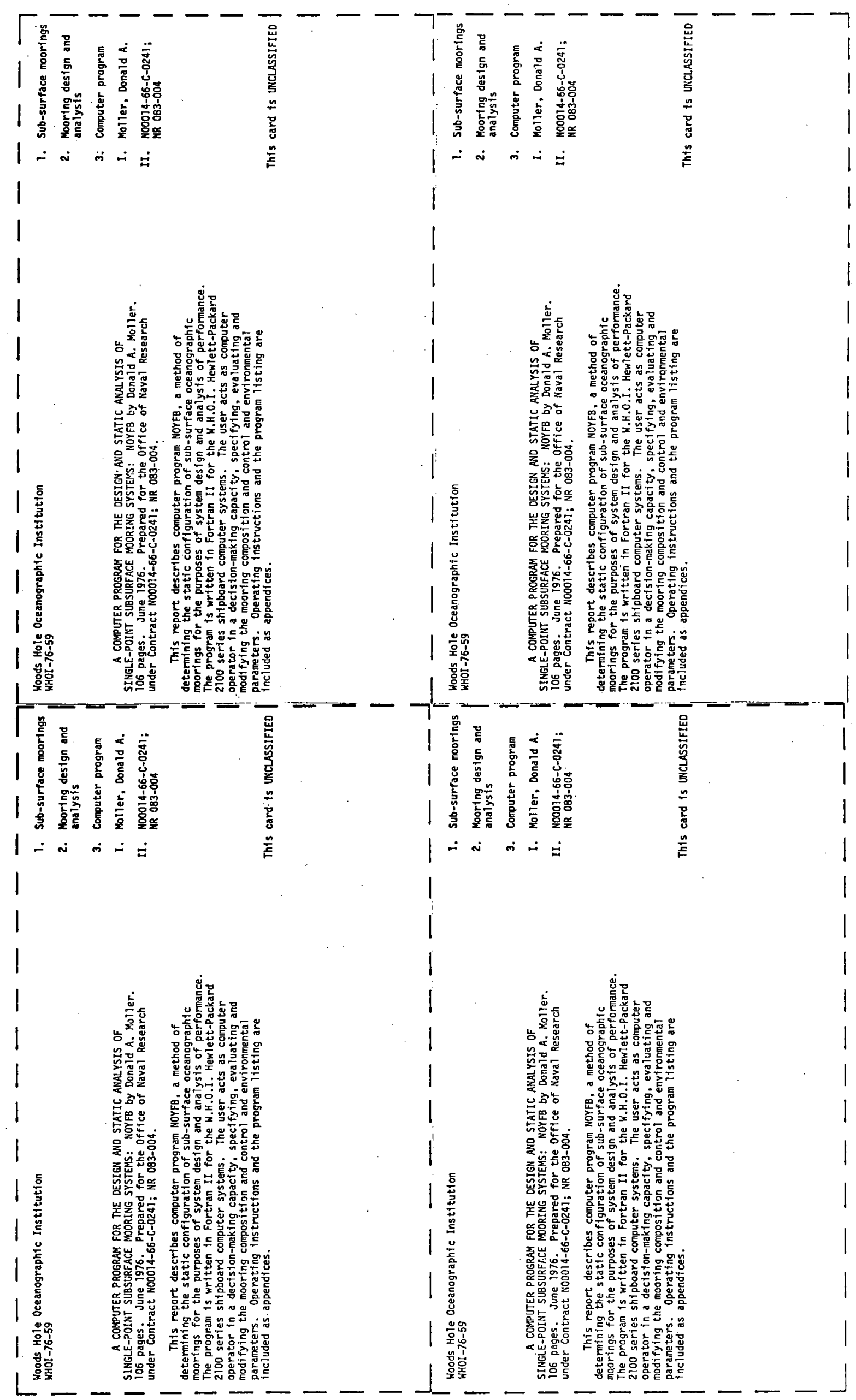




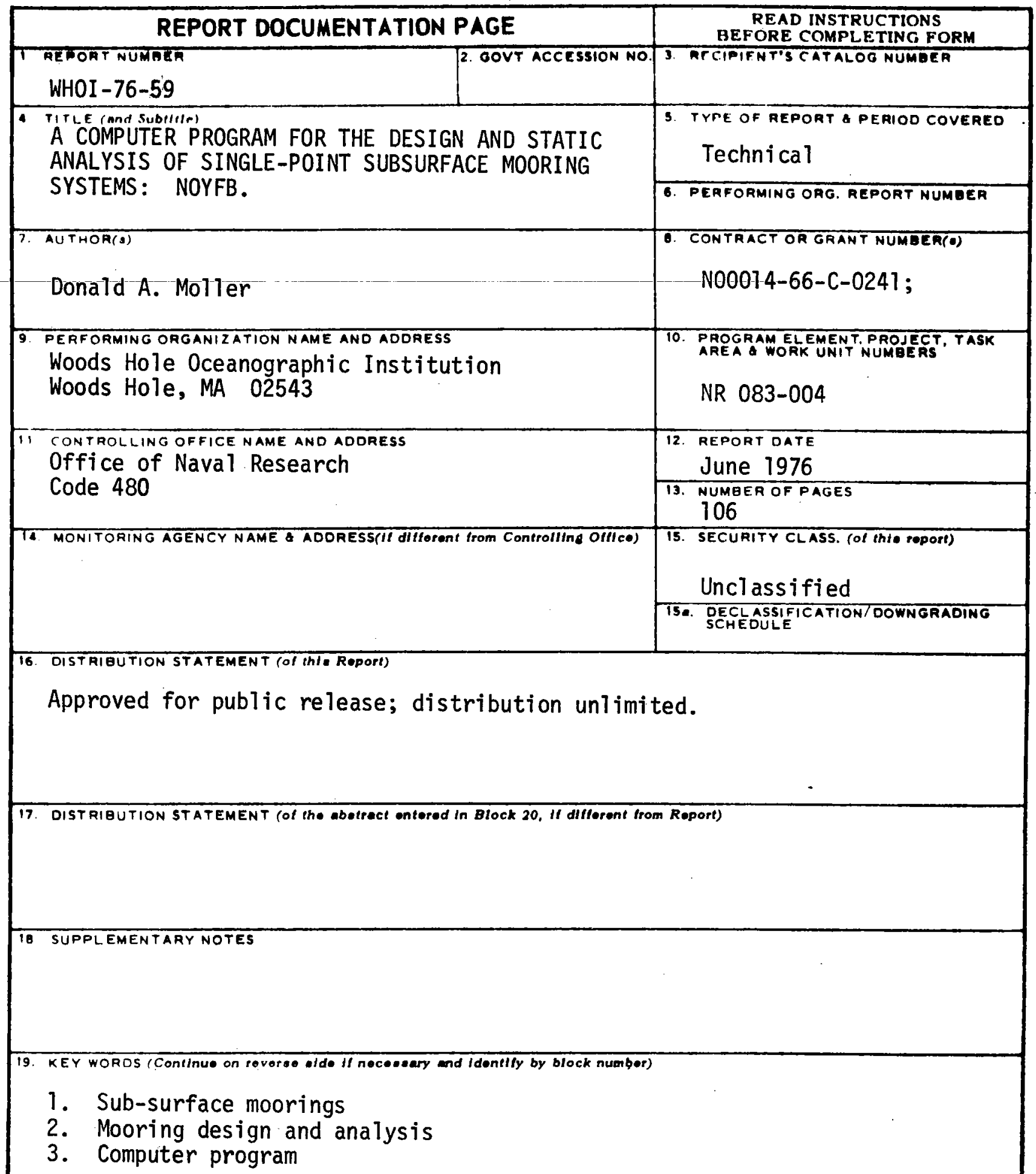

20. ABSTRACT (Continue on reveree alde if necoseary and ldentify by block numbor)

This report describes computer program NOYFB, a method of determining the static configuration of sub-surface oceanographic moorings for the purposes of system design and analysis of performance. The program is written in Fortran II for the W.H.O.I. Hewlett-Packard 2100 series shipboard computer systems. The user acts as computer operator in a decision-making capacity, specifying, evaluating and modifying the mooring composition and control and environmental parameters. Operating instructions and the program listing are included as appendices.

DD, FORM 1473 EDITION OF I NOV 65 IS OBSOLETE S/N $0102 \cdot 014 \cdot 6601$
UNCLASSIFIED $6 / 76$ 